CARLO MAGENTA DA CUNHA

ANATOMIA COMPARADA DOS MÚSCULOS EXTRAOCULARES EM RAIAS DA ORDEM MYLIOBATIFORMES (CHONDRICHTHYES, BATOIDEA)

São Paulo 2010 


\section{ANATOMIA COMPARADA DOS MÚSCULOS EXTRAOCULARES EM RAIS DA ORDEM MYLIOBATIFORMES (CHONDRICHTHYES,}

\section{BATOIDEA)}

Tese apresentada ao Programa de PósGraduação em Anatomia dos Animais Domésticos e Silvestres da Faculdade de Medicina Veterinária e Zootecnia da Universidade de São Paulo para obtenção do titulo de Doutor em Ciências

\section{Departamento:}

Cirurgia

Área de concentração:

Anatomia dos Animais Domésticos e

Silvestres

Orientador:

Prof. Dr. José Roberto Kfoury Júnior 
Autorizo a reprodução parcial ou total desta obra, para fins acadêmicos, desde que citada a fonte.

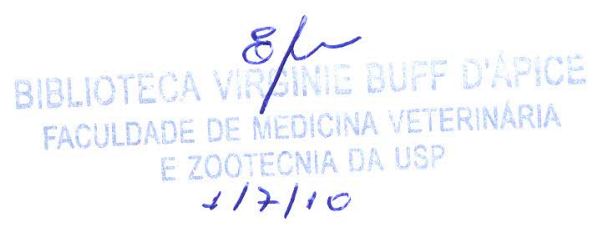

DADOS INTERNACIONAIS DE CATALOGAÇÃO-NA-PUBLICAÇÃO

(Biblioteca Virginie Buff D’Ápice da Faculdade de Medicina Veterinária e Zootecnia da Universidade de São Paulo)

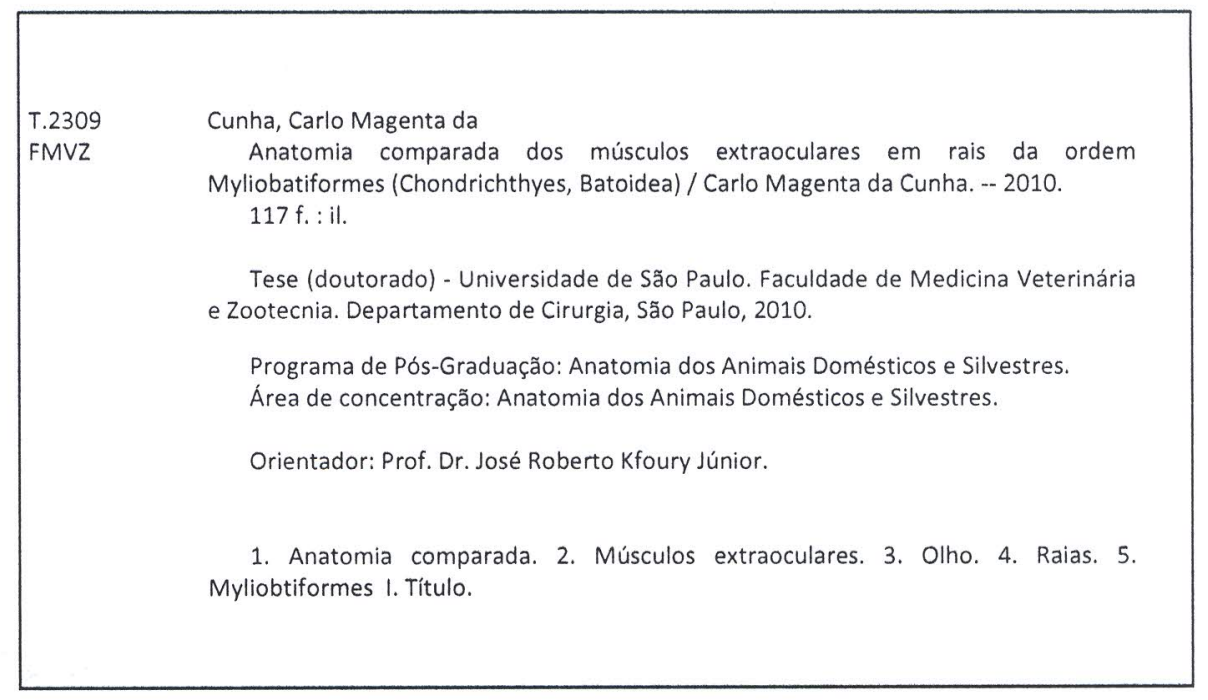




\begin{tabular}{cccc}
\hline & & ERRATA & \\
Folha & Parágrafo & Onde se lê & Leia-se \\
Ficha catalográfica & 2 & em rais da ordem & em raias da ordem \\
\hline
\end{tabular}




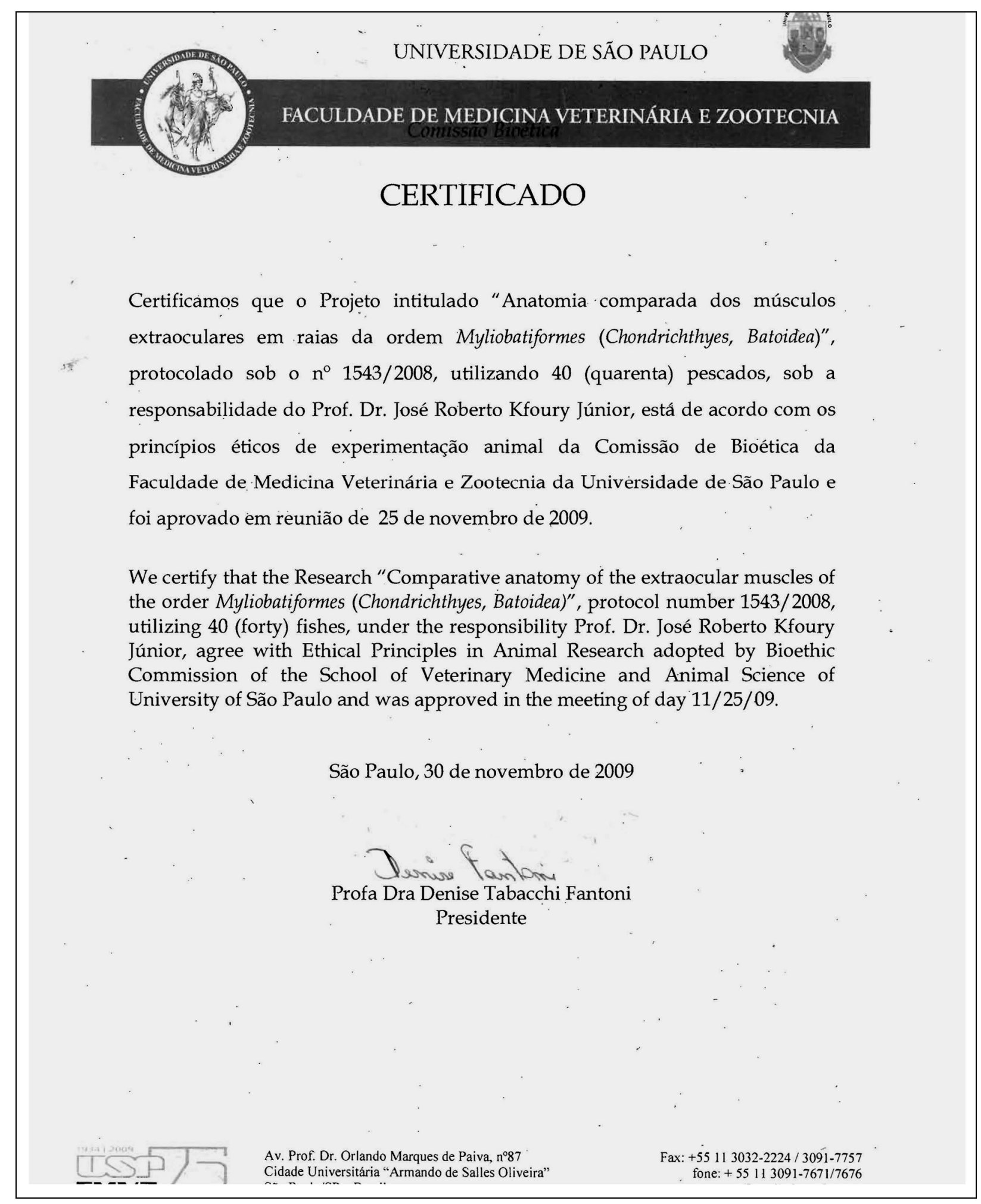




\section{FOLHA DE AVALIAÇÃO}

Nome: CUNHA, Carlo Magenta da

Título: Anatomia comparada dos músculos extraoculares em raias da ordem Myliobatiformes (Chondrichthyes, Batoidea)

Tese apresentada ao Programa de Pós-Graduação em Anatomia dos Animais Domésticos e Silvestres da Faculdade de Medicina Veterinária e Zootecnia da Universidade de São Paulo, para obtenção do título de Doutor em Ciências.

Data:

Banca Examinadora

Prof. Dr. Instituição:

Assinatura: Julgamento:

Prof. Dr. Instituição:

Assinatura: Julgamento:

Prof. Dr. Instituição:

Assinatura: Julgamento:

Prof. Dr. Instituição:

Assinatura: Julgamento:

Prof. Dr. Instituição: Julgamento: 
Esta pesquisa foi parcialmente financiada pela Coordenação de Aperfeiçoamento de Pessoal de Nível Superior (CAPES) 
"Um passo a frente e você não está mais no mesmo lugar"

(Chico Science \& Nação Zumbi) 
Dedico este trabalho à memória da saudosa amiga,

Tatiana Possato, pela dedicação de sua curta vida ao estudo das raias.

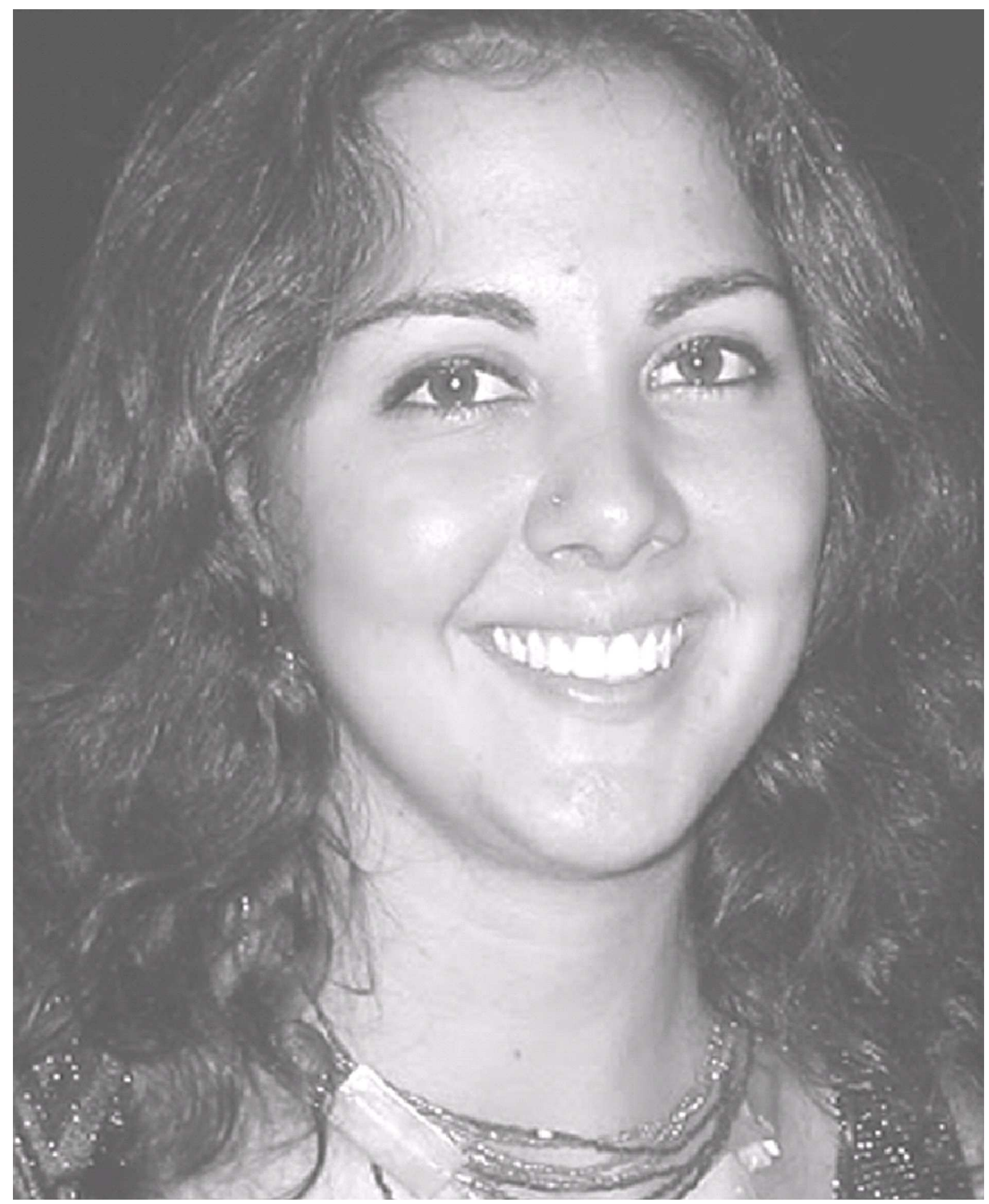

$(01 / 04 / 1978-31 / 05 / 2006)$

"A vida é a arte do encontro, embora haja tantos desencontros pela vida." 
Você não sabe quanta coisa eu faria

(Vinicius de Morais)

Além do que já fiz

Você não sabe até onde eu chegaria

Prate fazer feliz

Eu chegaria

Onde só chegam os pensamentos

Encontraria uma palavra que não existe

Pra te dizer nesse meu verso quase triste

Como é grande o meu amor

Você não sabe que os anseios do seu coração

São muito mais pra mim

Do que as razões que eu tenha

Pra dizer que não

E eu sempre digo sim

$E$ ainda que a realidade me limite

A fantasia dos meus sonhos me permite

Que eu faça mais do que as loucuras

Que já fiz pra te fazer feliz

Você só sabe que eu te amo tanto

Mas na verdade meu amor não sabe o quanto

E se soubesse iria compreender

Razões que só quem ama assim pode entender

Você não sabe quanta coisa eu faria

Por um sorriso seu

Você não sabe Até onde chegaria

Amor igual ao meu

Mas se preciso for eu faço muito mais

Mesmo que eu sofra

Ainda assim eu sou capaz

De muito mais do que as loucuras que já fiz

Pra te fazer feliz

(Roberto Carlos / Erasmo Carlos)

À minha esposa Luciana Galvão, esta música expressa tudo.

Simplesmente, Obrigado.

Te amo. 
"Para conhecermos os amigos é necessário passar pelo sucesso e pela desgraça. No sucesso, verificamos a quantidade $e$, na desgraça, a qualidade."

(Confúcio)

Aos grandes amigos Ademir Guerreiro (Dedê), Luciano Elias de Oliveira (LuC) e Luiz Gustavo Aleagi Nunes (Tatau) que no dia a dia estavam presentes, dando força, apoio e confiança. Vocês me fizeram perguntar várias vezes se são amigos ou irmãos. 
"Os momentos mais felizes da minha vida foram aqueles, (...) que pude passar em minha casa, com a minha família."

(Thomas Jefferson)

Todo meu respeito e agradecimento aos meus pais César e Cecília, meus irmãos Clóvis e Cláudia, minha esposa Luciana Galvão e minha filha Maria Lúcia. Vocês podem não saber, mas são meus maiores motivos de luta. 


\section{AGRADECIMENTOS}

Aos meus pais César Tavares da Cunha e Cecília Andrade Magenta da Cunha por todo apoio moral, psicológico e financeiro. Vocês são pessoas que fazem esse país melhor, por acreditarem na educação como instrumento transformador. Certamente sem vocês eu não chegaria até aqui.

Ao Prof. Dr. José Roberto Kfoury Júnior, por ter me aceitado como orientado, acreditado em meu trabalho e me ajudado inúmeras vezes durante todo processo da pós-graduação. Um amigo que serei sempre grato.

À Prof. ${ }^{a}$ Dr. ${ }^{a}$ Arani Nanci Bomfim Mariana pelo convite para a pós-graduação no programa de Anatomia dos Animais Domésticos e Silvestres da FMVZ/USP e claro por seus sábios e sempre pertinentes conselhos.

Ao Prof. Dr. Pedro Primo Bombonato pelos ensinamentos, amizade e também pelos valiosos apontamentos, sugestões na ocasião do Exame de Qualificação e ainda pela oportunidade de poder participar dos trabalhos de reabertura do Museu de Anatomia Veterinária (MAV).

Aos Professores do Departamento: Dr. Francisco Javier Hernandez Blazquez, Dr. Li Sei Watanabe, Dr. a Maria Angélica Miglino, Dr. a Paula de Carvalho Papa e Dr. Romeu Rodrigues de Souza pelos valiosos ensinamentos ao longo dos anos de pósgraduação.

Ao Prof. Dr. Luiz Ricardo Lopes de Simone, pela amizade, apoio e enorme incentivo. Um amigo a quem devo muito de minha formação.

Aos amigos do Laboratório de Ecotoxicologia da Universidade Santa Cecília: Dr. Aldo Ramos, Dr. Augusto César, Dr. Camilo D. S. Pereira e Fernando Cortez, pela amizade e toda atenção a mim dispensada desde o início de minha graduação.

Aos colegas do Laboratório de Técnicas Imunológicas Aplicadas à Morfofisiologia (LTIAM): Dr. a Ana Rita de Lima, Dr. a Janaína Munuera Monteiro, Maria Letícia Baptista Salvadori, Renata Stecca lunes, Dr. ${ }^{\underline{a}}$ Rosemary Viola Bosch e Thaís Martins Chucri pela amizade e apoio no decorrer deste trabalho. 
A todos os pescadores do Terminal Pesqueiro de Santos, em especial ao grande amigo Joaquim Gabriel Filho por ajudar na localização de barcos e no contato com colegas que trouxeram o precioso material deste estudo.

Às amigas: Bárbara L. Valentas pela elaboração caprichosa dos desenhos, Priscila Sotello pela ajuda na correção do abstract e ao primo Matheus Magenta pelo auxílio nos gráficos e tabelas deste trabalho.

Aos amigos João do Carmo Freitas e Raimundo Leal de Sousa, técnicos do Museu de Anatomia Veterinária (MAV), Prof. Dr. Plínio Pinto e Silva, por toda a atenção, dedicação, prontidão e auxílio nas atividades curriculares e extracurriculares, como também pelas valiosas trocas de experiências técnico-anatômicas, vocês são pessoas realmente especiais.

Aos amigos Ronaldo Agostinho da Silva e Dr. ․ Sandra Frieberger, técnicos do Laboratório de Histologia e Embriologia; Edinaldo Ribas Farias, técnico do Laboratório de Anatomia Macroscópica (LAM); Diogo Palermo Neto, técnico do Laboratório de Anatomia Microscópica e Imuno-histoquímica; e à Sr. ․ㅡ Fátima de Lourdes Minari, secretária do MAV pelo suporte dado a realização do trabalho.

Aos funcionários da Biblioteca Virginie Buff D'Ápice, pela prestatividade, profissionalismo, paciência e amizade, especialmente à Helena, Fernanda Cezar, Elza Faquim e Solange A. Santana. Vocês são pessoas que fazem desta, uma das melhores bibliotecas que freqüentei na Universidade de São Paulo.

Aos funcionários da Biblioteca do Museu de Zoologia da USP, pela amizade e prestatividade que sempre tiveram, especialmente à Airton de Almeida Cruz, Claudia Melo, Carmina Lupo, Dione Seripierri, Janete da Rocha, Marta Zamana, Maria da Conceição B. da Silva e Teresa Guimarães.

Helena, Fernanda Cezar, Elza Faquim e Solange A. Santana. Vocês são pessoas que fazem desta, uma das melhores bibliotecas que freqüentei na Universidade de São Paulo. 
Aos funcionários da secretaria de Pós-Graduação da FMVZ-USP, Joana Ferreira Dias de Vasconcelos, Carlos Alberto da Silva Vasconcelos, Dayse Maria Alves Flexa, especialmente à Cláudia Lima, pela enorme paciência e amizade.

Aos amigos Jaqueline Martins de Santana e Maicon Silva, secretários do Setor de Anatomia dos Animais Domésticos e Silvestres da FMVZ-USP, pela amizade e toda a prestatividade e paciência que dispuseram durante esses anos.

Aos amigos André Luis Casas, Camila Namie Tatsch Kikuchi, Luciano Elias de Oliveira e Marcello Machado pelas valiosas correções e sugestões dos manuscritos.

Ao Prof. Dr. Guilherme Henrique Pereira Filho (Jardim Botânico - RJ) e Dr. Alexandre de Freitas Azevedo (UERJ), pela importante ajuda nos testes estatísticos.

Ao amigo Raul Elias Pinto Jr., um grande amigo que sempre me apoiou para chegar até aqui.

Aos amigos da ictiologia: Dr. Ulisses Leite Gomes (UERJ), Dr. Hugo Ricardo Secioso Santos (UERJ), Dr. ํㅡㄹ Valéria Gallo (UERJ), Dr. José Lima de Figueiredo (MZUSP), Wagner Intelizano (UNIMES), Dr. Marcelo Rodrigues de Carvalho (IB-USP) e Thiago S. Meneses (GEES) pelo envio de material, referências, apoio e valiosas sugestões ao longo de todo processo.

Aos amigos da malacologia: Aline Boutros, Ana Dornellas (MZUSP), Bárbara L. Valentas (MZUSP), Carlos Henckes (CdB), Dr. a Cíntia Miyaji (UNIMONTE), Dr. Franklin Noel (MZUSP), Dr. Luiz. R. L. Simone (MZUSP), Dr. Paulino Souza (MZUSP), Vanessa Simão (MZUSP), Patrícia Oristiano (MZUSP), Rodrigo Marques (MZUSP), Dr. Sérgio Vanin (IB-USP) e Dr. ${ }^{\text {a }}$ Thelma Dias (UEPB), por todo apoio dado ao longo do trabalho.

Aos amigos pós-graduandos, pelos momentos de descontração e de seriedade, pelas alegrias compartilhadas e pelas tristezas consoladas, enfim, pela prazerosa convivência e sincera amizade, em especial à: Marcelo Mendes Alves, Matheus Tajra, Evander Bueno, Thiago Aloia, Carlos Sarmento, Camila Ercolini, Patrícia Facciotti, Marina Moreira, Simone Pereira, Renato Gerger, Leandro Fadel, Guilherme Burzon, Miryan Alva, Juliana Passos, Juliana Guimarães, Ana Paula Silva, Flavio 
Ribeiro, Karla Patrícia, Cristiane Wenceslau, André Franciolli, Marina Brito, Angélica Oliveira, Álvaro Galdos, João Carlos Morini Jr., André Gati, Regina Bolina, Renata Fontinele, Tatiana Carlesso dos Santos, Emerson Fioretto e Tânia Lima.

Aos afilhados Arthur Vasco de Toledo Aleagi Nunes e Jonathan Rodrigues pela paciência em muitos momentos de ausência. Amo vocês.

A memória do amigo Sr. Medeiros e de minha querida avó Hosana. Pessoas simples, de grande coração que sempre me estimularam a crescer como profissional e pessoa.

Aos companheiros Alcindo e Petrônio. 


\section{RESUMO}

CUNHA, C. M. da. Anatomia comparada dos músculos extraoculares em raias da ordem Myliobatiformes (Chondrichthyes, Batoidea). [Comparative anatomy of the extra ocular muscles of the order Myliobatiformes]. 2010. $117 \mathrm{f}$. Tese (Doutorado em Ciências) - Faculdade de Medicina Veterinária e Zootecnia, Universidade de São Paulo, São Paulo, 2010.

Os músculos extraoculares são responsáveis pela movimentação dos olhos em todos os vertebrados e estão agrupados em quatro músculos retos e dois oblíquos. Porém existem poucas descrições destes músculos para as raias. Neste estudo são descritos e comparados os músculos extraoculares de quatro espécies de raias Myliobatiformes que possuem habitat e hábitos alimentares distintos, sendo elas: Mobula thurstoni $(n=10)$, Pteroplatytrygon violacea $(n=10)$, Daysatis hypostigma $(n=10)$ e Gymnura altavela $(\mathrm{n}=10)$. Dasyatis hypostigma, $G$. altavela e $P$. violacea possuem o músculo reto dorsal, $\mathrm{m}$. reto ventral, $\mathrm{m}$. reto lateral, $\mathrm{m}$. reto medial, $\mathrm{m}$. obliquo dorsal e o $\mathrm{m}$. obliquo ventral. Em M. thurstoni não foram encontrados dois músculos oblíquos dorsal e ventral e sim apenas um músculo com uma cabeça e duas origens (bíceps). Diferenças significativas como à disposição do olho no condrocrânio, o afunilamento das fibras e local de inserção dos mm. oblíquos próximo ao ponto de inserção; a posição de cruzamento dos músculos reto medial e ventral com o pedículo óptico e a posição da inserção do músculo reto dorsal agruparam as espécies de acordo com seu habitat e modo de vida. Dasyatis hypostigma e G. altavela, raias bentônicas apresentaram o m. oblíquo dorsal mais desenvolvido do que os demais músculos. Em $P$. violacea, a inserção do músculo oblíquo dorsal ocorre no equador do bulbo e suas fibras não apresentam mudança na direção desde a origem à inserção. Em M. thurstoni, o m. reto lateral está suportado pela ação do músculo reto lateral $\beta$. Este músculo pode ser responsável por uma maior ação sinérgica com o músculo oblíquo bíceps. Este estudo mostrou que existem diferenças entre os músculos extraoculares, caindo, portanto a afirmativa de que os músculos extraoculares são "extraordinariamente constantes" em todos os vertebrados e abre-se um leque de opções de estudos comparativos para as raias que até então tiveram o estudo dos músculos extraoculares negligenciados.

Palavras-chave: Anatomia comparada. Músculos extraoculares. Raias. Myliobtiformes. 


\begin{abstract}
CUNHA, C. M. da. Comparative anatomy of the extraocular muscles of the order Myliobatiformes (Chondrichthyes, Batoidea). [Anatomia comparada dos músculos extraoculares em raias da ordem Myliobatiformes (Chondrichthyes, Batoidea)]. 2010. 117 f. Tese (Doutorado em Ciências) - Faculdade de Medicina Veterinária e Zootecnia, Universidade de São Paulo, São Paulo, 2010.
\end{abstract}

The extraocular muscles, responsible for the eye movements in all vertebrates, are classically grouped as four rectus muscles: rectus dorsal muscle, rectus ventral muscle, rectus lateral muscle and rectus medial muscle; and two oblique: oblique dorsal muscle and oblique ventral muscle; however, the description of these groups and their possible association with several species habits is very limited. Hence the objective of this study is to demonstrate the differences and singularities of the extraocular muscles in rays of diverse habitats and habits. This study used four species of rays of the Myliobatiformes order: Mobula thurstoni, pelagic stingray and planktofoga. Pteroplatytrygon violacea, pelagic stingray, predator of fish and squid; Dasyatis hypostigma and Gymnura altavela, both benthonic, predators of small fish and invertebrates. Ten heads of each species were decalcified and dissected to characterize and describe the extraocular muscles. The final results followed, qualitatively and quantitatively, the pattern of extraocular muscles found in vertebrate animals, for $P$. violacea, D. hypostigma e $G$. altavela species. But this pattern could not be established for $M$. thurstoni species because of, instead of two oblique muscles, only one muscle with two origins (biceps) was observed. There were also significant differences of the eye disposition in the chondrocranium; fibers narrowing down and on the place of insertion of oblique muscles near to the insertion point; the crossing position of the rectus medial and ventral muscles with the optical pedicle and the insertion position of the rectus dorsal muscle. Furthermore, this study shows that, distinctively from what has been known so far, the extraocular muscles are not the same for all species and present important anatomical differences that allow grouping the studied species according to their feeding behavior. In face of the obtained results, it is safe to conclude that the extraocular muscles are not "extraordinarily uniform" in all vertebrates and provide a range of options to comparative studies to various species that, until now, have had their study of extraocular muscles neglected.

Keywords: Comparative anatomy. Extraocular muscles. Rays. Myliobatiformes. 
LISTA DE ABREVIATURAS E SIGLAS

\begin{tabular}{|c|c|}
\hline II & Nervo óptico \\
\hline III & Nervo oculomotor \\
\hline IV & Nervo Troclear \\
\hline VI & Nervo abducente \\
\hline bo & Buldo do olho \\
\hline CM & Comprimento do músculo \\
\hline cr & Condrocranio \\
\hline DO & Diâmetro do olho \\
\hline DP & Desvio Padrão \\
\hline ep & Espiraculo \\
\hline es & Esclera \\
\hline LD & Largura do disco \\
\hline mo & Músculo obliquo \\
\hline MZUSP & Museu de Zoologia da Universidade de São Paulo \\
\hline nc & Nadadeira cefálica \\
\hline nd & Nadadeira peitoral \\
\hline no & Nervo óptico \\
\hline od & Músculo obliquo dorsal \\
\hline ol & Olho \\
\hline ov & Músculo obliquo ventral \\
\hline rb & Músculo reto lateral $B$ \\
\hline rd & Músculo reto dorsal \\
\hline rl & Músculo reto lateral \\
\hline $\mathbf{r} / \beta$ & músculo reto lateral $\beta$ \\
\hline
\end{tabular}




$\begin{array}{ll}\mathbf{r m} & \text { Músculo reto medial } \\ \mathbf{r r} & \text { Músculos retos } \\ \mathbf{r v} & \text { Músculo reto ventral } \\ \mathbf{t d i} & \text { Tendão de inserção } \\ \text { tdo } & \text { Tendão de origem } \\ \text { TPS } & \text { Terminal Público de Santos } \\ \text { UERJ } & \text { Universidade do Estado do Rio de Janeiro }\end{array}$




\section{LISTA DE FIGURAS}

Figura 1 - Aspectos anatômicos de Dasyatis hypostigma. A. superfície dorsal, B. ventral, C. região cefálica e D. olho direito em vista lateral

Figura 2 - Aspectos anatômicos da superfície dorsal do corpo inteiro e um mobulídeo (A) e detalhes de Mobula thurstoni (B e C). A. $M$. japanica, B. cabeça e C. lateral direita da região cefálica.

Figura 3 - Aspectos anatômicos do corpo de Pteroplatytrygon violacea. A. superfície dorsal, B. região cefálica e C. lateral direita da cabeça ...51

Figura 4 - Aspectos anatômicos do corpo de Gymnura altavela. A. superfície dorsal, B. superficie ventral, C. região cefálica, D. vista dorsal da região orbital direita e E. vista lateral direita da cabeça ...52

Figura 5 - Representação dos dados mensurados. A. vista dorsal de exemplar inteiro, B. vista ventral do $\mathrm{m}$. reto lateral e C. vista dorsal do bulbo do olho de G. altavela.

Figura 6 - Exemplo de técnica de cocção realizada em raia da espécie Rhinoptera brasiliensis para maceração dos arcos branquiais

Figura 7 - Técnica de maceração por dermestídeos. A. Vista geral da caixa de manutenção dos besouros. B e C. Detalhes dos besouros do gênero Dermestis consuminto tecido de estruturas esqueléticas. Crédito das imagens ao Dr. Hugo R. S. Santos (UERJ)

Figura 8 - Vista dorsal da região cefálica, demonstrando a angulação do equador do bulbo em relação à linha mediana do corpo de: $\mathbf{A}$. Dasyatis hypostigma, ângulo aproximado de 4우 B. Gymnura altavela ângulo aproximado de 3; C. Mobula thurstoni, ângulo aproximado de 0 o; D. Pteroplatytrygon violacea ângulo aproximado de $22^{\circ}$

Figura 9 - Região orbital com o respectivo bulbo do olho in situ de $D$. hypostigma. A. Cabeça, vista dorsal; B. Região orbital e bulbo do olho direito, vista dorsal; C. Região orbital e bulbo do olho esquerdo, vista lateral

Figura 10 - Musculatura extrínseca e bulbo do olho esquerdo de $D$. hypostigma in situ, A. Vista dorsal; B. Detalhe da inervação dos $\mathrm{mm}$. reto medial e dorsal. 
Figura 11 - Musculatura extrínseca do bulbo do olho direito de $D$. hypostigma em vistas A. dorsal; B, ventral; C, caudal e D. caudomedial......

Figura 12 - Musculatura extrínseca do bulbo do olho esquerdo de G. altavela; A. Disposição dos $\mathrm{mm}$. reto e oblíquo dorsal em vista dorsal; B. Disposição dos $\mathrm{mm}$. retos e oblíquos em vista ventral.

Figura 13 - Bulbo do olho esquerdo de G. altavela em vista ventral (A e B). A, músculos oblíquos rebatidos; $\mathbf{B}, \mathrm{m}$. oblíquo ventral rebatido, mostrando a inserção do $\mathrm{m}$. reto ventral.

Figura 14 - Região orbital e musculatura extraocular de M. thurstoni. A. Vista lateral da órbita direita. B. Vista dorsal do neurocrânio e bulbo do olho in situ (peça preparada por Dermestis sp.); C. Detalhe da localização das origens dos $\mathrm{mm}$. retos e oblíquos.

Figura 15 - Músculos extraoculares do bulbo dos olhos direito $(A$ e $D)$ e esquerdo (B e C) de $M$. thurstoni. A. Vista dorsal dos músculos extraoculares e suas relações com o neurocrânio e bulbo do olho; B. Detalhe do $\mathrm{m}$. reto lateral $\beta$ em vista dorsal; C. Vista lateral da relação dos $\mathrm{mm}$. reto lateral e ventral, seta indica o ponto de inserção do $\mathrm{m}$. reto lateral $\beta$; $\boldsymbol{D}$. Vista das origens dos $\mathrm{mm}$. retos ...79

Figura 16 - Músculos extraoculares do bulbo do olho direito de $M$. thurstoni.

A. Vista anterior do bulbo; B. vista posterior do bulbo

Figura 17 - Relação dos músculos extraoculares do bulbo do olho esquerdo de M. thurstoni. A. Vista lateroventral do bulbo; B. vista ventral do bulbo, com a parte ventral do $\mathrm{m}$. oblíquo rebatida

Figura 18 - Músculos extraoculares do bulbo do olho direito de M. thurstoni. A. Vista laterodorsal; B. vista dorsal; C. vista anterodorsal; D. vista posterolateral

Figura 19 - Músculos extraoculares do bulbo do olho direito de $M$. thurstoni.

A. Órbita com bulbo do olho removido; B. vista ventral

Figura 20 - Bulbo do olho e músculos extraoculares de $P$. violacea. A. Vista laterodorsal do bulbo do olho in situ. B. Vista dorsal do bulbo do olho e as relações dos $\mathrm{mm}$. retos medial e dorsal; e m. oblíquo dorsal; C. Relações das origens dos mm. retos medial e dorsal; e m. oblíquo dorsal

Figura 21 - Vistas ventrais do bulbo do olho direito de $P$. violaea. A, Relação dos $\mathrm{mm}$. oblíquo ventral e reto ventral; B. Seqüência da dissecção de $A$. inserção do $\mathrm{m}$. reto ventral e sua relação com 0 nervo óptico; e a inserção do m. oblíquo ventral

Figura 22 - Bulbo do olho direito com inserções musculares de $P$. violacea. A. Vista lateral, detalhe da inserção do $\mathrm{m}$. reto lateral e sua 
relação com o m. reto dorsal; B. Vista dorsal; inserção dos mm. reto dorsal e oblíquo dorsal. C. Detalhe de B; inserções dos $\mathrm{mm}$. reto dorsal e oblíquo dorsal.

Figura 23 - Músculos extraoculares e bulbo do olho esquerdo de $P$. violacea.

A. vista dorsal e B. vista lateral.

Figura 24 - Bulbo do olho e músculos extraoculares de $P$. violacea. A. Vista dorsal; B. vista medial; C. vista dorsocaudal com $\mathrm{m}$. oblíquo dorsal rebatido; D. vista caudal, com $\mathrm{mm}$. oblíquos dorsal e ventral rebatidos 


\section{LISTA DE GRÁFICOS}

Gráfico 1 - Distribuição das espécies estudadas em relação à profundidade e posição na coluna d'água e $D$. hypostigma (10-75 m), G. altavela (50-150 m), M. thurstoni (10-100 m) e P. violacea (50-150 m)

Gráfico 2 - Média e desvio padrão da relação do diâmetro do olho (DO) em relação ao comprimento dos $\mathrm{mm}$. retos medial $(R M)$, lateral $(R L)$, dorsal $(R D)$ e ventral $(R V)$; e dos $\mathrm{mm}$. oblíquos ventral $(\mathrm{OV})$ e dorsal $(\mathrm{OD})$ para as espécies $\mathrm{D}$. hypostigma (DH); G. altavela (GA); P. violacea (PV) e M. thurstoni (MT). As letras diferentes indicam diferenças detectadas pelo teste de Tukey

Gráfico 3 Analise de componentes Principais (PCA). Da relação do diâmetro do olho (DO) em relação ao $\mathrm{m}$. reto medial (RM); m. reto lateral $(R L) ; m$. reto dorsal $(R D) ; m$. reto ventral (RV); m. oblíquo ventral (OV) e m. oblíquo dorsal (OD) para as espécies $D$. hypostigma $(\mathrm{DH}) ; G$. altavela $(\mathrm{GA}) ; P$. violacea (PV) e M. thurstoni (MT) 


\section{LISTA DE TABELAS}

Tabela 1 - Número de amostras destinadas às respectivas técnicas. .48

Tabela 2 - Dados biométricos do bulbo do olho e músculos extraoculares de D. hypostigma, G. altavela, M. thurstoni e P. violacea .55

Tabela 3 - Fórmula para Solução descalcificadora, segundo Casas (2004) e Casas et al (2005) 57

Tabela 4 - Formato da inserção na esclera por espécies. .89 


\section{SUMÁRIO}

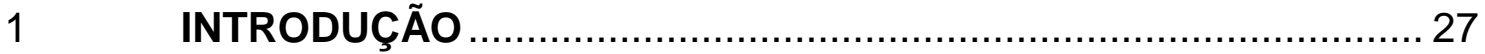

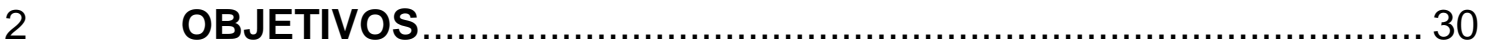

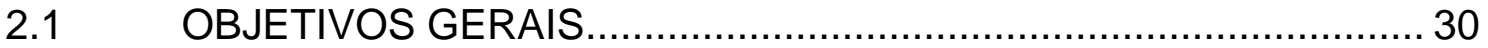

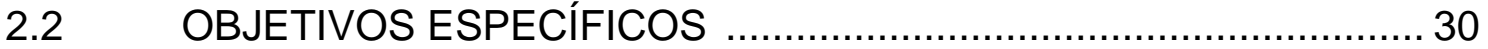

3 REVISÃO DE LITERATURA ................................................. 32

3.1 DASYATIS HYPOSTIGMA SANTOS \& CARVALHO, $2004 \ldots \ldots \ldots . . . . .32$

3.2 PTEROPLATYTRYGON VIOLACEA (BONAPARTE, 1832) ............. 34

3.3 GYMNURA ALTAVELA (LINNAEUS, 1758).............................. 35

3.4 MOBULA THURSTONI (LLOYD, 1908) ....................................... 35

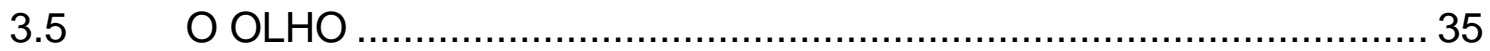

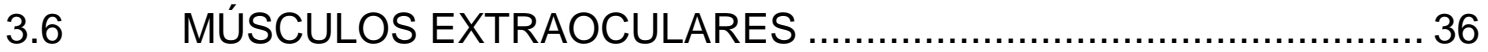

3.7 MÚSCULOS EXTRAOCULARES EM ELASMOBRÂNQUIOS ........... 37

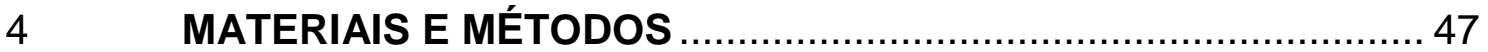

$4.1 \quad$ MATERIAIS ......................................................................... 47

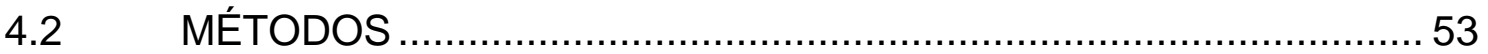

4.2.1 Análise Morfométrica dos Músculos Extraoculares.....................53

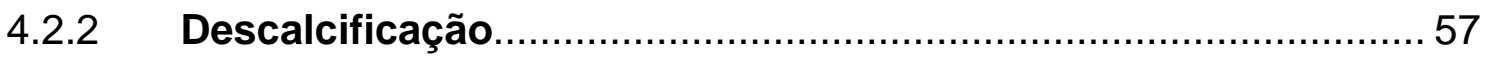

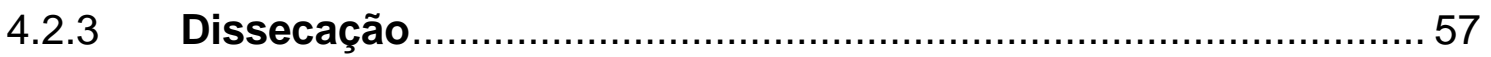

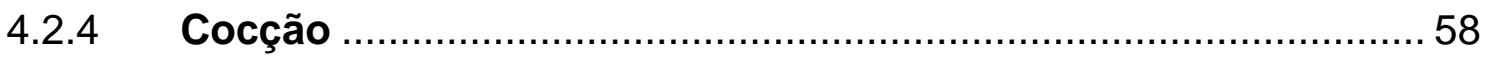

4.2.5 Técnica de maceração por desmestídeos................................. 58

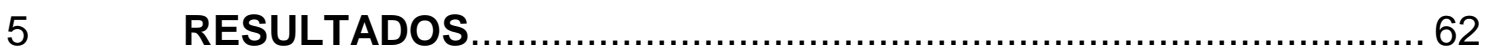

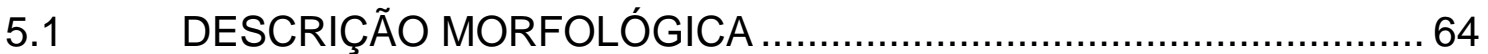

5.1.1 Dasyatis hypostigma Santos e Carvalho, 2004 ........................ 64

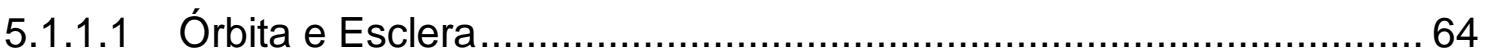

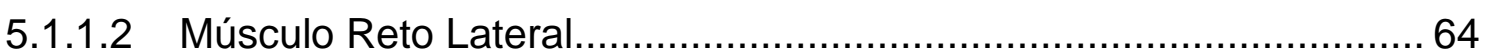

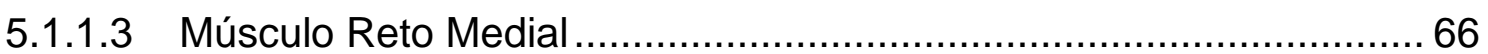

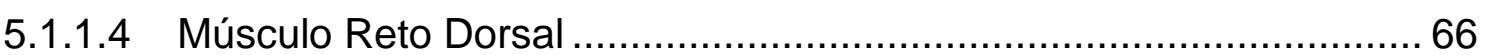

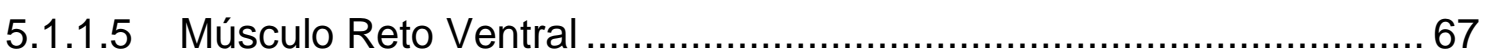

5.1.1.6 Músculo Oblíquo Dorsal ........................................................ 68

5.1.1.7 Músculo Oblíquo Ventral ...................................................... 68

5.1.2 Gymnura altavela (Linnaeus, 1758) .................................. 70

5.1.2.1 Órbita e Esclera...................................................................... 70

5.1.2.2 Músculo Reto Lateral........................................................... 70 
5.1.2.3 Músculo Reto Medial ................................................................... 71

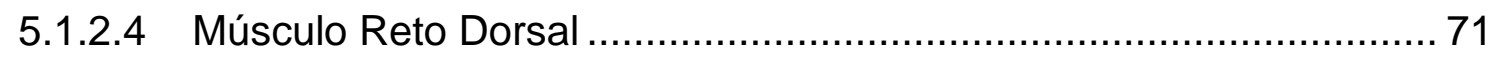

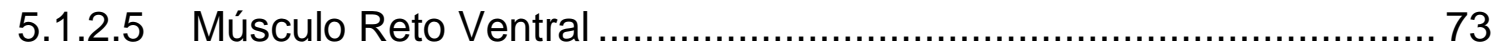

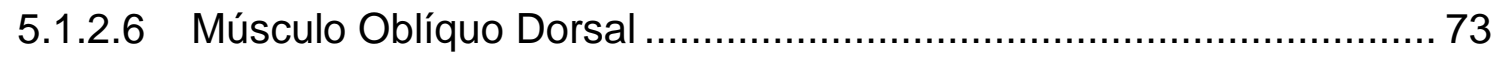

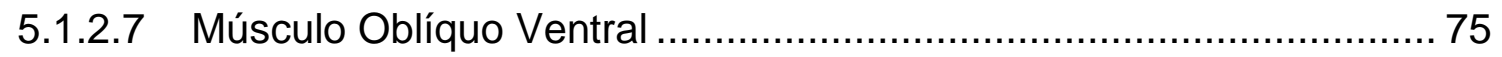

5.1.3 Mobula thurstoni (Lloyd, 1908).............................................. 75

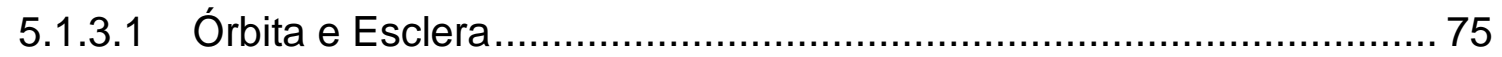

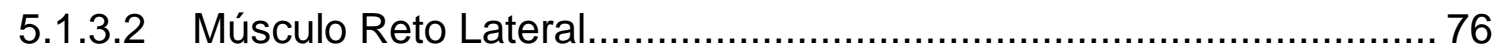

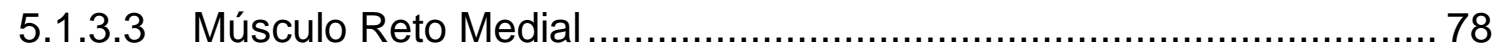

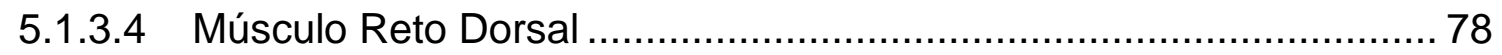

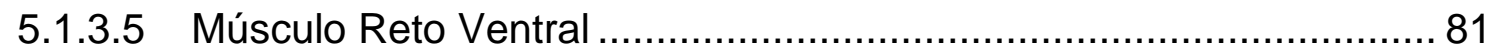

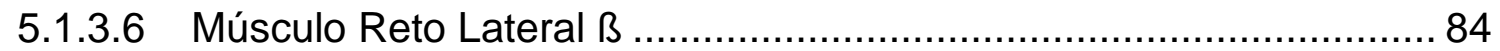

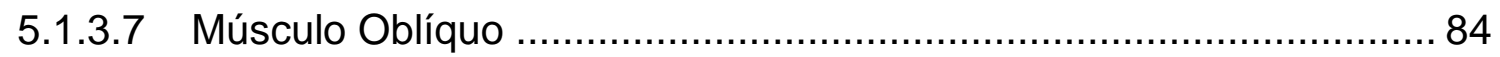

5.1.4 Pteroplatytrygon violacea (Bonaparte, 1832) ............................ 85

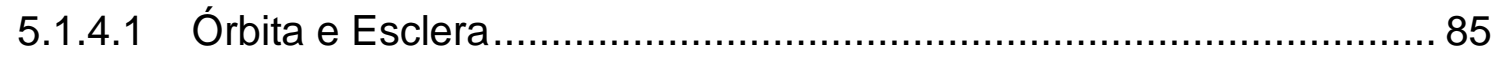

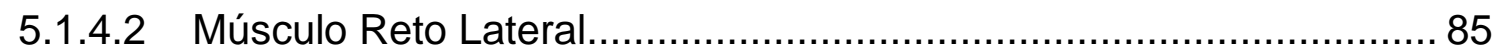

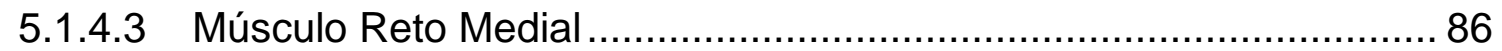

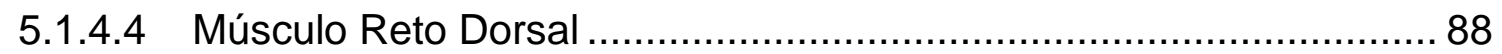

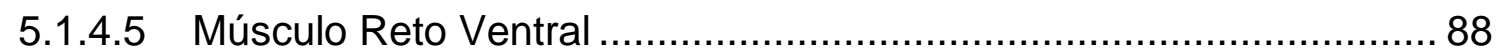

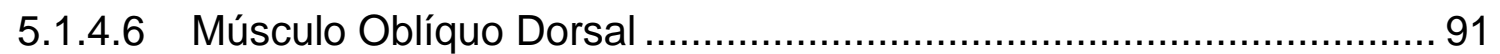

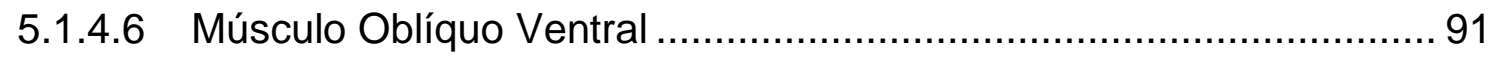

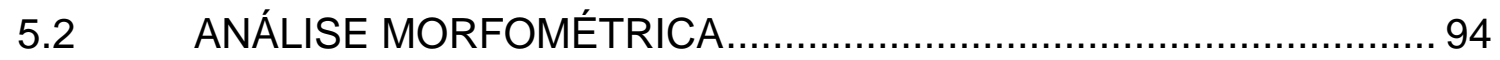

5.2.1 Análise do comprimento - ANOVA ………................................... 94

5.2.2 Análise de Componentes Principais (PCA) .................................... 94

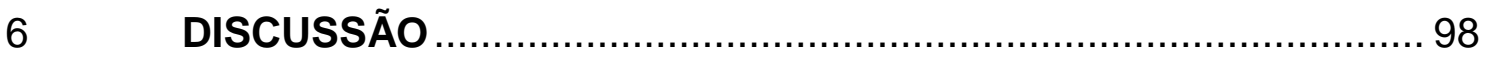

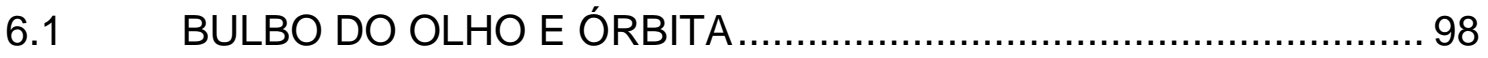

6.2 TENDÃO DE INSERÇÃO........................................................ 10

6.3 MÚSCULOS EXTRAOCULARES …................................................ 101

6.4 RELAÇÕES MORFO-ECOLÓGICAS........................................... 105

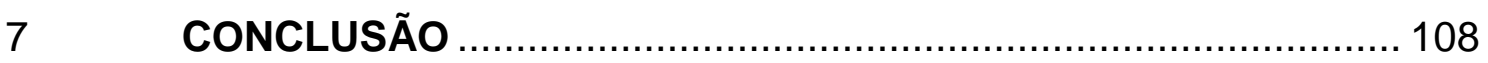

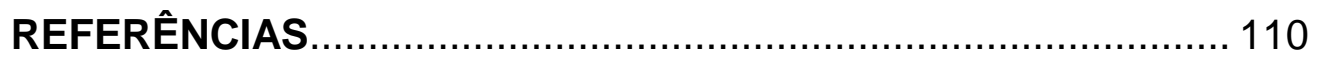


Introdução

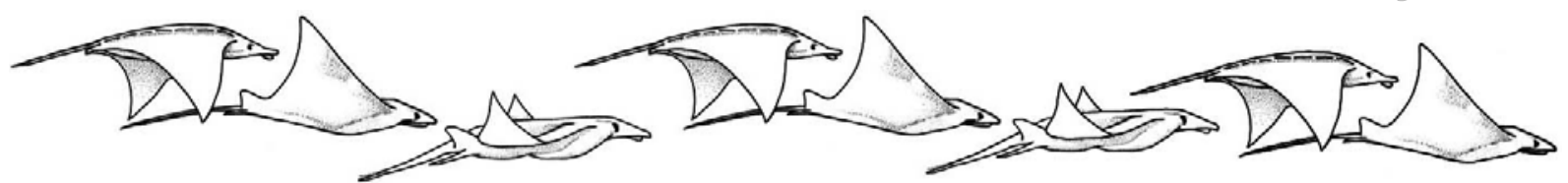




\section{INTRODUÇÃO}

Os Chondrichthyes, além de apresentarem uma grande diversidade morfológica, ocupam os mais diversos tipos de ambientes, sendo muitos grandes predadores de topo de cadeia nos ecossistemas marinhos (LAGLER et al., 1977; COMPAGNO, 1990; POUGH; HEISER; McFARLAND, 1999; NELSON, 2006, 2006), dotados de um sistema sensorial altamente especializado (MURRAY, 1960, 1962; THEISEN, 1986).

Embora predadores ativos, os elasmobrânquios foram geralmente descritos como tendo pequeno olho e pobre visão, usando muito mais outros sentidos como olfato, audição e eletrorecepção (GILBERT, 1963; COHEN, 1989). Entretanto, após a descoberta da dupla retina, contendo cones e bastonetes, em tubarões (GRUBER; HAMASAKI; BRIDGES, 1963; HAMASAKI; GRUBER, 1965) mais evidências surgiram quanto à funcionalidade dos olhos de tubarões e raias, mostrando a importância da visão em um grande número de espécies (GRUBER; COHEN, 1978; HUERTER; COHER, 1991; HART et al., 2006).

Os músculos extraoculares, responsáveis pela movimentação do bulbo do olho, são constantes em número, disposição e inervação nos vertebrados (GOODRICH, 1986). São conhecidos seis músculos, sendo destes quatro retos e dois oblíquos que, que apresentam a seguinte denominação: $m$. reto dorsal, $m$. reto ventral, $\mathrm{m}$. reto lateral, $\mathrm{m}$. reto medial, $\mathrm{m}$. oblíquo ventral e $\mathrm{m}$. oblíquo dorsal (NOMINA VETERINÁRIA, 2005). Na ação de movimentação do bulbo do olho eles formam três pares antagonistas e sinérgicos. Os músculos reto dorsal e reto ventral são responsáveis pelo movimento no eixo horizontal do bulbo do olho, direcionando o olho para cima ou para baixo. Os $\mathrm{mm}$. reto medial e reto lateral são responsáveis pelo movimento no eixo vertical, movimentando os olhos para frente e para trás; e o m. obliquo dorsal e m. oblíquo ventral são os responsáveis pela rotação do bulbo do olho no eixo óptico (HARDER, 1975; CARPENTER, 1977).

Como qualquer outra estrutura anatômica, os olhos exibem uma variação funcional e estrutural determinada por fatores ambientais, evolutivos e genéticos 
(HAIRSTON JR.; LI; EASTER, 1982). Vários estudos referentes a esta diversidade têm mostrado que a morfologia do olho em peixes pode variar, entre outros fatores, de acordo com a estratégia alimentar e com o habitat (MENEZES; WAGNER; ALF, 1981; HAIRSTON JR.; LI; EASTER, 1982; WILLIAMSON; KEAST, 1988; FANTA et al., 1994).

A alimentação e as relações intra e interespecíficas em um determinado ambiente são fatores dos mais importantes, ao lado da reprodução, para garantir a sobrevivência das espécies de uma comunidade. Avaliando-se estratégias comportamentais, como a detecção de alimento, verifica-se que elas variam conforme a espécie, possivelmente devido às estruturas sensoriais e locomotoras, dentre as quais o olho como uma das principais estruturas (FANTA et al., 1994).

No presente trabalho são descritos e comparados os aspectos morfológicos macroscópicos dos músculos extraoculares em quatro espécies de raias Myliobatiformes, comparando as diferenças e similaridades entre os grupos, com a hipótese de que a morfologia estabelece limites ao modo de vida de cada uma das espécies.

Dessa forma, espera-se que os resultados obtidos se tornem subsídios para estudos de homologia comparada com outros membros da ordem, partindo do princípio de que informações dessa natureza, ainda não relatadas na literatura, preenchem lacunas importantes no atual nível de entendimento sobre a biologia desses animais. 


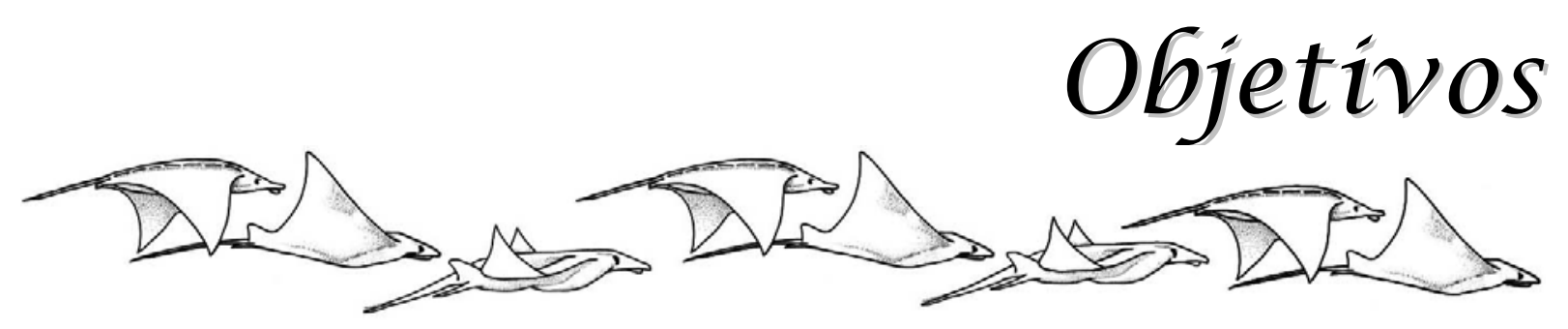




\section{OBJETIVOS}

\subsection{OBJETIVOS GERAIS}

O objetivo deste estudo foi descrever os aspectos morfológicos macroscópicos dos músculos extraoculares de quatro espécies de raias pertencentes à ordem Myliobatiformes, contemplando as suas relações com elementos e estruturas vizinhas, bem como identificar e comparar as diferenças e similaridades morfológicas entre as espécies, procurando evidenciar os limites estabelecidos pelo modo de vida de cada espécie em relação à morfologia encontrada.

\subsection{OBJETIVOS ESPECÍFICOS}

a) Descrever os aspectos morfológicos macroscópicos, sintópicos e esqueletotópicos dos músculos extraoculares de quatro espécies de raias: Dasyatis hypostigma, Gymnura altavela, Mobula thurstoni e Pteroplatytrygon violacea;

b) Descrever as características anatômicas dos músculos extraoculares das espécies propostas;

c) Comparar os aspectos morfológicos entre as espécies estudadas;

d) Identificar diferenças intraespecíficas;

e) Relacionar as similaridades e particularidades morfológicas com as características de interação ambiental da espécie. 
Revisão de Literatura 


\section{REVISÃO DE LITERATURA}

Visando facilitar a compreensão da informação obtida pelos autores seguintes, a nomenclatura foi padronizada segundo a Nomina Anatômica Veterinária - NAV (2005) sempre que necessário.

No Brasil são conhecidas 127 espécies de elasmobrânquios (LESSA et al., 1999,) sendo no estado de São Paulo, registradas 32 espécies, entre elas 7 espécies pertencentes à ordem Myliobatiformes (FIGUEIREDO, 1997; GADIG 1998).

A utilização de estudos morfológicos de tubarões e raias é relativamente vasta (DANIEL, 1934; HOLMGREN, 1941; GOHAR; BAYOUMI, 1959; HAMDY, 1959, 1961; GOHAR; HAMDY, 1963; KHALL, 1963; COMPAGNO, 1973; GILBERT, 1973; HARDER, 1975; GOODRICH, 1986; HAMDY; MIYAKE, 1988; MIYAKE; MCEACHRAN, 1991; MIYAKE; MCEACHRAN; HALL, 1992), sendo que trabalhos recentes de anatomia são encontrados em artigos relacionados à sistemática do grupo, tendo-se em vista evidenciar estruturas anatômicas que elucidem a sistemática dos taxa (NAKAYA, 1975, 1978; COMPAGNO, 1979; ANDRÉS; GUZMAN; MUÑOZ-CHAPULI, 1987; COMPAGNO, 1988; MIYAKE, 1988; MIYAKE; MCEACHRAN; HALL, 1992; LOVEJOY, 1995; GONZALÉZ-ISÁIS, 2003; CARVALHO; MAISEY; GRANDE, 2004; GONZALÉZ-ISÁIS; DOMÍNGUEZ, 2004) ou na utilização da anatomia para estudos morfofuncionais (WILGA; MOTTA, 1998; MOTTA; WILGA, 1999, 2001; PANTANO-NETO; SOUZA, 2002; CASAS, 2004; DEAN; MOTTA, 2004; WILGA, 2005).

\subsection{DASYATIS HYPOSTIGMA SANTOS \& CARVALHO, 2004}

Pertencente a família Dasyatidae, Dasyatis hypostigma, é uma espécie encontrada no litoral Sul e Sudeste do Brasil, habitando profundidades entre 10-75 metros (SANTOS; CARVALHO, 2004) (Gráfico 1). Assim como as outras espécies do gênero, vivem associadas ao substrato, forrageando o fundo de areia ou cascalho na busca de pequenos peixes, moluscos e crustáceos. Mede cerca de 60 


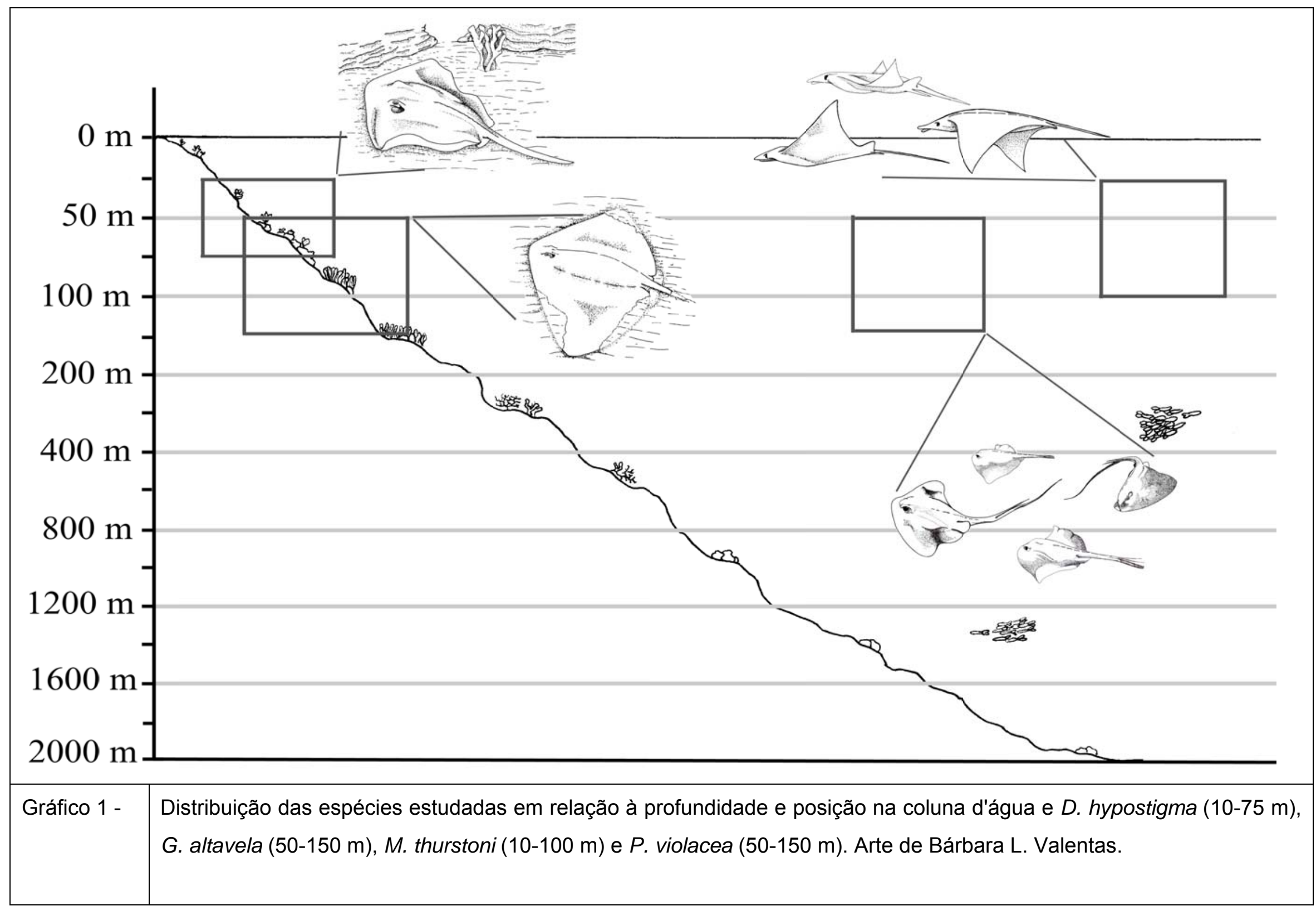


cm de largura de disco, e ocorre no litoral Sudoeste da América do Sul, entre Brasil e Argentina (MCEACHRAN; CARVALHO, 2002b; BORNATOWSKIA; ABILHOAA; CHARVET-ALMEIDA, 2009).

3.2 PTEROPLATYTRYGON VIOLACEA (BONAPARTE, 1832)

É uma raia de médio porte que atinge tamanho máximo de $80 \mathrm{~cm}$ de largura. Essa espécie possui afiadas fileiras de dentes, utilizados principalmente na captura de lulas e peixes. É uma espécie de distribuição circuntropical e subtropical (McEACHRAN; CARVALHO, 2002b; MOLLET, 2002; ELLIS, 2007), capturada em profundidades entre 50 e 150 metros (Gráfico 1), sendo o único representante da família Dasyatidae que vive na coluna d’água, em mar aberto (regiões pelágicas oceânicas) (WILSON; BECKETT, 1970; MCEACHRAN; CARVALHO, 2002b; SIQUEIRA; SANT'ANNA, 2007; VÉRAS et al., 2009).

3.3 GYMNURA ALTAVELA (LINNAEUS, 1758)

São conhecidas cerca de 40 espécies na família Gymnuridae, sendo que não Brasil é representado por duas espécies do Gymnura: G. altavela, com ocorrência para o litoral Sul, e G. micrura, com ocorrência para o litoral Norte (MCEACHRAN; CARVALHO, 2002c; NUNES; PIORSKI 2009).

Espécies deste gênero são morfologicamente caracterizadas por possuírem maior largura do que comprimento do disco (BIGELOW; SCHROEDER, 1953). Conhecida como raia borboleta ou raia Gereva, Gymnura altavela é uma espécie de grande porte que pode alcançar cerca de 2 metros de diâmetro. Vive sobre substrato de areia ou areno-lodoso em profundidades entre 0 e 50 metros (Gráfico 1),. É predadora de moluscos, crustáceos e pequenos peixes que captura no substrato (DAIBER; BOOTH, 1960; CAPAPÉ et al., 1992; MCEACHRAN; CARVALHO, 2002c). 
O gênero Mobula é o maior em número de espécies da família Mobulidae. Assim como outras espécies do gênero, Mobula thurstoni é uma espécie migratória, que nada usando as longas nadadeiras peitorais como asas. É uma espécie filtradora, que usa estruturas branquiais, conhecidas como rastros branquiais, para filtrar organismos que vivem na coluna d'água (plâncton) e pequenos cardumes de peixes (MCEACHRAN; CARVALHO, 2002a; MARSHALL; COMPAGNO; BENNETT, 2009).

Espécies deste gênero possuem grandes dimensões, podendo chegar a mais de 2 metros de largura. Forma grandes cardumes que chegam a mais de 500 indivíduos. No Brasil são conhecidas quatros espécies: M. japanica, M. tarapacana, M. hypostoma e $M$. thurstoni. Espécies do gênero estão espalhadas pelo mundo em profundidades de 50 a $200 \mathrm{~m}$ (Gráfico 1) de mares tropicais e sub-tropicais (NOTARBARTOLO-DI-SCIARA 1987; MCEACHRAN; CARVALHO, 2002a, CASAS et al., 2006).

\section{$3.5 \mathrm{O}$ OLHO}

O olho é um órgão que permite detectar a luz e transformar essa percepção em impulsos elétricos. Localiza-se na órbita, na qual seu formato e posição são importantes, pois há uma relação da posição do olho com o movimento de muitos animais (PRINCE, 1956; CARPENTER, 1977). A posição do olho na cabeça é uma característica importante e amplamente discutida. Os olhos podem estar localizados em frente à cabeça, de lado, ou em qualquer ângulo elevado ou não. A posição do olho está diretamente associada ao habitat, atividades e forma de predação do animal. Olhos voltados para frente da cabeça permitem um campo maior de visão, uma fixação binocular e também possibilita atividades diurnas, pois é durante o dia que esta capacidade pode ser bem mais utilizada, enquanto olhos localizados ao 
lado da cabeça possuem dois campos completamente diferentes, com pouca ou nenhuma sobreposição binocular (PRINCE, 1960). Neste processo, o tamanho do olho está diretamente relacionado à capacidade de visualização, já que aumenta a área de recepção de luz pela retina (PRINCE, 1960; WALLS, 1967; CARPENTER, 1977).

Nos peixes os olhos possuem estruturas e anexos oculares comuns a todos os vertebrados, como por exemplo: o nervo óptico (II) - função exclusivamente sensitiva que transporta as sensações visuais do olho para o encéfalo; a córnea parte anterior transparente e protetora do olho; cristalino ou lente - funciona como uma lente, participando dos meios refrativos do olho; retina - parte do olho responsável pela formação de imagens; esclera - túnica externa branca e fibrosa do globo do olho e os músculos extraoculares - responsáveis pela movimentação do bulbo do olho (WALLS, 1967; MUNZ, 1971; WALKER; HOMBERGER, 1992).

\subsection{MÚSCULOS EXTRAOCULARES}

Os músculos extraoculares são seis músculos que controlam os movimentos do olho. As ações dos músculos extraoculares dependem da posição do olho no momento da contração muscular (PRINCE, 1960).

Nos vertebrados os músculos extraoculares se dividem em dois grupos distintos, os retos e os oblíquos. Os músculos oblíquos se originam na parede rostromedial da órbita e se estendem caudal e obliquamente para se inserirem na superfície dorsal e na ventral da esclera. Os músculos retos se originam na parede caudomedial da órbita para se inserirem na esclera, sendo nomeados segundo seu ponto de inserção: reto dorsal, reto ventral, reto medial e reto lateral (HARDER, 1975; ROMER; PARSONS, 1985; GOODRICH, 1986; LIEM; WALKER; HOMBERGER, 1992; SUMMERS, 1999).

Os músculos extraoculares em vertebrados são extraordinariamente constantes em número, disposição e inervação. Com seis músculos, sendo quatro 
retos e dois oblíquos adaptados para movimentar os olhos em várias direções. Após o surgimento dos ciclostomatos, pequenas mudanças ocorreram, exceto pela adição do músculo retrator do bulbo em répteis e mamíferos, além dos músculos quadrado e piramidal em aves e usados para movimentar a membrana nictitante. (SLONAKER, 1921; GOODRICH 1958, 1986).

A inervação desses músculos segue o mesmo padrão em todos os vertebrados, de tal forma que o nervo oculomotor (III) inerva os $\mathrm{mm}$. reto medial, reto ventral e dorsal, além do $\mathrm{m}$. oblíquo ventral; o nervo abducente $(\mathrm{VI})$ inerva o $\mathrm{m}$. reto lateral e o nervo troclear (IV) inerva o m. oblíquo dorsal. (NEAL, 1915; SLONAKER, 1921; DANIEL, 1934; GOODRICH 1958; PRINCE, 1960; WALLS, 1967; HARDER, 1975; CARPENTER, 1977; GOODRICH, 1986; NICOL, 1989; WALKER; HOMBERGER, 1992; LIMA et al, 1997; LIEM; SUMMERS, 1999;).

Hifny e Misk (1982) estudaram as inserções dos tendões dos músculos extraoculares em cavalo, mula, jumento, vaca, búfalo, camelo, ovinos, caprinos, suínos, cães e gatos, no intuito de prover estudos para cirurgia. A anatomia desses tendões mostrou diferenças entre as espécies na forma, posição e direção das linhas de inserção.

\subsection{MÚSCULOS EXTRAOCULARES EM ELASMOBRÂNQUIOS}

Nos elasmobrânquios os músculos extraoculares seguem o mesmo padrão encontrado em outros vertebrados, sendo quatro músculos retos e dois músculos oblíquos, que se situam entre a órbita e a esclera, são responsáveis pela movimentação dos olhos e possuindo a mesma inervação que os demais vertebrados (NEAL, 1915; SLONAKER, 1921; DANIEL, 1934; GOODRICH, 1958; PRINCE, 1960; WALLS, 1967; HARDER, 1975; LIEM; CARPENTER, 1977; GOODRICH, 1986; WALKER; HOMBERGER, 1992; LIMA et al., 1997; SUMMERS, 1999).

O padrão dos músculos extraoculares tem mudado durante o curso da evolução dos placodermos e condrichthyes. De acordo com a reconstrução dos 
padrões de forames e miodomos em placodermos devonianos proposto por Young (1986), o músculo oblíquo ventral surge da depressão junto do forame do nervo óptico (II) ventralmente ao pedículo óptico. O músculo reto medial origina na parte dorsal ao pedículo óptico. Os outros músculos em placodermos se originam na parte postero-dorsal da órbita. Em holocéfalos, o músculo reto medial se origina na parte anteromedial da órbita, rostral ao forame do nervo óptico (II), enquanto a maior parte dos tubarões o músculo surge na parte posteromedial da órbita caudal ao forame do nervo óptico (II). O referido autor diz ainda que o padrão mantido em ambos holocéfalos e tubarões são idênticos (YOUNG, 1986).

A seguir serão apresentados os autores que descrevem os músculos extraoculares para espécies de elasmobrânquios, sendo citados em ordem cronológica crescente. Cada trabalho adota uma nomenclatura própria para estruturas similares. Para uniformizar e facilitar o entendimento seguirá a nomenclatura proposta pela NAV.

Von Bonde (1933) estudou a anatomia da cabeça do gênero Sphyrna, tubarões da família Sphyrnidae cujo crânio é prolongado lateralmente (tubarãomartelo), entre outros aspectos, descreveu os músculos extraoculares. Consoante o autor, devido à forma da cabeça e o arranjo dos olhos, os músculos extraoculares não são homólogos a nenhuma outra espécie de elasmobrânquio. Estes músculos são arranjados em dois grupos. O primeiro compreende os músculos oblíquo dorsal e ventral, que se encontram na extremidade rostral da órbita. Estes músculos são curtos e estão inseridos na parte anterior da esclera.

Edgeworth (1935) diz que o bulbo do olho é movido pelos músculos extraoculares. Em Chondrichthyes, teleósteos e dipnoi, com exceção de Neoceratodus que possui apenas cinco músculos, sendo o $\mathrm{m}$. reto ventral ausente. Embora o autor não tenha descrito os músculos extraoculares, as seguintes espécies são ilustradas e podemos dizer que:

Dos músculos de Squalus sp.:

Apenas a vista ventral a esclera esquerda é ilustrada, mostrando que os $\mathrm{mm}$. retos se originam no mesmo ponto em que o pedículo óptico se articula com a órbita. 
Os $\mathrm{mm}$. reto lateral, medial e ventral são finos e alongados, porém a ilustração permite a visualização de um pequeno trecho do $\mathrm{m}$. reto dorsal. Os $\mathrm{mm}$. oblíquos se originam anteriormente na órbita, sendo o $\mathrm{m}$. oblíquo dorsal visivelmente mais largo e curto que o m. oblíquo ventral (EDGEWORTH, 1935).

Dos músculos de Mustelus laevis:

A órbita esquerda é ilustrada, mostrando que possui os seis músculos extraoculares. Os $\mathrm{mm}$. oblíquos se originam no mesmo ponto, na parte posteromedial da órbita. Os $\mathrm{mm}$. reto medial e reto dorsal se destacam em tamanho dos demais músculos. O $\mathrm{m}$. reto lateral é mais curto que dos demais músculos extraoculares e possui duas cabeças (EDGEWORTH, 1935).

Dos músculos de Heptranchias perlo:

A órbita esquerda é ilustrada, mostrando topograficamente a posição dos $\mathrm{mm}$. retos e oblíquos. Os $\mathrm{mm}$. retos se originam na parte anterior da órbita, não aparecendo sua relação com o pedículo óptico. Apesar de seccionados, fica claro que os mm. oblíquos são maiores em relação aos mm. retos (EDGEWORTH, 1935).

Oliva (1967) descreve a topografia e compara o diâmetro horizontal dos olhos como o comprimento dos músculos extraoculares dos tubarões (Squalus, Etmopterus, Squatina, Scyliorhinus, "Pristiurus") e raias (Raja, Torpedo, Dasyatis). As raias do gênero Dasyatis e Torpedo, e tubarões do gênero Squatina possuem músculos extraoculares mais longos, enquanto a raia Raja e os tubarões Squalus e Etmopterus possuem os mais curtos. O autor relaciona a organização oculomotora dos elasmobrânquios com seus respectivos modos de vida apresentando discussões com base filogenética.

Isomura (1981) comparou o arranjo dos músculos extraoculares entre peixes, anfíbios, répteis, aves e mamíferos, utilizando-se de 27 espécies diferentes. Nesta comparação foram usadas tubarões do gênero Alopias e Mustelus. Observou-se nos peixes (teleósteos e elasmobrânquios) quatro $\mathrm{mm}$. retos e dois $\mathrm{mm}$. oblíquos que se desenvolvem claramente. As diferenças relatadas pelo autor entre teleósteos e elasmobrânquios, diz respeito à inervação, de forma que em teleósteos o $\mathrm{m}$. reto dorsal é inervado pelo ramo dorsal do nervo oculomotor (III), enquanto os $\mathrm{mm}$. reto 
medial, oblíquo ventral e reto dorsal são invervados pelo ramo ventral do nervo oculomotor (III). Nos elasmobrânquios, o m. reto medial é inervado pelo ramo superior do nervo oculomotor (III). Ainda segundo o autor, embora os músculos recebam seus nomes e funções de acordo com o local de inserção na esclera, em Hippocampus a inserção do $\mathrm{m}$. oblíquo dorsal cruza com a inserção do $\mathrm{m}$. reto dorsal, e a inserção do $\mathrm{m}$. oblíquo ventral também cruza com a inserção do $\mathrm{m}$. reto ventral.

Miyake (1988) ao estudar a sistemática do gênero Urotrygon, descreve comparativamente a anatomia de dez espécies do gênero. O autor identifica os seis músculos extraoculares e os descreve da seguinte forma:

O m. obliquo dorsal origina-se na parte anterodorsal da órbita, ventral ao canal pré-orbital e se insere na parte médiodorsal da esclera, sobrepondo às inserções dos músculos oblíquos (=reto) dorsal e medial.

O m. oblíquo ventral origina-se na porção próximolateral da placa basal, com algumas fibras estendendo-se mais anteriormente à face ventral da cápsula nasal próxima ao septo internasal ventral. A inserção do oblíquo inferior está na porção médioventral da esclera, ventral à inserção do m. reto ventral.

A origem de todos os músculos retos está localizada na parte posterodorsal da órbita, caudal ao forame do $\mathrm{n}$. oculomotor (III). Os $\mathrm{mm}$. reto dorsal e medial se inserem na parte mediodorsal da esclera, ventral à inserção do $\mathrm{m}$. oblíquo dorsal. $\mathrm{O}$ $\mathrm{m}$. reto lateral se insere na parte caudoventral da esclera. $\mathrm{O}$ m. reto ventral se insere na parte anteroventral da esclera, de forma que o ponto de inserção sobrepõe o ponto de inserção do $\mathrm{m}$. oblíquo inferior.

Nishida (1990) entre várias características anatômicas utilizou também a musculatura cefálica e visceral na tentativa de esclarecer a filogenia dos Myliobatidoidei. Sobre os músculos extraoculares em Myliobatoidei o autor diz que compreendem em seis partes e os descreve da seguinte forma:

Músculos oblíquos dorsal e ventral que se originam na superfície posterior da cápsula nasal entre os forâmens do canal pré-orbital, inserem-se nos lados superior e inferior da esclera. 
Músculo oblíquo dorsal é dividido em duas partes em muitos Myliobatoidea, mas em outros esta condição não foi notada.

Músculos reto dorsal, ventral, lateral e medial se originam na parte superior da órbita, justamente na ao redor da base do pedículo óptico.

O Músculo reto é o mais fino e se estende anteriormente e se insere na esclera sobre a inserção do músculo obliquo. Ainda segundo o autor, em alguns myliobatoidea o músculo reto se origina na porção distal do processo pós-orbital e se divide antes da inserção na esclera.

O músculo reto passa ao longo do pedículo óptico e se insere na região ventral do da esclera, abaixo da inserção do Músculo oblíquo.

Ainda de acordo com o autor, apenas em Hexatrygon os músculos extraoculares são reduzidos, nas demais espécies de myliobatoideos e grupos externos os músculos são muito similares. Embora tenha visto tal redução nos músculos extraoculares em Hexatrygon, nenhum dado sobre a musculatura extraocular foi utilizado nas análises filogenéticas.

Gomes, Santos e Medina (1991) estudaram um exemplar adulto de Dasyatis say (espécie posteriormente descrita como D. hypostigma) com anoftalmia (ausência do olho) do lado esquerdo. Embora não tenha sido descrito olho normal, não anolftalmico, os autores apresentam uma figura na qual podemos inferir que, os músculos do olho direito do mesmo exemplar estudado apresentam-se normalmente, observando-se os músculos obliquo dorsal, reto medial e reto dorsal; e ventralmente o ramo do músculo oblíquo dorsal, o músculo obliquo ventral e parte do músculo reto lateral. No olho esquerdo, anoftálmico, os músculos alcançam o pedículo óptico e somente o músculo reto dorsal não está totalmente conectado a ele. Ainda consoante os autores, esse fato deve ter ocorrido em fase pré-natal, provavelmente por motivos genéticos, uma vez que não há cicatriz e devido a boa aparência dos músculos do lado esquerdo.

Ainda segundo Gomes, Santos e Medina (1991), uma das ilustrações fornecidas, se refere ao olho direito (normal) e mostra a sobreposição da inserção do 
m. oblíquo dorsal sobre a inserção do $\mathrm{m}$. reto medial. Pode-se também observar que as origens dos músculos retos partem da porção caudal da órbita, próxima a articulação do pedículo óptico e os músculos oblíquos partem na porção rostral da órbita, ventralmente ao processo pré-orbital. A esclera não ocupa toda órbita e existe um largo espaço entre a esclera e a órbita, de forma que os músculos se apresentam levemente esticados, não sendo possível tirar informações sobre os tendões.

A musculatura da cabeça também foi utilizada por Shirai (1992) como auxílio na definição da superordem Squalea.

Walker e Homberger (1992) descrevem os músculos oblíquos e retos para Squalus acanthias. De acordo com o autor, os $\mathrm{mm}$. oblíquos surgem na porção rostromedial da órbita e se inserem na esclera, de forma que o $\mathrm{m}$. oblíquo dorsal na porção dorsal e o m. oblíquo ventral na porção ventral da esclera. Os músculos retos se originam na porção caudomedial da órbita, de forma que o músculo reto dorsal se insere na porção dorsal da esclera, adjacente à inserção do músculo oblíquo dorsal e o músculo reto ventral na porção ventral da esclera ao lado da inserção do músculo oblíquo ventral. O músculo reto medial se insere na porção anterior da esclera e o músculo reto lateral na porção posterior. Ainda segundo o autor, as estruturas básicas dos músculos extraoculares dos mamíferos é muito similar às encontradas no gênero Squalus, porém difere em detalhes que o autor não os cita.

Lima et al. (1997) descreve e compara os músculos da região cefálica prébranquial em Sphyrna lewini e Rhizoprionodon lalandi, sendo eles os músculos levator palatiquadrati, levator hyomandibularis, levator labii superior e adductor mandibulae, além dos seis músculos extraoculares. A seguinte descrição é dada para os músculos de ambas as espécies "achatados e expandindo-se", isso porque ele considera os músculos extraoculares das duas espécies como "morfologicamente semelhantes".

Lima et al. (1997) descrevem os músculos extraoculares em Sphyrna lewini e Rhizoprionodon lalandi como:

Dos músculos de Sphyrna lewini: 
Os músculos oblíquos são curtos quando comparados com os retos, sua origem ocorre na junção da parede lateral da cápsula nasal e a distal da asa do processo pré-orbital, sendo que no trajeto para se inserir na esclera eles se separam de forma que o músculo oblíquo dorsal se insere na porção anterodorsal e o músculo oblíquo ventral na porção anteroventral da esclera.

Os músculos retos se originam fusionados na porção caudal ao pedículo óptico, se separando à medida que se aproximam da cápsula óptica, aderindo ao pedículo óptico e aos nervos ópticos (II), oculomotor (III) e abducente (VI).

O músculo reto dorsal se insere adjacente ao $\mathrm{m}$. oblíquo dorsal, na porção mediodorsal da esclera e o $\mathrm{m}$. reto ventral insere-se adjacente à inserção do $\mathrm{m}$. obliquo ventral na porção medioventral da esclera. $\mathrm{O}$. reto medial se insere na porção medioanterior e o m. reto lateral na porção medioposterior da esclera.

Dos músculos de Rhizoprionodon lalandi:

O músculo oblíquo ventral se origina ventralmente ao processo pós-orbital, e em seu trajeto cruza o m. obliquo dorsal antes de se inserir na porção anterosuperior da esclera.

O m. oblíquo dorsal se origina na margem do forame pro-óptico e se insere na porção posterodorsal da esclera.

Estudos morfológicos são muito escassos na família Mobulidae (CASAS, et al. 2006), a qual está inserido o gênero Mobula, principalmente por se tratar de espécies de grande porte (>1 m) (NOTARBARTOLO-Di-SCIARA, 1987; DOMÍNGUEZ; GONZÁLEZ-ISÁIS, 2007). Gohar e Bayoumi (1959) estudaram morfologicamente os sistemas digestivo, respiratório, urogenital e nervoso de Mobula kuhlii e Manta ehrenbergi (=Manta birostris) no Mar Vermelho, além de apresentar detalhes sobre a dentição e os arcos branquiais, com o objetivo de conhecer a anatomia desses animais, porém não dando nenhuma informação sobre nenhum tipo de musculatura. 
A musculatura da cabeça foi estudada nos tubarões Heptranchus maculatus (DANIEL, 1934) Squalus acanthias (GANS; PARSONS, 1964; GILBERT, 1986; LAGLER et al., 1977) Negaprion brevirotris (MOTTA; WILGA, 1995), Ginglymostoma cirratum (MOTTA; WILGA, 1999), Carcharias taurus (CASAS, 2004), e em raias do gênero Mobula (DOMíNGUEZ; GONZÁLEZ-ISÁIS, 2007), do gênero Potamotrygon (PANTANO-NETO; SOUZA, 2002) e do gênero Urotrygon e Urolophus (MIYAKE, 1988).

A seguir os trabalhos de González-Ísaís (2003); González-Isáis e Domínguez (2004) e Dominguez e González-Isáis (2007) tratam da musculatura cefálica da superfamília Myliobatoidea, porém em nenhum dos trabalhos os autores estudaram a musculatura extraocular desses animais. Contudo, trazem importantes resultados comparativos entre as espécies e cm o modo de vida desses animais.

González-Isáis (2003) descreveu e comparou a musculatura cefálica dorsal e ventral de membros da superfamília Myliobatoidea, dentre os quais Gymnura marmorata, G. micrura, Mobula munkiana e M. thurstoni. Entre os resultados obtidos pela autora, a anatomia agrupou as espécies estudadas de acordo com seus hábitos de predação. O arranjo da musculatura ventral encontrado para as espécies do gênero Gymnura concordou os hábitos de espécies similares, como Rhinobatus lentiginosus que tem como dieta pequenos peixes, crustáceos e moluscos (WILGA; MOTTA, 1998). Ainda segundo a autora, as espécies estudadas do gênero Mobula apresentaram significante redução da musculatura ventral, tendo os $\mathrm{mm}$. depressor mandibular e coracohiomandibular ausente, devido possivelmente ao modo de predação desta espécie que mantém a boca aberta por longos períodos para filtrar a água que contém os organismos como pequenos crustáceos, que se alimenta.

González-Isáis e Domínguez (2004) a fim de obter resultados filogenéticos, estudos morfológicos se utilizando do esqueleto e musculatura da superfamília Myliobatoidea. Dentre as espécies de sua análise utilizou Gymnura marmorata, G. micrura, Mobula munkiana, M. tarapacana e M. thurstoni. Em seus resultados agrupou os gêneros Gymnura e Aetoplatea em um grupo e os gênero Mobula, Rhinoptera, Manta, Aetomylaeus, Aetobatus e Myliobatis em outro grupo. 
Dominguez e González-Isáis (2007) estudaram a anatomia do gênero Mobula principalmente descrevendo seu esqueleto e os músculos superficiais da cabeça. Embora tenham encontrado significante diferença na anatomia das espécies estudadas, apenas uma ilustração esquemática dos músculos extraoculares foi apresentada no trabalho.

McComb e Kajiura (2008) analisou o campo de visão, de forma a testar quantitativamente a visão monocular e binocular, das raias Dasyatis sabina (binocular), Raja eglenteria (binocular), Rhinoptera bonasus (monocular) e Urobatis jamaicensis (binocular) 


\section{Materiais e Métodos}

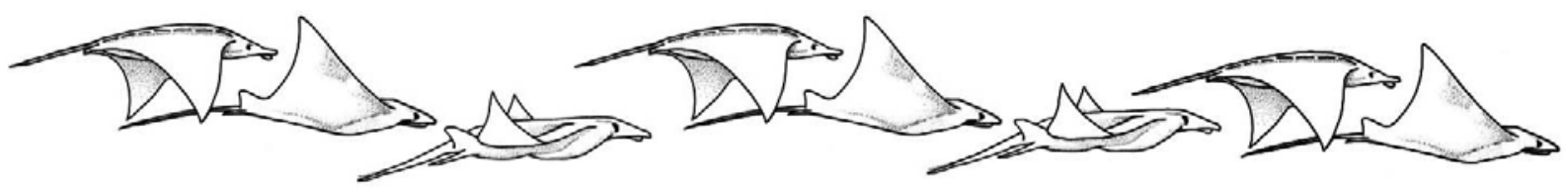




\section{MATERIAIS E MÉTODOS}

A seguir cada etapa pertinente aos materiais e aos métodos empregados neste estudo será descrita no decorrer deste capítulo com a intenção de facilitar a réplica do mesmo e posterior confronto dos dados por outros pesquisadores.

\subsection{MATERIAL}

Utilizamos cabeças de raias de quatro gêneros e espécies diferentes, todos pertencentes à ordem Myliobatiformes. As espécies utilizadas foram: Mobula thurstoni, família Mobulidae (Figura 2); Pteroplatytrygon violacea, família Dasyatidae (Figura 3); Dasyatis hypostigma, família Dasyatidae (Figura 1); Gymnura altavela, família Gymnuridae (Figura 4).

Os espécimes foram solicitados aos pescadores da frota pesqueira que atuam no Sudeste e Sul do Brasil. Essas frotas são sediadas em Guarujá, Ita Fish Transportes e Comércio de Pescados e Santos, no Terminal Público de Santos (TPS).

No total foram utilizadas 10 exemplares de cada espécie, totalizando 40 raias, sendo destinadas ao processo de descalcificação para serem dissecadas; cocção e maceração por desmestídeos (Tabela 1).

O processamento do material foi realizado no Laboratório de Anatomia Macroscópica do Setor de Anatomia dos Animais Domésticos e Silvestres do Departamento de Cirurgia da Faculdade de Medicina Veterinária e Zootecnia da Universidade de São Paulo. Os animais foram identificados conforme a chave de identificação de Figueiredo (1997) para P. violacea e G. altavela, Gadig, Namora e Motta (2003) para M. thurstoni, e Santos e Carvalho (2004) para D. hypostigma. Depois de fixadas com injeções intramusculares de solução aquosa de formol tamponado a $4 \%$, foram estocadas, em total imersão, em recipientes contendo a mesma solução e com capacidade de volume 5 vezes maior do que o volume do 
material imerso. Após 48 horas as peças foram transferidas para recipientes contendo solução de álcool etílico a $70 \%$, onde foram permanentemente mantidas em imersão.

Os espécimes de $M$. thurstoni e $P$. violacea foram obtidos através de embarcações de pesca do Atum (Atuneiros) que acidentalmente pescam essas espécies com espinhel de superfície. Como não possuem valor comercial são descartada pelos pescadores.

Os espécimes de $D$. hypostigma são pescados por redes de arrasto de camarão (Arrasto de porta), entre profundidades de 50-70 metros. No mesmo tipo de pesca são encontradas outras espécies do mesmo gênero, como por exemplo, $D$. centroura. A escolha por $D$. hypostigma se deu pelo fato desta espécie possuir uma estrutura sensorial em forma de "W" localizado entre o quinto par de fendas branquiais, facilitando a identificação da espécie apenas pela cabeça.

Os espécimes de G. altavela foram obtidos por pescadores que operam com embarcações do tipo Parelha, entre profundidades de 25-45 metros. Apenas oito exemplares foram obtidos com os pescadores, deste forma outros dois exemplares foram emprestados pelas coleção do Museu de Zoologia da Universidade de São Paulo (MZUSP 32063) e Coleção de Ictiologia da Universidade do Estado do Rio de Janeiro (UERJ.Did.08).

Tabela 1- Número de amostras destinadas às respectivas técnicas

\begin{tabular}{lccc}
\hline \multirow{2}{*}{ Espécies } & \multicolumn{3}{c}{ Técnica } \\
\cline { 2 - 4 } & Descalcificação & Cocção & Maceração \\
\hline G. altavela & 8 & 2 & 0 \\
D. hypostigma & 8 & 2 & 0 \\
M. thurstoni & 6 & 0 & 1 \\
P. violacea & 8 & 2 & 0 \\
\hline
\end{tabular}




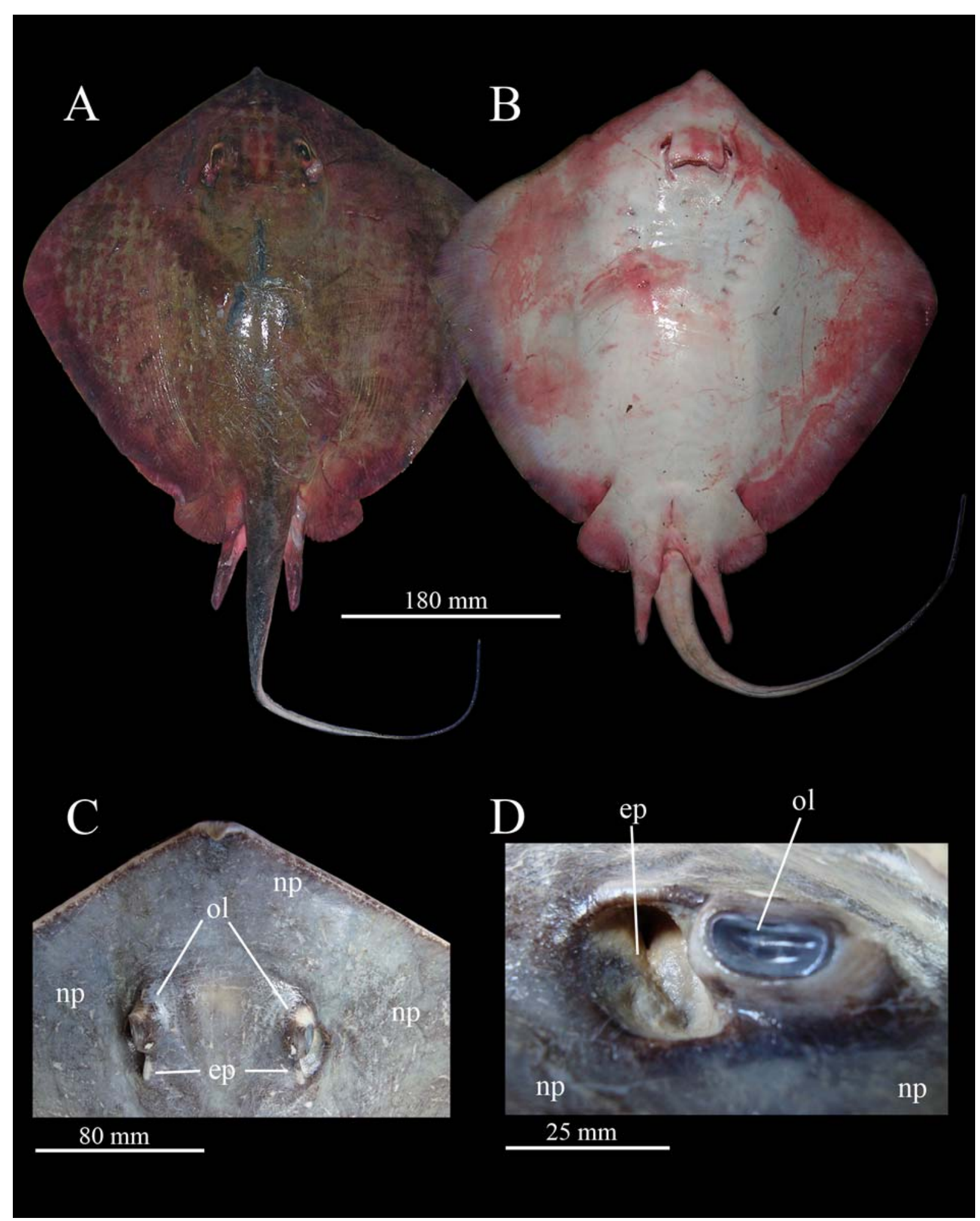

Figura $1(A-D)$ - $\quad$ Aspectos anatômicos de Dasyatis hypostigma. A. superfície dorsal, B. ventral, C. região cefálica e D. olho direito em vista lateral. Legenda: es, espiráculo; np, nadadeira peitoral; ol, olho 


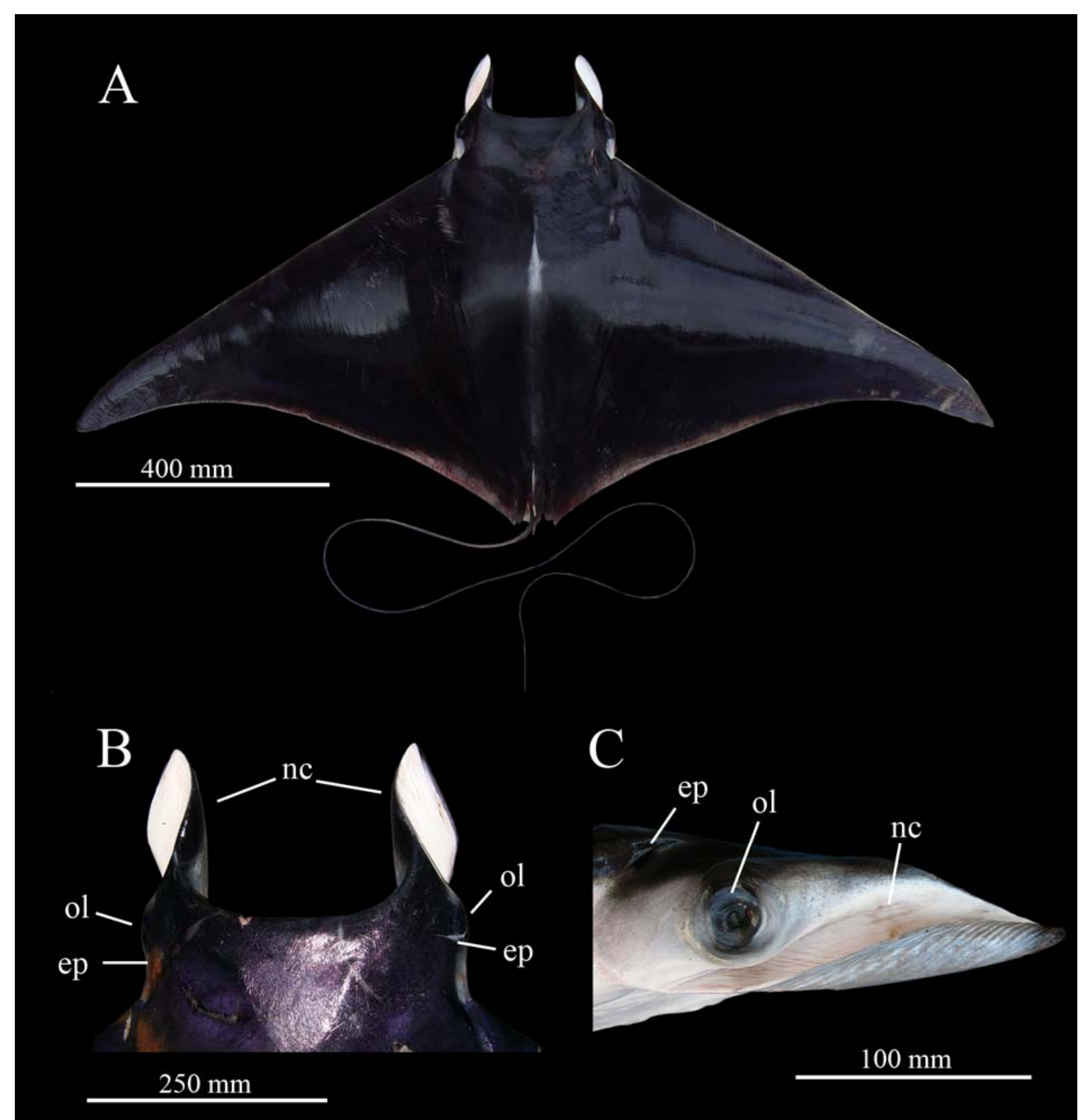

Figura $2(A-C)$ - Aspectos anatômicos da superfície dorsal do corpo inteiro e um mobulídeo (A) e detalhes de Mobula thurstoni (B e C). A. M. japanica, B. cabeça e $\mathbf{C}$. lateral direita da região cefálica Legenda: es, espiráculo; nc, nadadeiras cefálicas; ol, olho 


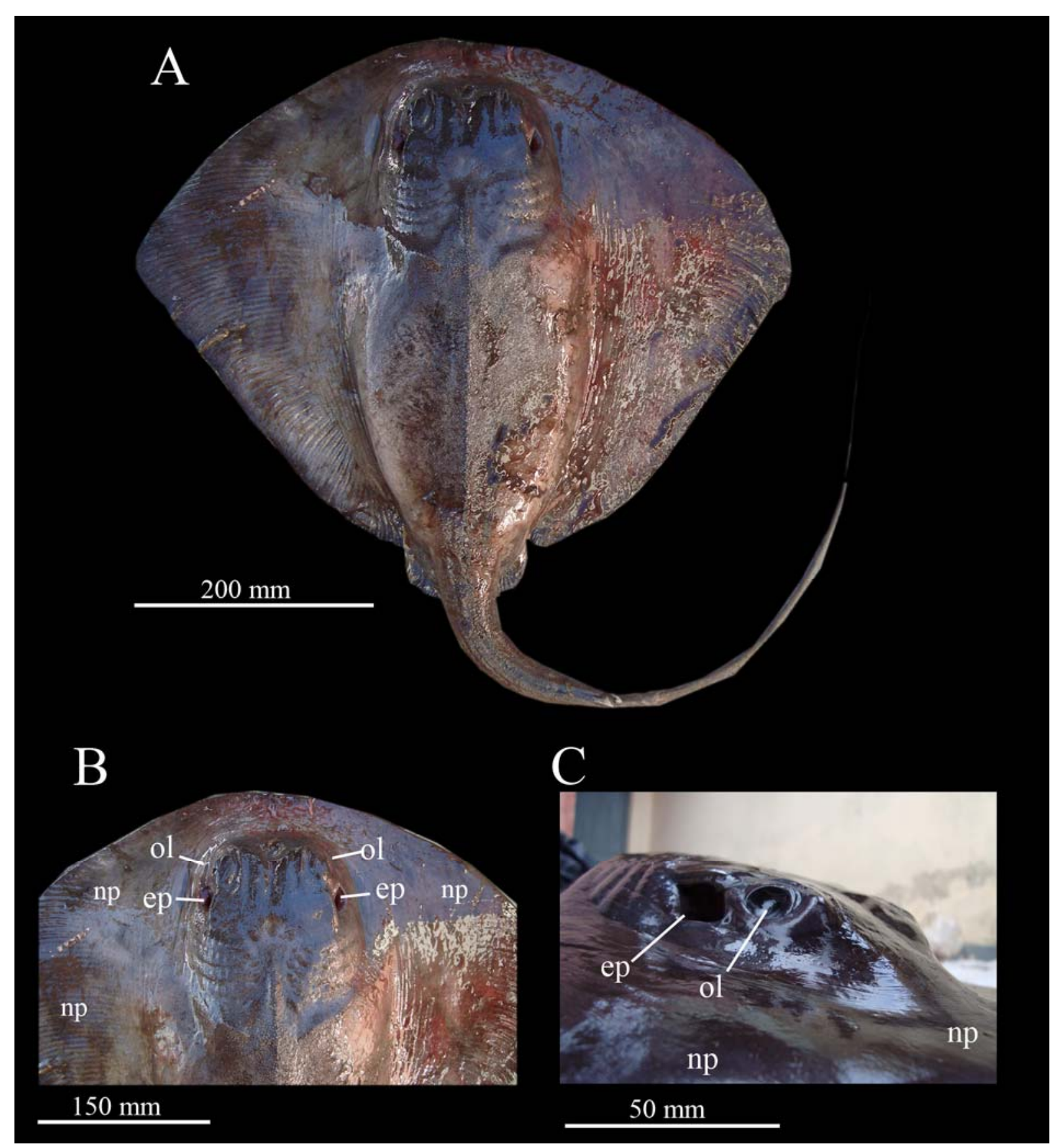

Figura $3(\mathrm{~A}-\mathrm{C})$ - $\quad$ Aspectos anatômicos do corpo de Pteroplatytrygon violacea. A. superfície dorsal, B. região cefálica e C. lateral direita da cabeça Legenda: es, espiráculo; np, nadadeira peitoral; ol, olho 


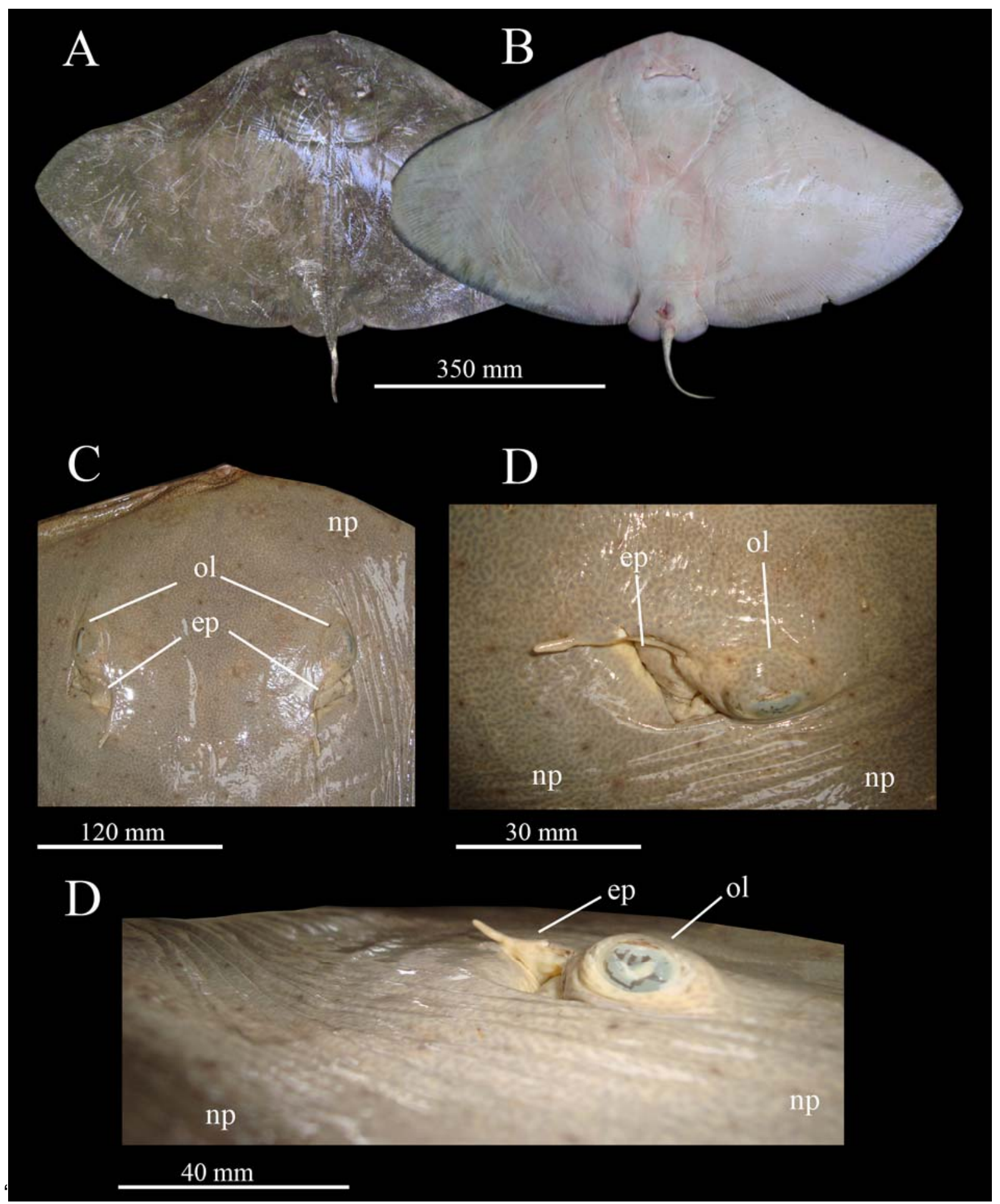

Figura $4(A-D)$ - $\quad$ Aspectos anatômicos do corpo de Gymnura altavela. A. superfície dorsal, B. superficie ventral, C. região cefálica, D. vista dorsal da região orbital direita e E. vista lateral direita da cabeça. Legenda: es, espiráculo; np, nadadeira peitoral; ol, olho 


\subsection{MÉTODOS}

Embora tenhamos usado 10 exemplares de quatro espécies diferentes de raias, apenas o olho direito foi mensurado.

As descrições anatômicas foram realizadas com ambos os olhos, sendo ilustrado sempre o melhor material disponível de cada espécie.

\subsubsection{Análise Morfométrica dos Músculos extraoculares}

Um Paquímetro convencional foi utilizado para medidas de comprimento do disco (CD); largura do disco (LD); diâmetro do olho (DB); comprimento dos mm. reto dorsal (RD), reto lateral $(R L)$, reto ventral (RV) e reto medial; comprimento dos $\mathrm{mm}$ oblíquo ventral (OV) e oblíquo dorsal (OD); largura do ventre (vt); comprimento dos tendões de origem (tdo) e tendão de inserção (tdi). Todos os dados biométricos estão diponibilizados na Tabela 2.

A medida dos músculos foi tirada considerando o ponto de origem ao ponto de inserção, considerando os respectivos tendões quando visível (Figura 5). Os dados morfométricos mensurados foram: Diâmetro do Bulbo (DB); comprimento dos mm. reto dorsal $(R D)$, reto lateral $(R L)$, reto ventral $(R V)$ e reto medial $(R M)$; comprimento dos $\mathrm{mm}$. oblíquo ventral (OV) e oblíquo dorsal (OD); largura do ventre (vt); comprimento dos tendões de origem (tdo) e tendão de inserção (tdi) (Figura 5). Todas as médias são fornecidas em milímetros $(\mathrm{mm})$ seguidas do seu desvio padrão (média $\pm \mathrm{DP})$. Tendões menores do que 1 milímetro $(>1 \mathrm{~mm})$ não puderam ser mensurados, nesses casos foi atribuído o valor zero.

Para a descrição dos músculos utilizou-se as medidas do comprimento do músculo (CM), tendão de inserção (tdi); tendão de origem (tdo); Diâmetro horizontal do olho (DO). Já as análises comparativas entre as espécies foram utilizadas as medidas de RD, RL, RM, RV, OV e OD. O músculo de Mobula thurstoni apresenta 
duas cabeças e uma cauda. Para comparações morfométricas foram consideradas medidas separadas (OV e OD) uma vez que os limites de cada um são distinguíveis.

Foram usadas as proporções entre cada músculo e o diâmetro do bulbo do olho (RD/DO, RL/DO, RV/DO, RM/DO, OV/DO, OD/DO) para as comparações entre as espécies estudas.

Os testes de ANOVA e Tukey foram utilizados para verificar homogeneidade das variâncias e normalidade, respectivamente, das proporções obtidas. Uma Analise de Variância (ANOVA) foi utilizada para testar diferenças significativas das proporções dos músculos (RD/DO, RL/DO, RV/DO, RM/DO, OV/DO, OD/DO) entre as espécies amostradas e, quando necessário, foi aplicado o teste a posteriori de Tukey.

Uma Análise de componentes Principais (PCA) foi utilizada para sintetizar as relações entre as medidas dos músculos e as espécies amostradas.

Para as análises univariadas foi utilizado o pacote Statistica 7.0 e as análises multivariadas foram realizadas com auxílio do programa MVSP v.3.1. 


\begin{tabular}{|c|c|c|c|c|c|c|c|c|c|c|c|c|c|c|c|c|c|c|c|c|c|c|c|c|c|c|c|c|c|c|c|c|c|c|c|c|c|c|c|c|c|c|c|c|}
\hline & \multicolumn{10}{|c|}{ Dasyatis hypostigma } & Media \pm & \multicolumn{11}{|c|}{ Pteroplatytrygon violacea } & Media \pm & \multicolumn{10}{|c|}{ Gymnura altavela } & Media \pm & \multicolumn{9}{|c|}{ Mobula thurstoni } & Media \pm \\
\hline & 1 & & & 4 & & 6 & 7 & & 9 & 10 & $D P$ & 1 & 2 & 3 & 4 & 5 & 6 & 7 & 8 & 9 & 10 & 1 & $D P$ & 1 & 2 & 3 & 4 & 5 & 6 & 7 & 8 & & 10 & $D P$ & 1 & 2 & & 45 & & & 78 & & & $\mathrm{DP}$ \\
\hline$C D$ & 0 & 0 & 0 & 0 & 0 & 0 & 0 & 0 & 0 & 0 & 0 & 330 & 340 & 370 & 330 & 340 & 360 & 330 & 335 & 365 & 335 & 336 & 0 & 220 & 222 & 228 & 221 & 229 & 300 & 221 & 451 & 0 & 0 & 0 & 0 & 0 & 0 & 0 & 0 & 0 & 0 & 0 & 0 & 0 \\
\hline LD & 0 & 0 & 0 & 0 & 0 & 0 & 0 & 0 & 0 & 0 & 0 & 465 & 481 & 472 & 469 & 450 & 470 & 467 & 473 & 474 & 467 & 468 & 0 & 430 & 431 & 437 & 431 & 440 & 445 & 431 & 820 & 0 & 0 & & & & 0 & 0 & 0 & 0 & 0 & & & \\
\hline DO & 13 & & 14 & 15 & 13 & 13 & 13 & 14 & 15 & 15 & $13,9 \pm 0,87$ & 27 & 30 & 28 & 27 & 30 & 30 & 28 & 27 & 28 & 30 & 28 & $28,5 \pm 1,35$ & 11 & 11 & 12 & 11 & 12 & 12 & 11 & 16 & & 17 & $12,8 \pm 2,30$ & 29 & 30 & 30 & 323 & 3 & 303 & 323 & & 230 & $3031,1 \pm 1,44$ \\
\hline RL & 20 & 20 & 21 & 21 & 19 & 21 & 20 & 19 & 21 & 20 & $20,2 \pm 0,79$ & 26 & 27 & 26 & 26 & 26 & 27 & 27 & 26 & 27 & 27 & 26 & $26,5 \pm 0,52$ & 16 & 16 & 17 & 16 & 17 & 17 & 16 & 28 & 27 & 28 & $8 \pm 5,45$ & 56 & 58 & 57 & & 58 & 5 & & & 57 & $7,2 \pm 0,63$ \\
\hline RL.vt & 6 & 6 & 7 & 7 & 6 & 6 & 7 & 6 & 6 & 7 & $6,4 \pm 0,51$ & 6 & 6 & 6 & 6 & 6 & 6 & 6 & 6 & 6 & 6 & 6 & $5,9 \pm 0,30$ & 3,2 & & 3 & & 3 & 3 & 3 & 5 & 5 & 6 & $3,7 \pm 1,30$ & 13 & 14 & 14 & 151 & 15 & 1 & 14 & 51 & 414 & $4 \quad 14,1 \pm 0,73$ \\
\hline RL.tdo & 2 & 1 & 2 & 2 & 2 & 2 & 3 & 2 & 2 & 3 & $2,1 \pm 0,60$ & 0 & 0 & 0 & 0 & 0 & 0 & 0 & 0 & 0 & 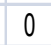 & 0 & 0 & & & 3 & 2,7 & 3 & & & & 3 & 4 & $1,4 \pm 2,00$ & 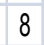 & & 8 & 8 & 8 & 7 & 88 & 87 & & $8 \quad 7,77 \pm 0,46$ \\
\hline RL.tdi & 4 & 3 & 4 & 4 & 3 & 4 & 3 & 3 & 3 & 4 & $3,5 \pm 0,53$ & 7 & 7 & 7 & 7 & 8 & 9 & 8 & 7 & 9 & 9 & 7 & $7,8 \pm 0,91$ & 3 & 4 & 4 & & 4 & 4 & 3 & 6 & 5 & 6 & $4,2 \pm 1,11$ & 8 & 9 & 8 & 9 & 9 & 8 & 8 & & 8 & $8,3 \pm 0,49$ \\
\hline RM.vt & 4 & 5 & 4 & 5 & 4 & 4 & 5 & 4 & 5 & 5 & $4,5 \pm 0,53$ & 5 & 5 & 5 & 5 & 5 & 5 & 5 & 5 & 5 & 5 & 5 & $5,0 \pm 0$ & 3 & 3 & 4 & 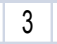 & 4 & 4 & & 6 & 6 & 6 & $4,2 \pm 1,31$ & 7 & 9 & 8 & 9 & 9 & 8 & 8 & & 8 & $8,2 \pm 0,63$ \\
\hline RM.tdo & 4 & 4 & 5 & 5 & 4 & 5 & 5 & 3 & 4 & 5 & $4,4 \pm 0,70$ & 2 & 2 & 2 & 1 & 2 & 2 & 2 & 1 & 2 & 2 & 2 & $1,7 \pm 0,40$ & 4 & 4 & 4 & 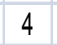 & 4 & 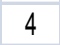 & & 6 & 5 & 6 & $4,8 \pm 0,81$ & 3 & & 2 & 3 & 3 & 3 & 2 & & 3 & $2,8 \pm 0,42$ \\
\hline RM.tdi & 5 & 5 & 5 & 5 & 4 & 5 & 5 & 3 & 5 & 5 & $4,7 \pm 6,70$ & 3 & 2 & 2 & 2 & 3 & 2 & 2 & 2 & 3 & 2 & 2 & $2,3 \pm 0,48$ & 1 & 1 & 1 & 1 & 1,3 & 1,5 & & 3 & 3 & 4 & $1,7 \pm 1,10$ & 8 & 11 & 91 & & & & & & 110 & $10 \quad 10,7 \pm 1,33$ \\
\hline $\mathrm{RD}$ & 18 & 18 & 17 & 18 & 17 & 17 & 17 & 17 & 16 & 18 & $17,3 \pm 0,67$ & 17 & 19 & 17 & 16 & 17 & 16 & 17 & 15 & 19 & 19 & 17 & $12,2 \pm 1,39$ & 10.2 & 10 & 10,8 & 10 & 11 & 12 & 10 & 27 & & 27 & $15,3 \pm 7,65$ & 45 & 48 & 464 & 474 & 47 & 464 & 174 & 74 & 747 & $746,7 \pm 0,82$ \\
\hline RD.tdo & 0 & 0 & 0 & 0 & 0 & 0 & 0 & 0 & 0 & 0 & 0 & 0 & 0 & 0 & 0 & 0 & 0 & 0 & 0 & 0 & 0 & 0 & 0 & 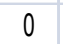 & & 0 & & & & & 5 & 4 & 5 & $3,2 \pm 0,36$ & & & 5 & 6 & & 6 & 5 & 5 & & $65,66 \pm 0,51$ \\
\hline RD.tdi & 0 & 0 & 0 & 0 & 0 & 0 & 0 & 0 & 0 & 0 & 0 & 6 & 7 & 6 & 5 & 6 & 7 & 6 & 5 & 7 & 7 & 6 & $2 \pm 0,78$ & 0 & 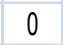 & & & 0 & & & 1 & 1 & 1 & $1,0 \pm 0$ & 4 & & 3 & 3 & 4 & 4 & 3 & 4 & & $43,66 \pm 0,51$ \\
\hline RD.vt & 6 & 6 & 7 & 6 & 6 & 7 & 6 & 6 & 7 & 6 & $6,3 \pm 0,48$ & 7 & 8 & 7 & 6 & 8 & 8 & 7 & 6 & 8 & 8 & 7 & $7,3 \pm 0,80$ & 3.5 & 3,8 & 4 & 3,8 & 4 & 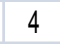 & & 6 & 5 & 6 & $4,4 \pm 0,90$ & 12 & 12 & 12 & & & 1 & 11 & & 1212 & $1212,1 \pm 0,56$ \\
\hline RV & 25 & 24 & 25 & 24 & 24 & 25 & 22 & 24 & 24 & 24 & $24,1 \pm 0,87$ & 25 & 25 & 24 & 23 & 25 & 25 & 24 & 24 & 25 & 25 & 24 & $24,5 \pm 0,70$ & 16,5 & 17 & 16 & 17 & 17 & 17 & 16 & 20 & & 20 & $17,6 \pm 1,50$ & 54 & 54 & 555 & & & & & & 54 & $545,2 \pm 1,13$ \\
\hline RV.tdi & 3 & 2 & 3 & 3 & 3 & 3 & 2 & 2 & 2 & 2 & $2,5 \pm 0,52$ & 3 & 2 & 2 & 2 & 3 & 2 & 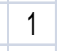 & 2 & 3 & 2 & 2 & $2 \pm 0,63$ & 3 & 2 & 3 & & & & & & 3 & 3 & $2,8 \pm 0,42$ & & & 4 & 5 & 4 & 4 & 4 & & & $4 \quad 4,33 \pm 0.50$ \\
\hline$R L \beta$ & 0 & 0 & 0 & 0 & 0 & 0 & 0 & 0 & 0 & 0 & 0 & 0 & 0 & 0 & 0 & 0 & 0 & 0 & 0 & 0 & 0 & & 0 & c & ( & 0 & & 0 & & & 0 & 0 & 0 & 0 & 27 & 28 & 272 & & & 282 & 272 & 62 & 2526 & $2627,1 \pm 1.15$ \\
\hline RLB.vt & & 0 & 0 & 0 & 0 & 0 & 0 & 0 & 0 & ( & 0 & 0 & 0 & 0 & 0 & 0 & & 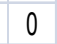 & ( & 0 & 0 & & c & ( & 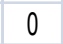 & & & 0 & & & & 0 & 0 & & & & 9 & 81 & 10 & 9 & 88 & & & $7 \quad 8,4 \pm 0,84$ \\
\hline RV.vt & 6 & 5 & 6 & 6 & 6 & 6 & 6 & 6 & 5 & 5 & $5,7 \pm 0,48$ & 4 & 6 & 5 & 4 & 5 & 6 & 5 & 3 & 6 & 6 & 5 & $0 \pm 1,05$ & 3,8 & 3 & 4 & 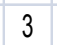 & 4 & 4 & & 5 & 4 & 4 & $3,7 \pm 0,60$ & 11 & 11 & 101 & 111 & 11 & 101 & 10 & & 1211 & $110,8 \pm 0,63$ \\
\hline$O D$ & 27 & 26 & 26 & 25 & 25 & 26 & 26 & 25 & 25 & 24 & $25,5 \pm 0,85$ & 22 & 24 & 22 & 22 & 22 & 24 & 22 & 21 & 24 & 24 & 23 & $22,7 \pm 1,16$ & 8 & 8 & 8,5 & 8 & 8 & 9 & 8 & 21 & 20 & 20 & $11,8 \pm 5,86$ & 31 & 34 & 323 & & & 313 & 323 & & 3333 & $33 \quad 32,4 \pm 0,96$ \\
\hline OD.tdo & & 0 & & 0 & 0 & 0 & 0 & 0 & 0 & 0 & 0 & 0 & 0 & 0 & 0 & 0 & & & 0 & 0 & 0 & 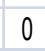 & & & & 1 & 1 & & & & 1 & 1 & 1 & $1,0 \pm 0$ & & & 0 & 0 & 0 & 0 & 0 & & & 0 \\
\hline OD.vt & & & & & & & & & & & $, 0 \pm 0,66$ & 16 & 17 & 18 & 17 & 16 & 17 & 16 & 16 & 16 & 17 & 18 & $16,7 \pm 0,70$ & 8 & $\xi$ & 8,5 & 7,7 & 8 & 0 & 1 & 13 & & 14 & $9,5 \pm 2,70$ & 18 & 17 & 181 & & & 1 & 17 & & & $17 \quad 17,2 \pm 0,63$ \\
\hline OD.tdi & 4 & 4 & 4 & 5 & 4 & 4 & 5 & 3 & 4 & 5 & $4,2 \pm 0,63$ & 2 & 2 & 2 & 1 & 2 & 2 & 2 & 1 & 2 & 2 & 2 & $1,80 \pm 0,42$ & 1 & 1 & 1 & 1 & 1 & 1 & 1 & 1 & 1 & 1 & $1,0 \pm 0$ & 3 & & 3 & 3 & 4 & 3 & 3 & & 3 & $3 \quad 3,2 \pm 0,42$ \\
\hline OV & 25 & 25 & 25 & 24 & 24 & 25 & 24 & 25 & 23 & 24 & $24,4 \pm 0,71$ & 27 & 26 & 27 & 26 & 25 & 27 & 27 & 27 & 26 & 26 & 27 & $26,3 \pm 0,82$ & 10.1 & 10,5 & 11 & 10 & 11 & 12 & 10 & 20 & 18 & 18 & $13,1 \pm 3,92$ & 31 & 34 & 333 & 333 & 333 & 323 & 323 & & 3433 & $3332,8 \pm 0,91$ \\
\hline OV.tdo & 0 & 0 & 0 & 0 & 0 & 0 & 0 & 0 & 0 & 0 & 0 & 0 & 0 & 0 & 0 & 0 & 0 & 0 & 0 & 0 & 0 & 0 & 0 & 0 & 0 & 0 & & 0 & 0 & & 0 & 0 & 0 & & 0 & 0 & 0 & 0 & 0 & 0 & 0 & & 0 & 0 \\
\hline OV.vt & 16 & & 16 & 15 & 15 & 16 & 14 & 15 & 15 & 15 & $15,3 \pm 0,67$ & 11 & 11 & 11 & 10 & 11 & 11 & 12 & 10 & 11 & 11 & 10 & $10,9 \pm 0,56$ & 3.8 & 3,8 & 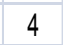 & 3 & 4 & 4,2 & 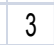 & 9 & 8 & 9 & $5,1 \pm 2,4$ & 13 & 16 & 151 & & 16 & 141 & 151 & & 1515 & $5 \quad 15,1 \pm 0,99$ \\
\hline OV.tdi & 5 & 5 & 4 & 4 & 4 & 5 & 3 & 4 & 5 & 4 & $4,3 \pm 0,65$ & 2 & 2 & 1 & 1 & 2 & 2 & 1 & 1 & 2 & 2 & 1 & $1,60 \pm 0,51$ & 1 & 1 & 1 & 1 & 1 & 2 & 1 & 3 & 3 & 3 & $1,70 \pm 0,94$ & 3 & 3 & 3 & 3 & 4 & 3 & 3 & 4 & 43 & $3 \quad 3,2 \pm 0,42$ \\
\hline Sexo & M & $\mathrm{F}$ & 0 & 0 & 0 & 0 & 0 & 0 & 0 & ( & 0 & 0 & $\mathrm{~F}$ & $\mathrm{~F}$ & $\mathrm{~F}$ & 0 & $\mathrm{~F}$ & $\mathrm{~F}$ & $\mathrm{~F}$ & 0 & $F$ & $F$ & 0 & M & M & $\mathrm{F}$ & $F$ & $F$ & M & $r$ & M & 0 & 0 & & & 0 & 0 & 0 & 0 & 0 & 0 & & & \\
\hline
\end{tabular}

Tabela 2 - Dados biométricos do bulbo do olho e músculos extraoculares de D. hypostigma, G. altavela, M. thurstoni e P. violacea. Legenda: CD, comprimento do disco; LD, largura do disco; DO, diâmetro do olho; RL, $\mathrm{m}$. reto lateral; $\mathbf{R L} \boldsymbol{\beta}, \mathrm{m}$. reto lateral $\beta, \mathbf{R M}, \mathrm{m}$. reto medial; $\mathrm{RD}, \mathrm{m}$. reto dorsal; RV, m. reto ventral; OD, m. oblíquo dorsal; OV, m. oblíquo ventral; vt, ventre muscular; tdo, tendão de origem; tdi, tendão de inserção. $\mathbf{0}$ = não mensurados. 


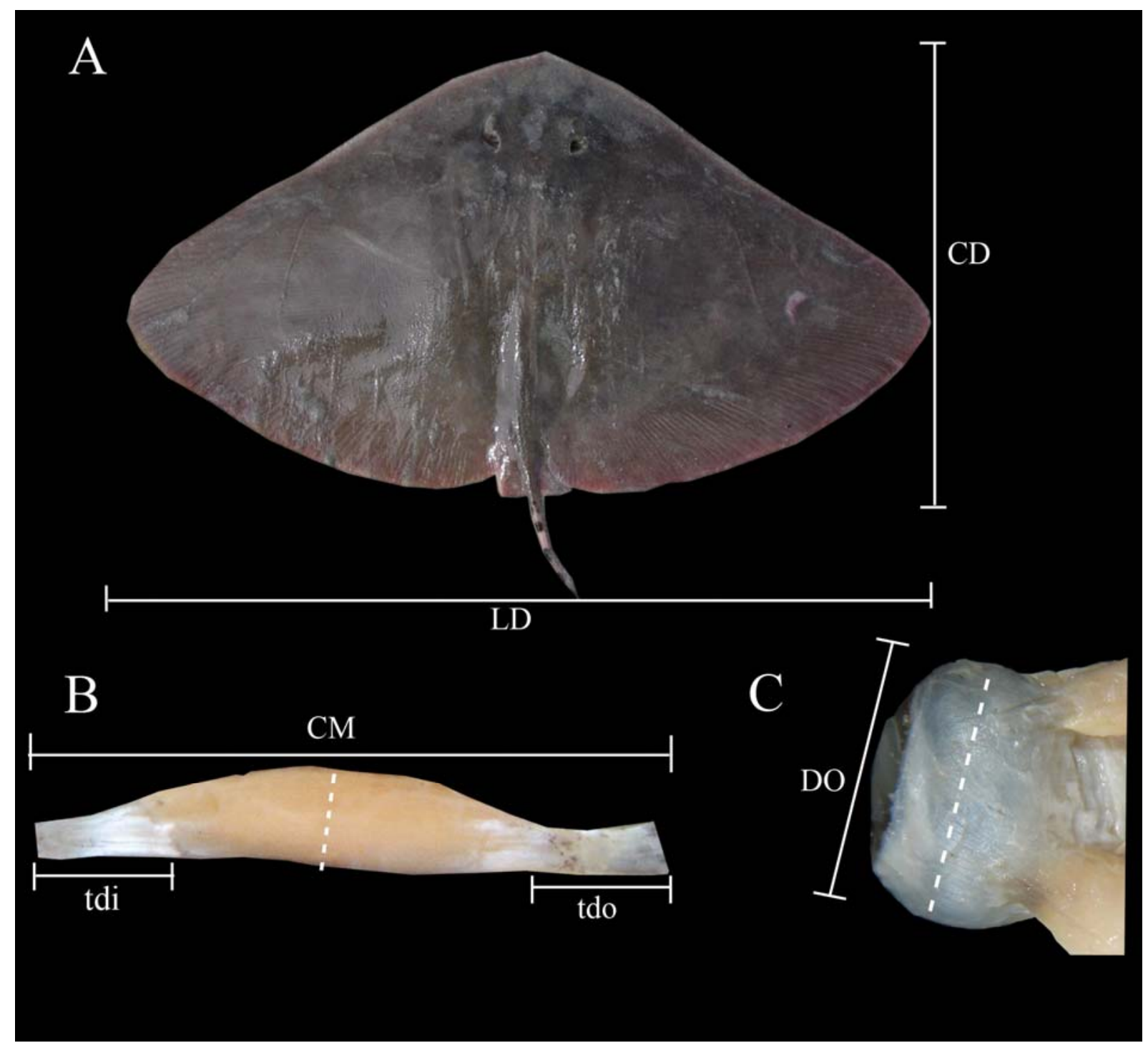

Figura $5(\mathrm{~A}-\mathrm{C})$ - $\quad$ Representação dos dados mensurados. A. vista dorsal de exemplar inteiro, B. vista ventral do $\mathrm{m}$. reto lateral e C. vista dorsal do bulbo do olho de G. altavela. Legenda: CD, Comprimento do disco; CM, Comprimento do músculo; DO, Diâmetro horizontal do olho; LD, Largura do disco; Pontilhado em B, ventre muscular; Pontilhado em C, equador do bulbo do olho; tdi, Tendão de inserção; tdo, tendão de origem 


\subsubsection{Descalcificação}

Parte do material estudado passou pelo processo de descalcificação, um processo que possibilita o amolecimento da pele, tecido conjuntivo e tecido cartilagíneo, destacando a coloração dos músculos e nervos, de forma que os eles tomam coloração amarelada, durante a dissecação de uma peça anatômica (CASAS, 2004).

O processo utilizado neste trabalho segue o proposto Intelizano (1999), no auxílio na dissecação de peixes ósseos. Casas (2004) e Casas et al (2005) refinaram a técnica com sucesso na descalcificação de cabeças de tubarões, Carcharias taurus (Tabela 3).

Tabela 3 - Fórmula para Solução descalcificadora, segundo Casas (2004) e Casas et al (2005)

\begin{tabular}{lcc}
\hline Reagente & Concentração & Diluição \\
\hline Ácido Clorídrico & $50 \%$ & $45 \%$ \\
Ácido Acético & $4 \%$ & $22 \%$ \\
Álcool Etílico & $50^{\circ} \mathrm{GL}$ & $11 \%$ \\
Água & $100 \%$ & $22 \%$ \\
\hline
\end{tabular}

\subsubsection{Dissecação}

As dissecações foram realizadas com o auxílio de instrumental cirúrgico convencional e a olho desarmado. O material dissecado foi registrado utilizando-se máquina fotográfica digital Sony $\mathrm{W}-110$ e os fundos das imagens trabalhados com o programa Photoshop 7.0.

Inicialmente realizando incisão próxima ao equador a esclera, retiramos a pele e posteriormente a fáscias a fim de expor a esclera e os músculos oculares. 


\subsubsection{Cocção}

O processo consiste na utilização de água fervente para a remoção dos tecidos, a fim de expor e isolar o esqueleto. Acondicionando a cabeça em uma bacia plástica, lentamente administrou-se água quente fervente.

Com o auxílio de pinças anatômicas de diversos tamanhos, o tecido amolecido e desprendido das cartilagens foi removido, preservando-se as articulações entre os elementos cartilaginosos, até que a peça se apresentasse totalmente limpa (Figura 6).

\subsubsection{Técnica de maceração por desmestídeos}

A técnica de maceração por dermestídeos consiste na utilização de besouros do gênero Dermestis para consumirem tecidos e manter apenas as estruturas esqueléticas. Como as espécies estudadas são cartilaginosas, apenas as que possuem maior dimensão podem passar por este processo, as demais foram diafanizadas ou coccionadas.

A cartilagem, característica desses animais tende a deformar e perder proporção por serem comidas pelos besouros. Desta forma é preferível aplicar a técnica em espécimes maiores que possuem pontos calcificados na cartilagem. Por este motivo, apenas uma cabeça de $M$. thurstoni passou por este processo, por ser espécie de maiores proporções (<200 mm) (Figura 7-A-C). 

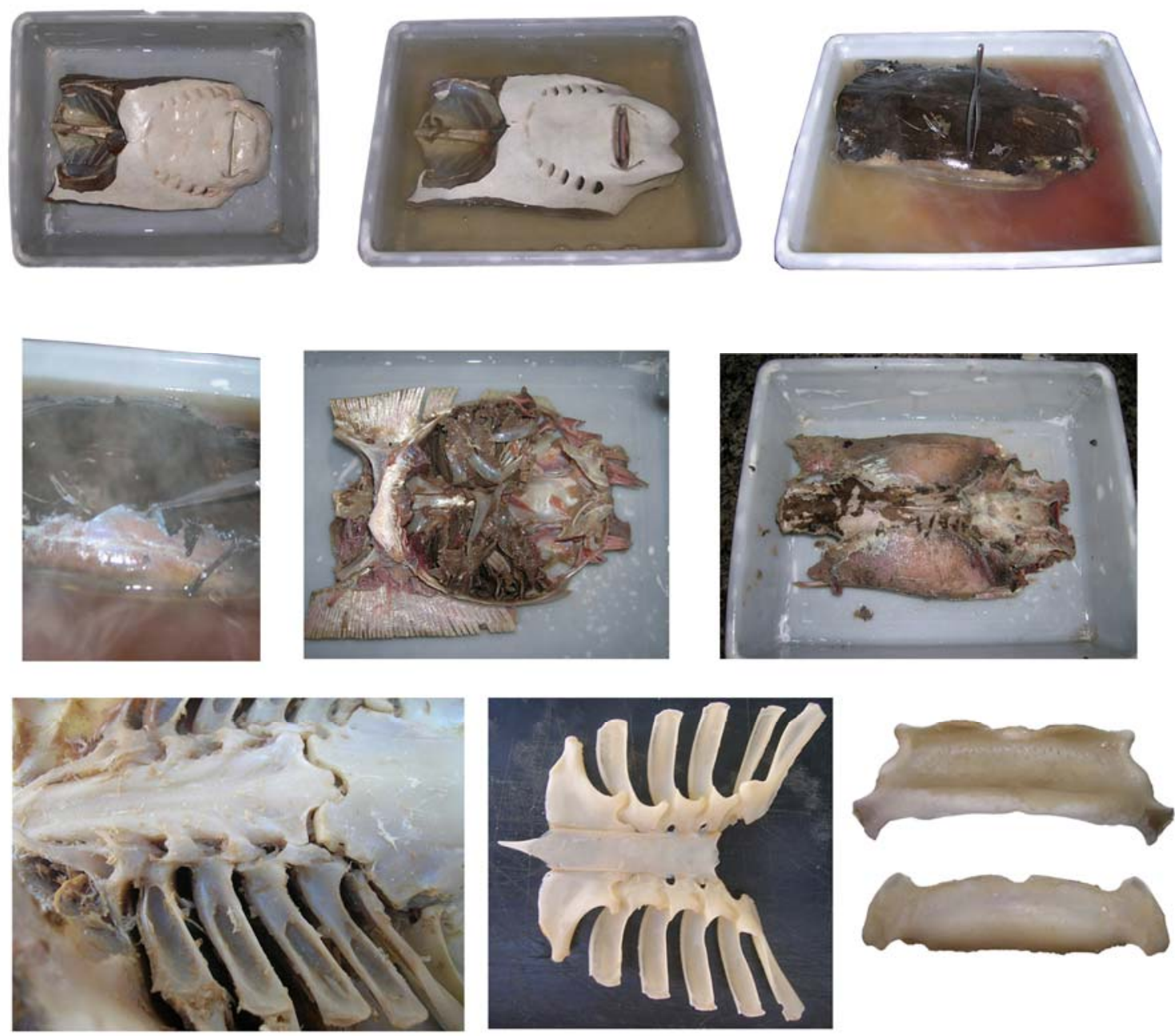

Figura 6 - Exemplo de técnica de cocção realizada em raia da espécie Rhinoptera brasiliensis para maceração dos arcos branquiais 

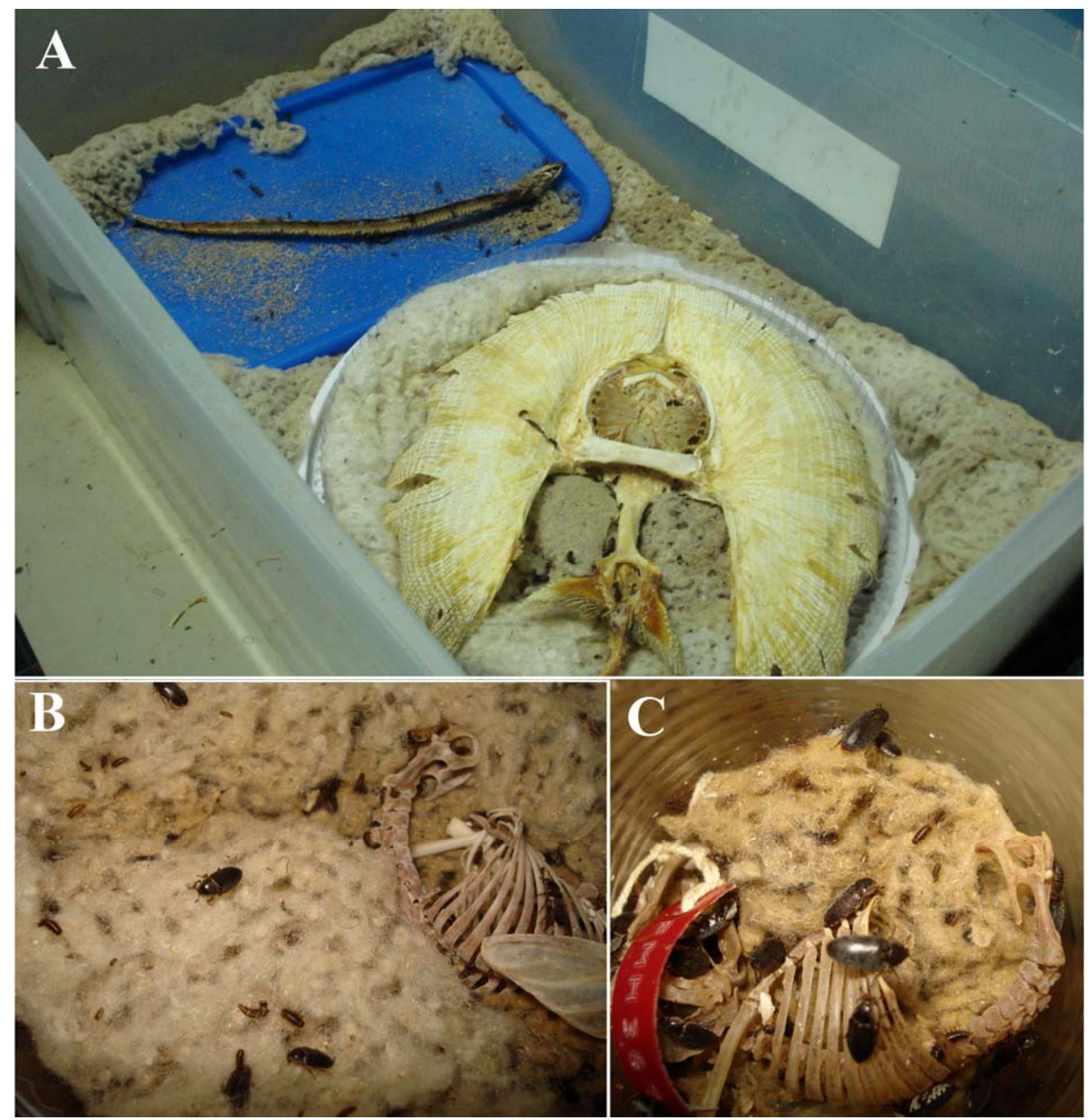

Figura $7(A-C)$ - Técnica de maceração por dermestídeos. A. Vista geral da caixa de manutenção dos besouros. B e C. Detalhes dos besouros do gênero Dermestis consuminto tecido de estruturas esqueléticas. Crédito das imagens ao Dr. Hugo R. S. Santos (UERJ) 
Resultados

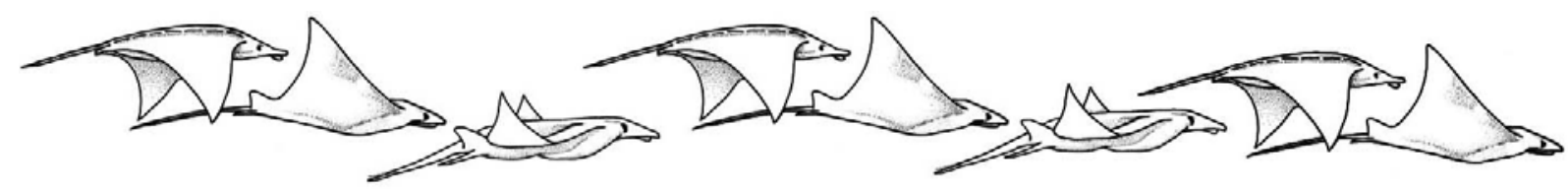




\section{RESULTADOS}

Os resultados apresentados a seguir serão separados por espécie e em ordem alfabética de gênero (Dasyatis, Gymnura, Mobula e Pteroplatytrygon). A sequência ordem das descrições será apresentada da seguinte forma: órbita, esclera, m. reto lateral, $\mathrm{m}$. reto medial, $\mathrm{m}$. reto dorsal, $\mathrm{m}$. reto ventral, $\mathrm{m}$. oblíquo dorsal e o m. oblíquo ventral.

A identificação dos músculos foi possível devido à orientação dada pela inervação e pelo local de inserção dos músculos na esclera. A disposição do tendão de inserção em relação ao equador do bulbo do olho também foram observadas, descritas e comparadas (Tabela 4).

Embora um estudo dos nervos cranianos não tenha sido parte do objetivo deste trabalho, observamos que todas as espécies de raias estudadas apresentaram a inervação dos músculos conforme sugerido pela bibliografia consultada, de tal forma que o nervo oculomotor (III) inerva os $\mathrm{mm}$. retos medial, ventral e dorsal, além do $\mathrm{m}$. oblíquo ventral; o nervo abducente $(\mathrm{VI})$ inerva o $\mathrm{m}$. reto lateral e o nervo troclear (IV) inerva o m. oblíquo dorsal. A inervação de alguns destes músculos pôde ser registrada e encontra-se ilustrada nesta seção.

A musculatura extrínseca de todas as espécies de raias estudadas está localizada completamente no interior da órbita (Figura 8-A a D). Os mm. retos estão dispostos na parte dorsocaudal, o m. oblíquo ventral segue dorsalmente e o $\mathrm{m}$. oblíquio dorsal na parte mediorostral da órbita. 


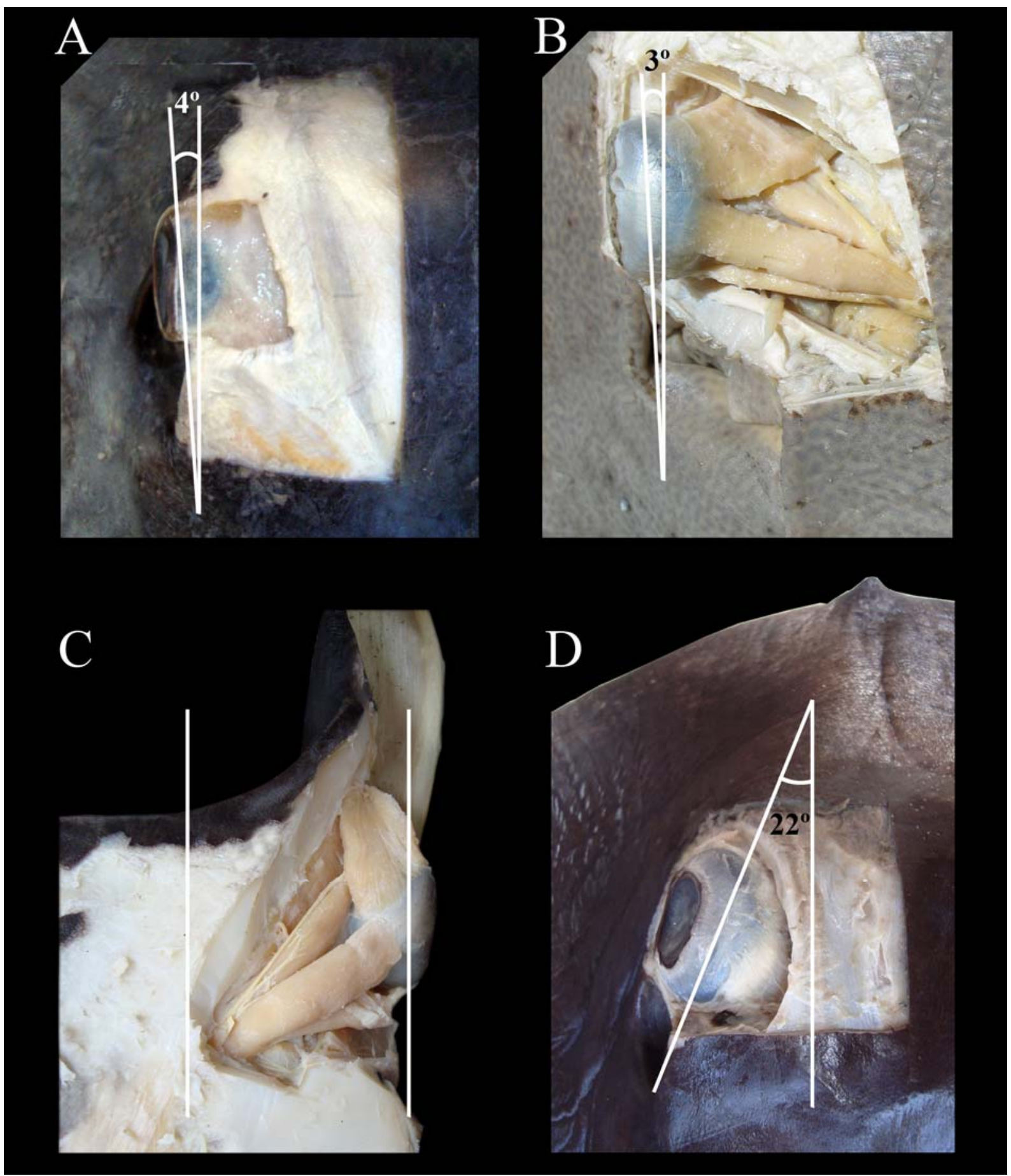

Figura $8(A-D)$ - Vista dorsal da região cefálica, demonstrando a angulação do equador do bulbo em relação à linha mediana do corpo de: A. Dasyatis hypostigma, ângulo aproximado de $4^{\circ}$; B. Gymnura altavela ângulo aproximado de $3^{\circ}$; C. Mobula thurstoni, ângulo aproximado de $0^{\circ}$; D. Pteroplatytrygon violacea ângulo aproximado de $22^{\circ}$ 


\subsection{DESCRIÇÃO MORFOLÓGICA}

Os resultados obtidos das descrições morfológicas de cada uma das espécies estudadas estão descritos nas subseções desta seção.

\subsubsection{Dasyatis hypostigma Santos e Carvalho, 2004}

Serão apresentados nas seções a seguir os resultados obtidos de Dasyatis hypostigma.

\subsubsection{1 Órbita e Esclera}

Caracteristicamente, o crânio dos dasiatídeos está circundado pela nadadeira peitoral. Esta se estende da cintura pélvica até a extremidade rostral do crânio, descrevendo a forma de um disco (Figuras 1-A-B e 9-A). Em D. hypostigma o bulbo do olho $(13,9 \pm 0,87 \mathrm{~mm})$ se projeta levemente para fora da órbita (Figura 1-D e E e 9-C e D) e seu equador forma um ângulo aproximado de $4^{\circ}$ em relação à linha mediana do corpo (Figura 8-A).

\subsubsection{Músculo Reto Lateral}

O m. reto lateral $(20,2 \pm 0,79 \mathrm{~mm})$ se origina ventralmente ao $\mathrm{m}$. reto dorsal por um tendão curto $(2,1 \pm 0,60 \mathrm{~mm})$. É fusiforme e comprimido lateroventralmente (Figura 11-C). A largura do seu ventre $(6,4 \pm 0,51 \mathrm{~mm})$ é maior do que a da sua cabeça e sua cauda (Figura 11-B). Em seu trajeto, sua face dorsal segue paralelamente à face ventral do $\mathrm{m}$. reto dorsal (Figura 11-C). O tendão de inserção 
(3,5 $\pm 0,53 \mathrm{~mm})$ se fixa logo posteriormente ao equador do bulbo (Figura 11-A), configurando uma linha de fixação oblíqua em relação a este.

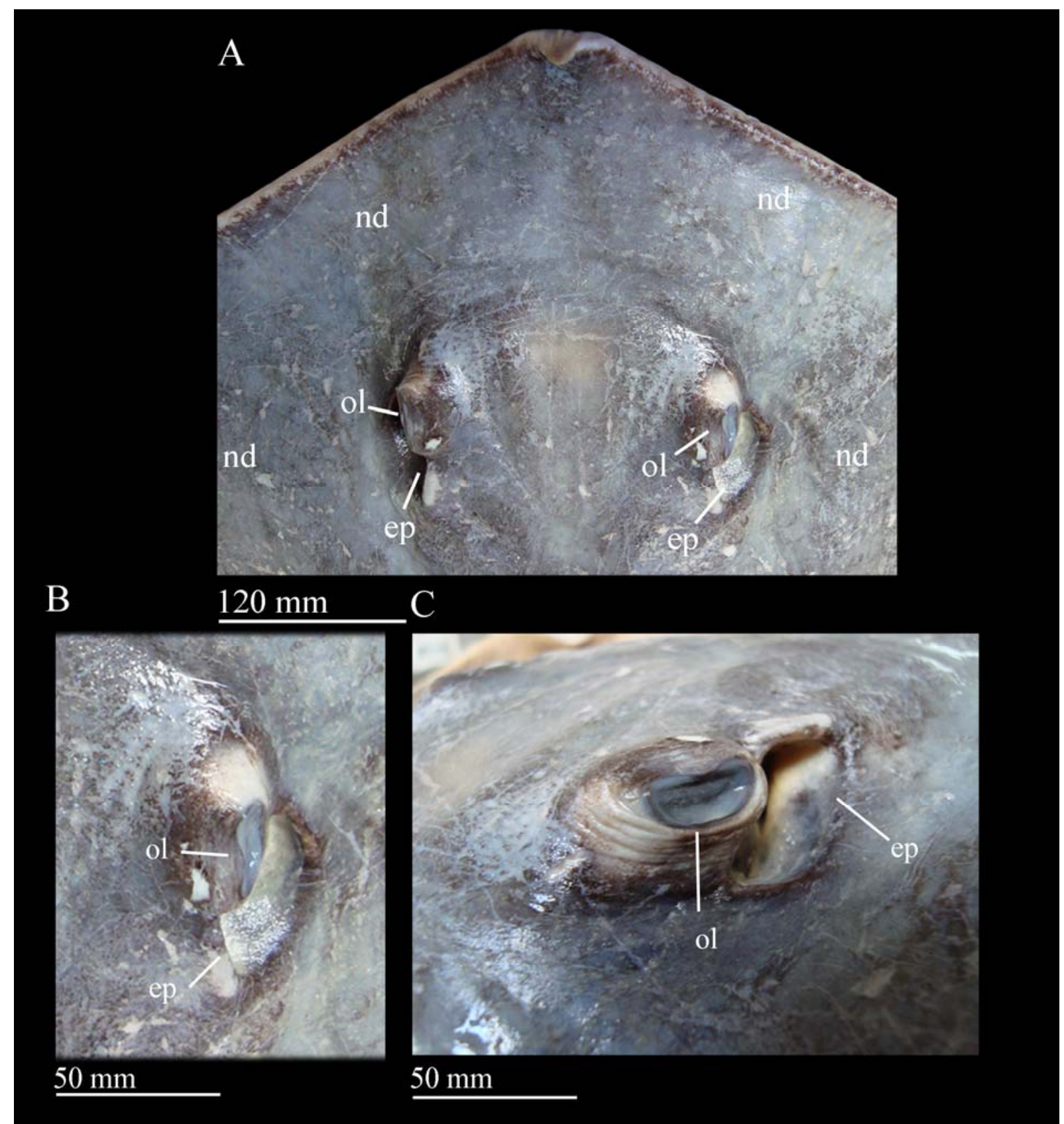

Figura 9 (A-C) - $\quad$ Região orbital com o respectivo bulbo do olho in situ de D. hypostigma. A. Cabeça, vista dorsal; B. Região orbital e bulbo do olho direito, vista dorsal; C. Região orbital e bulbo do olho esquerdo, vista lateral. Legenda: ep, espiráculo; nd, nadadeira peitoral; ol, olho 


\subsubsection{Músculo Reto Medial}

O $\mathrm{m}$. reto medial $(23,4 \pm 0,70 \mathrm{~mm}$ ) (Figura $11-\mathrm{A}$ e D) se origina cranioventralmente ao $\mathrm{m}$. reto dorsal (Figura 11-A) e dorsocaudalmente ao pedículo óptico (Figura 11-B) por um fino tendão $(4,4 \pm 0,70 \mathrm{~mm})$. É o mais esguio dos músculos, apresenta forma fusiforme e é achatado dorsoventralmente. Apresenta praticamente a mesma largura $(4,5 \pm 0,53 \mathrm{~mm})$ em todo o seu comprimento, desde a cabeça, passando pelo ventre, até a cauda, porém há um sutil estreitamento em sua origem. Em seu trajeto, segue cranialmente, mas de forma oblíqua, ao $\mathrm{m}$. reto dorsal, em direção ao m. oblíquo dorsal (Figura 11-A). Cruza dorsalmente o pedículo óptico (Figura 11-D) e se insere no pólo anterior da esclera, em um ponto adjacente à articulação do pedículo óptico, entre este e o ponto de emergência do nervo óptico na esclera, de tal forma que as fibras do $\mathrm{m}$. oblíquo dorsal recobrem totalmente o seu ponto de inserção (Figura 11-D). O n. troclear (IV) cruza o seu ventre em um ponto muito próximo à inserção. O tendão de inserção $(4,7 \pm 6,7 \mathrm{~mm})$ configura uma linha de fixação oblíqua em relação ao limbo corneal.

\subsubsection{Músculo Reto Dorsal}

O músculo reto dorsal $(17,3 \pm 0,67 \mathrm{~mm})$ origina-se por um tendão muito curto $(>1,0 \mathrm{~mm}$ ), localizado dorsocaudalmente à origem do $\mathrm{m}$. reto medial (Figuras 11-A e D e 10-A e B), dorsalmente ao $\mathrm{m}$. reto lateral e dorsocaudalmente ao $\mathrm{m}$. reto ventral (Figura 11-B). Apresenta forma triangular e suas fibras se expandem gradativamente à medida que se aproximam do ponto de inserção na esclera (Figura 10-A), de modo que a largura de seu ventre $(6,3 \pm 0,48 \mathrm{~mm})$ é maior do que a largura da cabeça e menor do que a largura da cauda (Figura 11-A). Sua face ventral encontra-se paralela à face dorsal do $\mathrm{m}$. reto lateral em praticamente toda sua extensão (Figura 11-A e B). Em seu percurso, segue para a esclera dorsocaudalmente ao pedículo óptico. Insere-se dorsalmente na esclera, caudalmente ao equador do bulbo (Figura 11-A). Seu tendão de inserção $(>1,0 \mathrm{~mm})$ configura uma linha de fixação côncava 
em relação ao equador que, embora muito próxima à inserção do m. oblíquo dorsal, não se sobrepõe a esta (Figuras 10-A e 11-A).

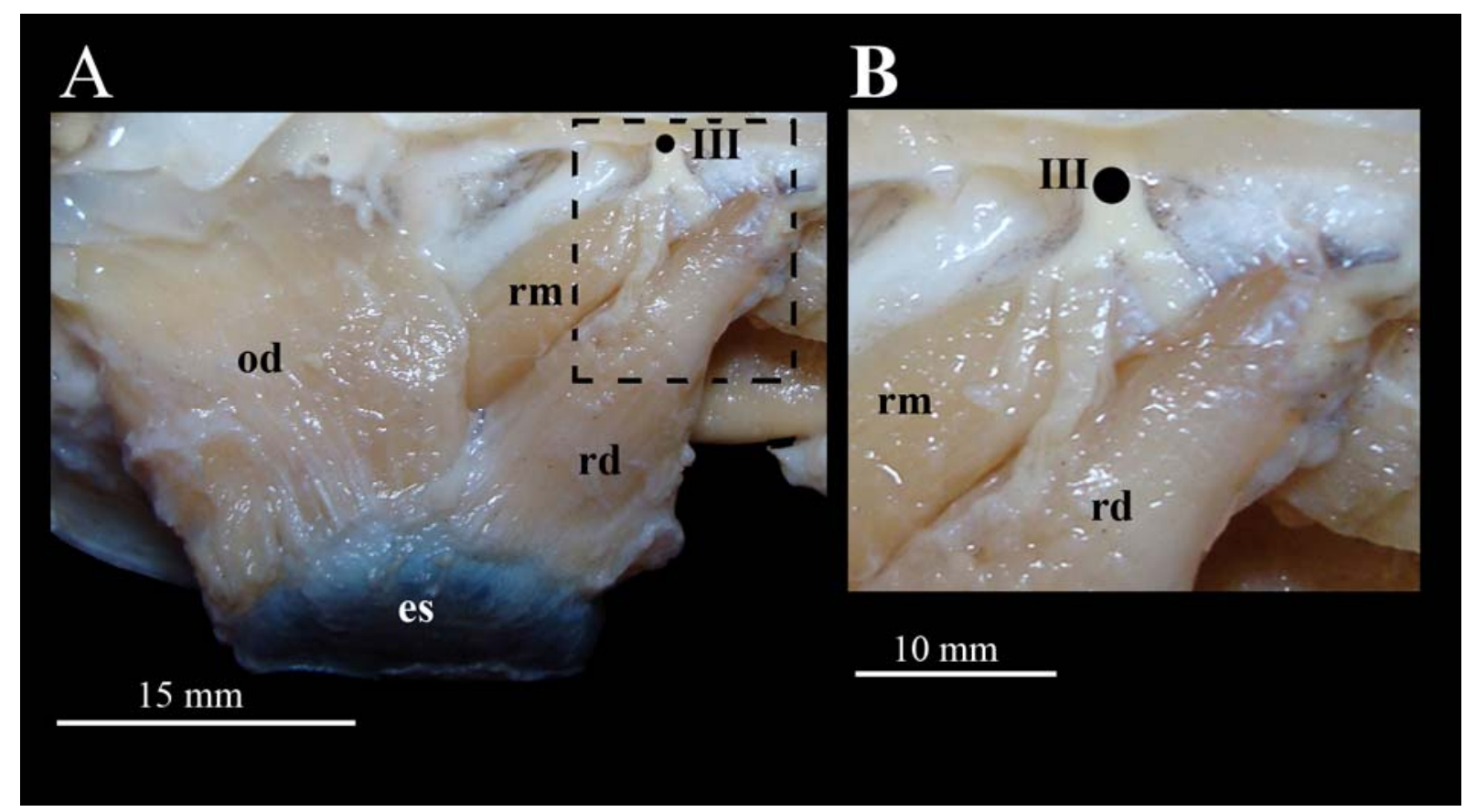

Figura $10(\mathrm{~A}$ e B) - Musculatura extrínseca e bulbo do olho esquerdo de $D$. hypostigma in situ, A. Vista dorsal; B. Detalhe da inervação dos $\mathrm{mm}$. reto medial e dorsal. Legenda: III, n. oculomotor; bo, bulbo do olho; od, m. oblíquo dorsal; rm, m. reto medial; rd, $m$. reto dorsal

\subsubsection{Músculo Reto Ventral}

O $\mathrm{m}$. reto ventral $(24,1 \pm 0,87 \mathrm{~mm})$ possui um longo $(5,5 \pm 0,70 \mathrm{~mm})$ tendão de origem que parte ventralmente à origem do $\mathrm{m}$. reto medial e cranialmente à origem dos $\mathrm{mm}$. reto lateral e reto dorsal (Figura 11-B). É um músculo fusiforme que apresenta a largura de seu ventre $(6,3 \pm 0,48 \mathrm{~mm})$ maior do que a largura da sua cabeça e da sua cauda (Figura 11-B). Em seu trajeto cruza ventralmente o terço médio do pedículo óptico para se inserir na esclera entre o ponto de emergência do $\mathrm{n}$. óptico e a inserção do $\mathrm{m}$. oblíquo ventral, que cobre completamente o seu ponto de inserção (2,5 \pm 0,52 mm) (Figura 11-B), estendido como uma linha de fixação côncava em relação ao equador do bulbo. 


\subsubsection{Músculo Oblíquo Dorsal}

O músculo oblíquo dorsal $(25,5 \pm 0,85 \mathrm{~mm})$ se origina da extremidade rostrodorsal da órbita, juntamente com o m. oblíquo ventral (Figura 11-A), por meio de um tendão muito curto (>1,0 mm). É um músculo delgado, largo e achatado dorsoventralmente, cuja largura do ventre $(5,4 \pm 1,90 \mathrm{~mm})$ é a mesma que a da cabeça e a da cauda (Figura 11-A). Insere-se caudalmente ao equador do bulbo e o seu tendão de inserção $(4,2 \pm 1,50 \mathrm{~mm})$ forma uma linha de fixação côncava em relação a este, recobrindo a inserção do m. reto medial (Figura 11-D).

\subsubsection{Músculo Oblíquo Ventral}

O músculo oblíquo ventral $(24,4 \pm 0,71 \mathrm{~mm})$ se origina da parte rostroventral da órbita, juntamente com o m. oblíquo dorsal (Figura 11-B), por meio de um tendão muito curto $(>1,0 \mathrm{~mm})$. É um músculo triangular, delgado e achatado dorsoventralmente. Suas fibras se expandem a medida que seguem em direção à cauda e voltam a se afunilar bruscamente quando próximas da inserção (Figura 11$B)$, de modo que a largura do ventre muscular $(15,3 \pm 0,67 \mathrm{~mm})$ é maior do que a da cabeça e a da cauda. Seu tendão de inserção $(4,3 \pm 0,65 \mathrm{~mm})$ recobre a inserção do m. reto ventral (Figura 11-B) ao se fixar na esclera, caudalmente ao equador do bulbo e configurando uma linha de fixação côncava em relação a este. 


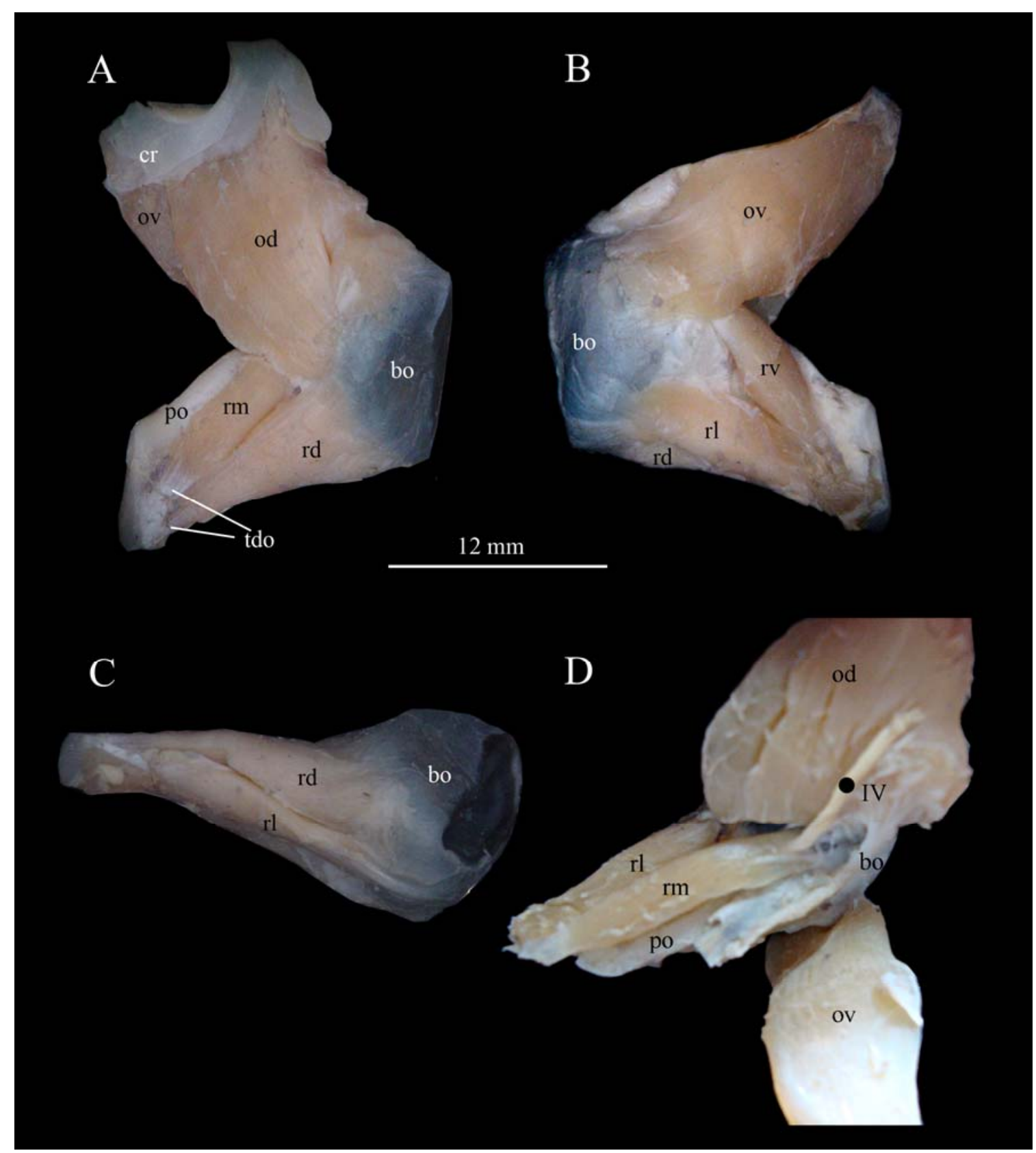

Figura $11(A-D)$ - Musculatura extrínseca do bulbo do olho direito de $D$. hypostigma em vistas A. dorsal; B, ventral; C, caudal e D. caudomedial. Legenda: IV, n. troclear; cr, crânio; od, m. oblíquo dorsal; ov, m. oblíquo ventral; po, pedículo; rd, $\mathrm{m}$. reto dorsal e seu tendão de origem (tdo); rm, m. reto medial e seu tendão de origem (tdo); rl, m. reto lateral; rv, m. reto ventral; óptico 


\subsubsection{Gymnura altavela (LINNAEUS, 1758)}

Nas seções a seguir serão apresentados os resultados obtidos de Gymnura altavela.

\subsubsection{1 Órbita e Esclera}

O crânio de Gymnura altavela está circundado pela nadadeira peitoral, estendida até a sua extremidade rostral, descrevendo a forma de um disco ovalado (Figura 4-B, D e E). A esclera $(12,8 \pm 2,30 \mathrm{~mm})$ desta espécie se projeta além da órbita (Figura 4-D) e o equador do bulbo forma um ângulo aproximado de $3^{\circ} \mathrm{em}$ relação à linha mediana do corpo (Figura 8-B).

\subsubsection{Músculo Reto Lateral}

$\mathrm{O}$ m. reto lateral $(19,8 \pm 5,45 \mathrm{~mm})$ possui um tendão $(1,4 \pm 2,00 \mathrm{~mm})$ muito esguio em sua origem, localizado ventralmente ao $\mathrm{m}$. reto dorsal $\mathrm{e}$ caudoventralmente aos $\mathrm{mm}$. retos ventral e medial (Figuras 12-B e 13-A). É um músculo alongado, cuja largura do ventre $(3,7 \pm 1,30 \mathrm{~mm})$ é praticamente a mesma da cabeça e maior que da cauda, que se afunila a medida que se aproxima do ponto de inserção (Figura 12-B). Segue paralelamente ao m. reto dorsal em quase todo seu trajeto, desviando para se inserir na parte caudoventralmente da esclera (Figura 12-B). Sua inserção ocorre próximo ao equador do bulbo, por meio de um delgado e longo tendão (4,2 \pm 1,11 mm) (Figura 13-A). Seu tendão de inserção configura uma linha de fixação oblíqua em relação ao equador do bulbo. 


\subsubsection{Músculo Reto Medial}

O $\mathrm{m}$. reto medial $(19,0 \pm 6,01 \mathrm{~mm})$ possui em sua origem um delgado e longo tendão $(4,8 \pm 0,81 \mathrm{~mm})$, localizado dorsalmente à origem do $\mathrm{m}$. reto ventral $\mathrm{e}$ cranialmente aos $\mathrm{mm}$. retos dorsal e lateral (Figura 12-A). É um músculo que se alarga à medida que se aproxima do seu ponto de inserção na esclera, de forma que o ventre $(4,2 \pm 1,31 \mathrm{~mm})$ se torna mais largo do que a cabeça e mais estreito que a cauda (Figura 13-B). Em seu trajeto, da origem à inserção, cruza dorsalmente a parte medial do pedículo e do nervo ópticos (Figura 12-A). Após cruzar com o m. oblíquo dorsal ventralmente, se insere da esclera por meio de um curto tendão $(1,7 \pm$ $1,10 \mathrm{~mm}$ ), entre o equador e o ponto de emergência do n. óptico (Figura 13-B). Seu tendão de inserção configura uma linha de fixação côncava em relação ao equador do bulbo.

\subsubsection{Músculo Reto Dorsal}

O $\mathrm{m}$. reto dorsal $(15,3 \pm 7,65 \mathrm{~mm})$ possui em sua origem um delgado tendão $(3,2 \pm 0,36 \mathrm{~mm})$, posicionado caudalmente ao $\mathrm{m}$. reto medial e dorsalmente aos $\mathrm{mm}$. retos lateral e ventral. (Figura 12-A). É um músculo alongado, que possui um longo tendão de origem $(3,2 \pm 0,36 \mathrm{~mm})$ que se destaca visivelmente da cabeça produzindo um afunilamento do músculo nessa região (Figura 12-A). Devido à sua forma alongada a largura do seu ventre $(3,7 \pm 1,30 \mathrm{~mm})$ é praticamente a mesma da cabeça e da cauda (Figura 12-A). Segue paralelamente ao m. reto lateral em quase todo seu trajeto, desviando dorsocaudalmente para se inserir na esclera, logo caudalmente ao equador do bulbo (Figura 12-A), por meio de um curto tendão $(1,0 \pm$ $0 \mathrm{~mm}$ ) (Figura 12-A), configurando uma linha reta, paralela a este. 


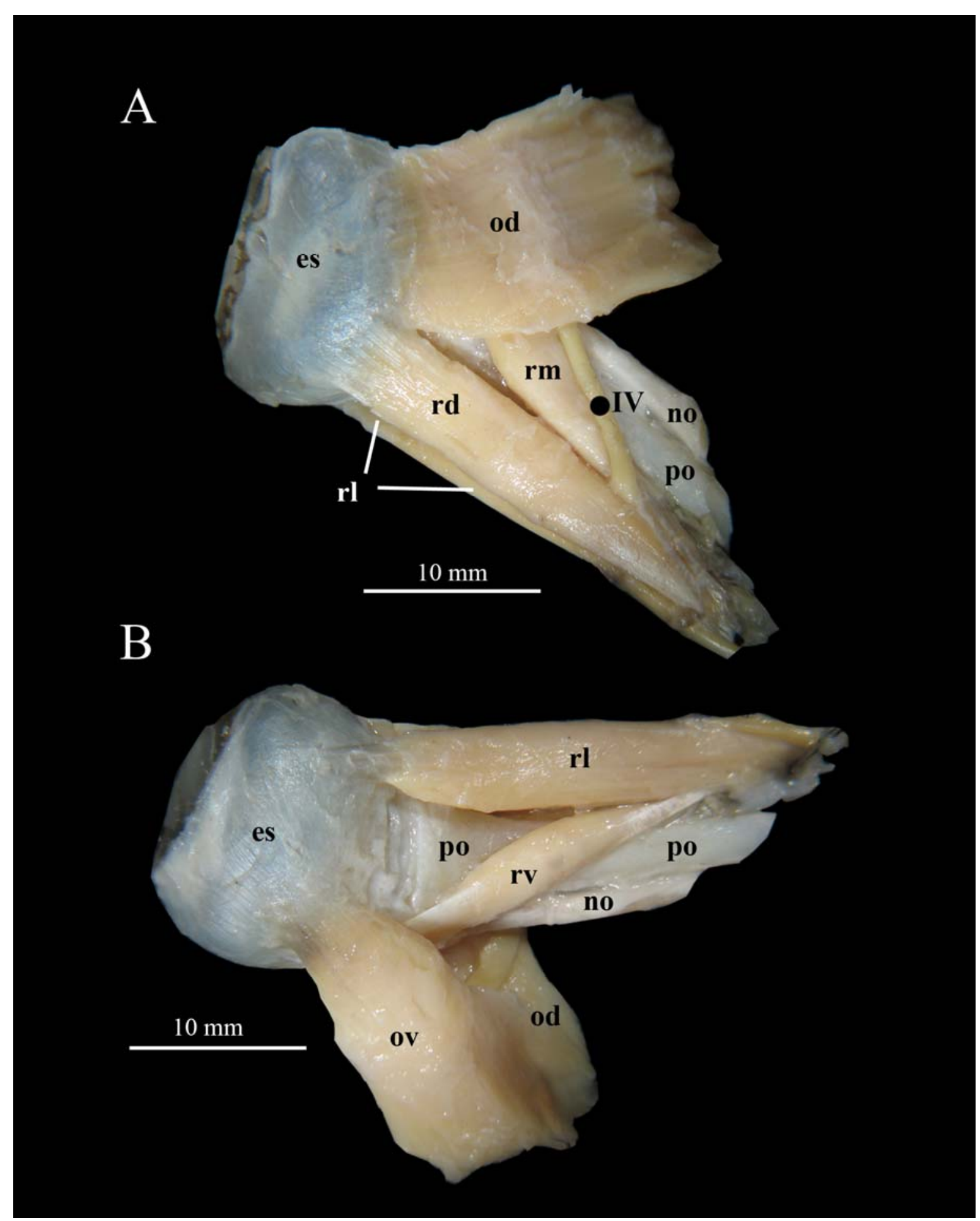

Figura 12 (A e B) - Musculatura extrínseca do bulbo do olho esquerdo de G. altavela; A. Disposição dos $\mathrm{mm}$. reto e oblíquo dorsal em vista dorsal; B. Disposição dos $\mathrm{mm}$. retos e oblíquos em vista ventral. Legenda: IV, n. troclear; es, esclera; no, nervo óptico; od, m. oblíquo dorsal; ov, m. obliquo ventral; po, pedículo óptico; rd, m. reto dorsal; rv, $\mathrm{m}$. reto ventral; $\mathbf{r l}, \mathrm{m}$. reto lateral; $\mathbf{r m}, \mathrm{m}$. reto medial 


\subsubsection{Músculo Reto Ventral}

O $\mathrm{m}$. reto ventral $(17,6 \pm 1,50 \mathrm{~mm})$ possui em sua origem um delgado e longo tendão $(6,0 \pm 0,50 \mathrm{~mm})$, posicionado ventralmente aos $\mathrm{mm}$. reto dorsal, reto lateral e reto medial. (Figuras 12-B e 13-A). É um músculo alongado, cuja largura do seu ventre $(3,7 \pm 0,60 \mathrm{~mm})$ é maior que a da cabeça e da cauda (Figura 13-A). Em seu trajeto, cruza ventralmente a parte medial do pedículo óptico (Figura 12-B) e se insere, por um tendão curto $(3,7 \pm 0,60 \mathrm{~mm})$, em um ponto adjacente à inserção do m. oblíquo ventral, muito próximo à articulação do pedículo óptico com a esclera e o ponto de emergência do n. óptico (Figura 13-A). Seu tendão de inserção configura uma linha oblíqua de fixação em relação ao equador do bulbo.

\subsubsection{Músculo Oblíquo Dorsal}

O m. oblíquo dorsal $(11,8 \pm 5,86 \mathrm{~mm})$ possui em sua origem um curto e delgado tendão $(1,0 \pm 0 \mathrm{~mm})$, posicionado dorsalmente ao $\mathrm{m}$. oblíquo ventral. (Figura 12-B). É um músculo largo, achatado dorsoventralmente, cuja largura do seu ventre $(9,5 \pm 2,70 \mathrm{~mm})$ é igual à largura da cabeça e da cauda, o que lhe confere um aspecto retangular (Figura 12-A). Em seu trajeto, da origem à inserção, sua face ventral segue paralelamente à face dorsal do $\mathrm{m}$. oblíquo ventral no decorrer do seu primeiro terço de extensão, em seguida, cruza dorsalmente o $\mathrm{m}$. reto medial de forma a recobrir toda a sua área de inserção (Figuras 12-A e 13-B). Insere-se craniodorsalmente na esclera por meio de um curto tendão $(1,0 \pm 0 \mathrm{~mm})$ anteriormente ao equador do bulbo (Figura 12-A). Na inserção, o tendão configura uma linha oblíqua em relação ao equador do bulbo. A extremidade posterior da sua linha de inserção se encontra muito próxima à extremidade anterior da linha de inserção do m. reto dorsal, no entanto estas não se sobrepõem (Figura 12-A). 


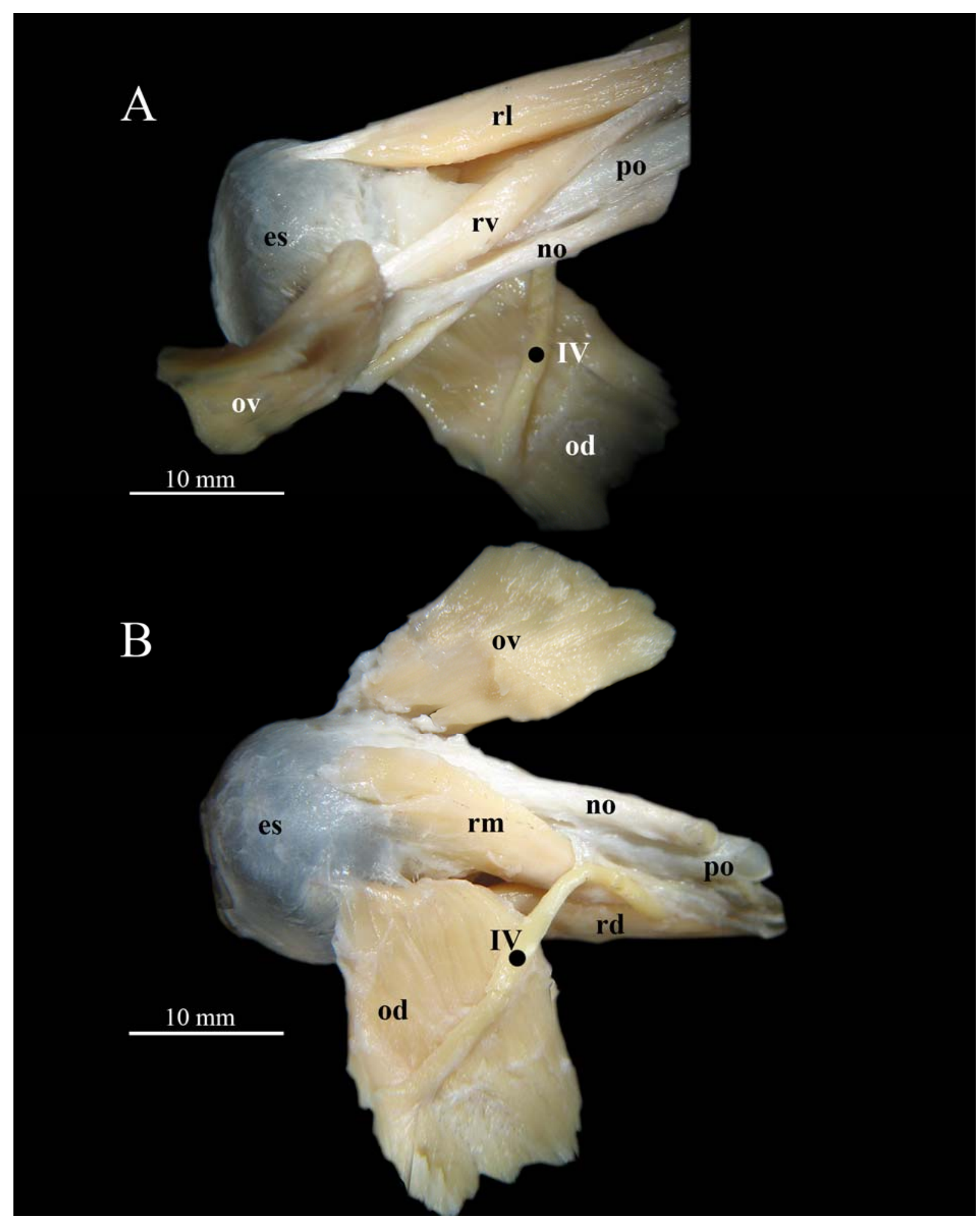

Figura $13(\mathrm{~A}$ e B) - $\quad$ Bulbo do olho esquerdo de $G$. altavela em vista ventral (A e B). A, músculos oblíquos rebatidos; $\mathbf{B}, \mathrm{m}$. oblíquo ventral rebatido, mostrando a inserção do $\mathrm{m}$. reto ventral. Legenda: IV, n. troclear; es, esclera; no, n. óptico; od, m. oblíquo dorsal; ov, m. obliquo ventral; po, pedículo óptico; rd, m. reto dorsal; rv, m. reto ventral; rl, m. reto lateral; rm, m. reto medial 


\subsubsection{Músculo Oblíquo Ventral}

O m. oblíquo ventral $(13,1 \pm 3,92 \mathrm{~mm})$ possui em sua origem um curto tendão (>1,0 mm), posicionado ventralmente aos $\mathrm{mm}$. oblíquo dorsal (Figura 12-B). É um músculo largo, achatado dorsoventralmente, cuja largura do ventre $(5,1 \pm 2,40 \mathrm{~mm})$ é maior que a cauda e menor que a da cabeça (Figura 12-B). Em seu trajeto, da origem à inserção, a face ventral do músculo segue paralelamente à face ventral do m. oblíquo dorsal no decorrer do seu primeiro terço de extensão (Figura 12-B). Insere-se na parte medioventralmente da esclera por um curto tendão $(1,7 \pm 0,94$ $\mathrm{mm}$ ) (Figura 12-B) e de tal forma que em seu trajeto se sobrepõem à inserção do $\mathrm{m}$. reto ventral e ao ponto de emergência do nervo óptico (Figura 13-A). Seu tendão de inserção configura uma linha de fixação oblíqua em relação ao equador do bulbo.

\subsubsection{Mobula thurstoni (Lloyd, 1908)}

Nas seções a seguir serão apresentados os resultados obtidos de Mobula thurstoni.

\subsubsection{1 Órbita e Esclera}

Os olhos de $M$. thurstoni se localizam nas extremidades laterais da cabeça, caudalmente à nadadeira cefálica, nadadeira característica dos animais pertencentes à família Mobulidae. O equador do bulbo $(31,3 \pm 1,48 \mathrm{~mm})$ está posicionado paralelamente à parede lateral da órbita (Figura 8-C), não formando ângulo de inclinação.

A cavidade orbital de $M$. thurstoni é rasa, de forma que após a dissecção e remoção de todos os músculos e fáscias, o bulbo se apresenta protraído, com a esclera projetada além da margem orbital (Figura 14 A-C) 


\subsubsection{Músculo Reto Lateral}

$\mathrm{O}$ m. reto lateral $(57,2 \pm 0,67 \mathrm{~mm})$ se origina caudalmente à origem dos $\mathrm{mm}$. reto dorsal e reto medial e dorsalmente à origem do $\mathrm{m}$. reto ventral (Figura 15-A e $D)$, por meio de um curto tendão $(7,77 \pm 0,44 \mathrm{~mm})$. Apresenta forma de leque e margens espessas, além de um sulco ventral, presente no terço distal e estendido até próximo à sua inserção (Figura 18-A). A largura do seu ventre $(14,1 \pm 0,78 \mathrm{~mm})$ é maior que a da cabeça e menor do que a da cauda. Em seu trajeto, segue caudoventralmente ao $\mathrm{m}$. reto dorsal e dorsocaudalmente ao $\mathrm{m}$. reto ventral (Figuras $15-A, C$ e 18-B). Sua margem cranial segue paralelamente ao $\mathrm{m}$. reto ventral (Figuras 15-C e 18-B). Insere-se na esclera, logo anteriormente ao equador do bulbo (Figura 15-A e C). O tendão de inserção $(8,33 \pm 0,50 \mathrm{~mm})$ configura uma linha de fixação convexa em relação ao equador do bulbo. Em sua parte dorsal, em um ponto próximo a inserção na esclera, e muito próxima à inserção do m. reto dorsal, onde o m. reto lateral é mais robusto, se insere um músculo cilíndrico que se origina no crânio logo dorsorostralmente a órbita (Figura 15-C). 

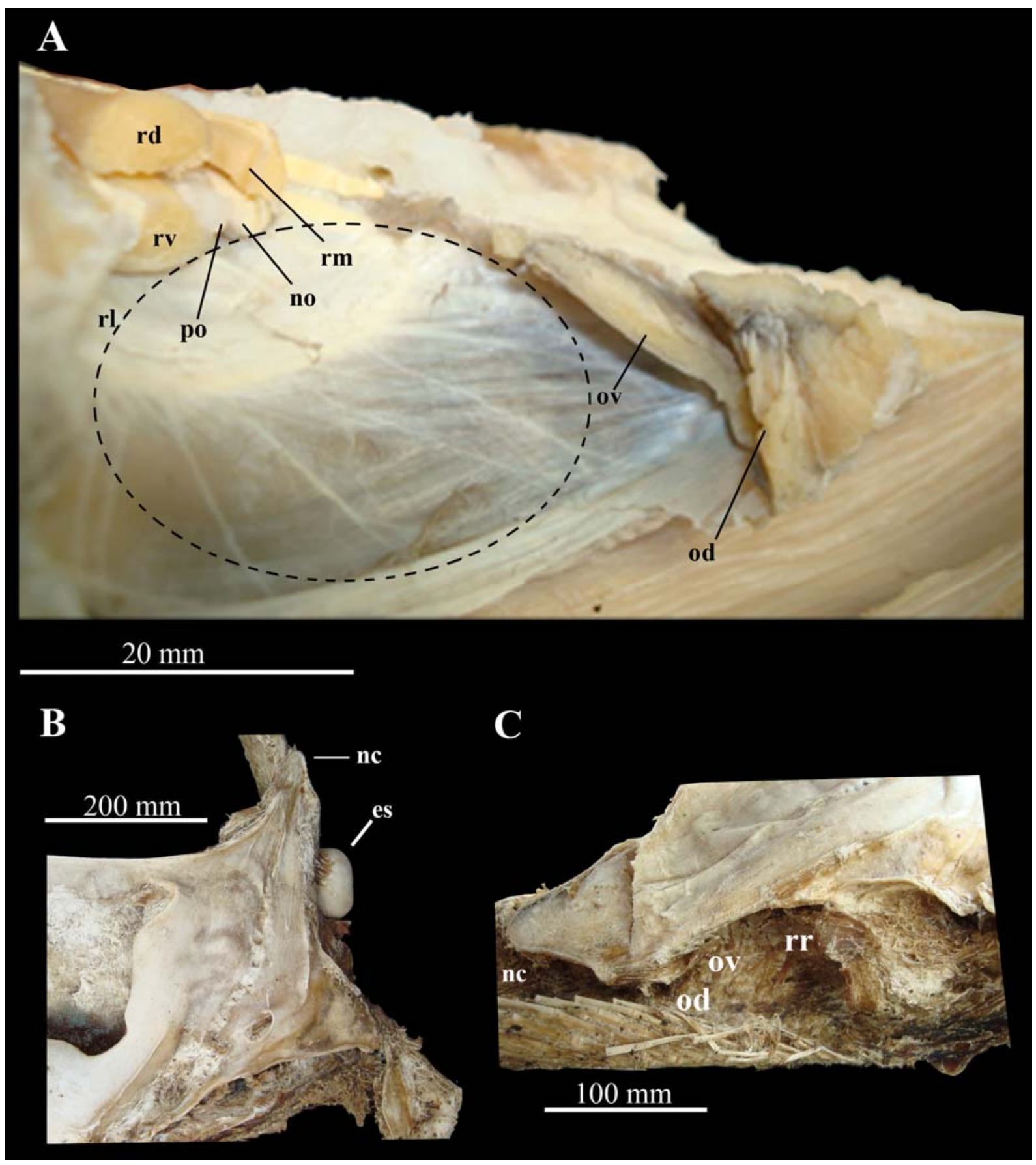

Figura $14(\mathrm{~A}-\mathrm{C})$ - $\quad$ Região orbital e musculatura extraocular de $M$. thurstoni. A. Vista lateral da órbita direita. B. Vista dorsal do neurocrânio e bulbo do olho in situ (peça preparada por Dermestis sp.); C. Detalhe da localização das origens dos $\mathrm{mm}$. retos e oblíquos. Legenda: área pontilhada, localização do bulbo; es, esclera; no, nervo óptico; od, m. oblíquo dorsal; ov, m. obliquo ventral; po, pedículos óptico; rd, m. reto dorsal; rv, $\mathrm{m}$. reto ventral; $\mathbf{r l}, \mathrm{m}$. reto lateral; $\mathbf{r m}, \mathrm{m}$. reto medial; $\mathbf{n c}$, nadadeira cefálica; $\mathbf{r r}, \mathrm{mm}$. retos. 


\subsubsection{Músculo Reto Medial}

O $\mathrm{m}$. reto medial $(63,10 \pm 1,16 \mathrm{~mm})$ se origina por meio de um fino tendão $(2,77 \pm 0,44 \mathrm{~mm})$ que parte de uma área rostral à origem dos $\mathrm{mm}$. reto dorsal (Figura $15-A$ ), reto lateral e reto ventral (Figura 15-D). É um músculo fusiforme, com leve achatamento dorsoventral (Figura 16-A) e seu ventre $(8,22 \pm 0,66 \mathrm{~mm}$ ) (Figuras 15-A e 16-A) é mais largo do que a sua cabeça e a sua cauda. Em seu trajeto, segue em direção rostral e, em seu terço inicial, paralelamente ao $\mathrm{m}$. reto dorsal e ao pedículo óptico (Figura 15-A). Em seguida, após um brusco afunilamento do seu ventre se continua por um longo tendão $(10,70 \pm 1,39 \mathrm{~mm})$. Este se insere na esclera, entre o equador do bulbo e o limbo corneal (Figura 16-A), adjacente à inserção do músculo oblíquo (Figura 16-A) e configura uma linha oblíqua em relação ao equador do bulbo.

\subsubsection{Músculo Reto Dorsal}

O Músculo reto dorsal $(10,70 \pm 1,39 \mathrm{~mm})$ se origina por um fino tendão $(5,5 \pm$ $0,52 \mathrm{~mm}$ ), que parte craniodorsalmente à origem do $\mathrm{m}$. reto lateral (Figura 18-B e D), dorsalmente à origem do $\mathrm{m}$. reto ventral (Figura 18-C e D) e dorsocaudalmente à origem do $\mathrm{m}$. reto medial (Figura 18-B). É um músculo delgado e fusiforme que, dentre os músculos retos, é o que apresenta o maior ventre muscular $(12,1 \pm 0,60$ $\mathrm{mm}$ ), o qual é praticamente da mesma largura que a cabeça e a cauda (Figura 18$B)$. Em seu trajeto, sua face ventral segue paralela à face dorsal do $\mathrm{m}$. reto ventral em quase metade de seu comprimento (Figura 18-C). Segue rostralmente para se inserir na esclera, logo anteriormente ao equador do bulbo (Figuras 15-A e 18-B) e dorsalmente ao pedículo óptico (Figuras 15-D e 16-A). Seu tendão de inserção (3,66 $\pm 0,50 \mathrm{~mm}$ ) configura uma linha de fixação convexa em relação ao equador do bulbo, a qual converge para um ponto próximo à inserção m. oblíquo dorsal, entretanto sem se sobrepor a esta. (Figuras 15-A e 18-B). 


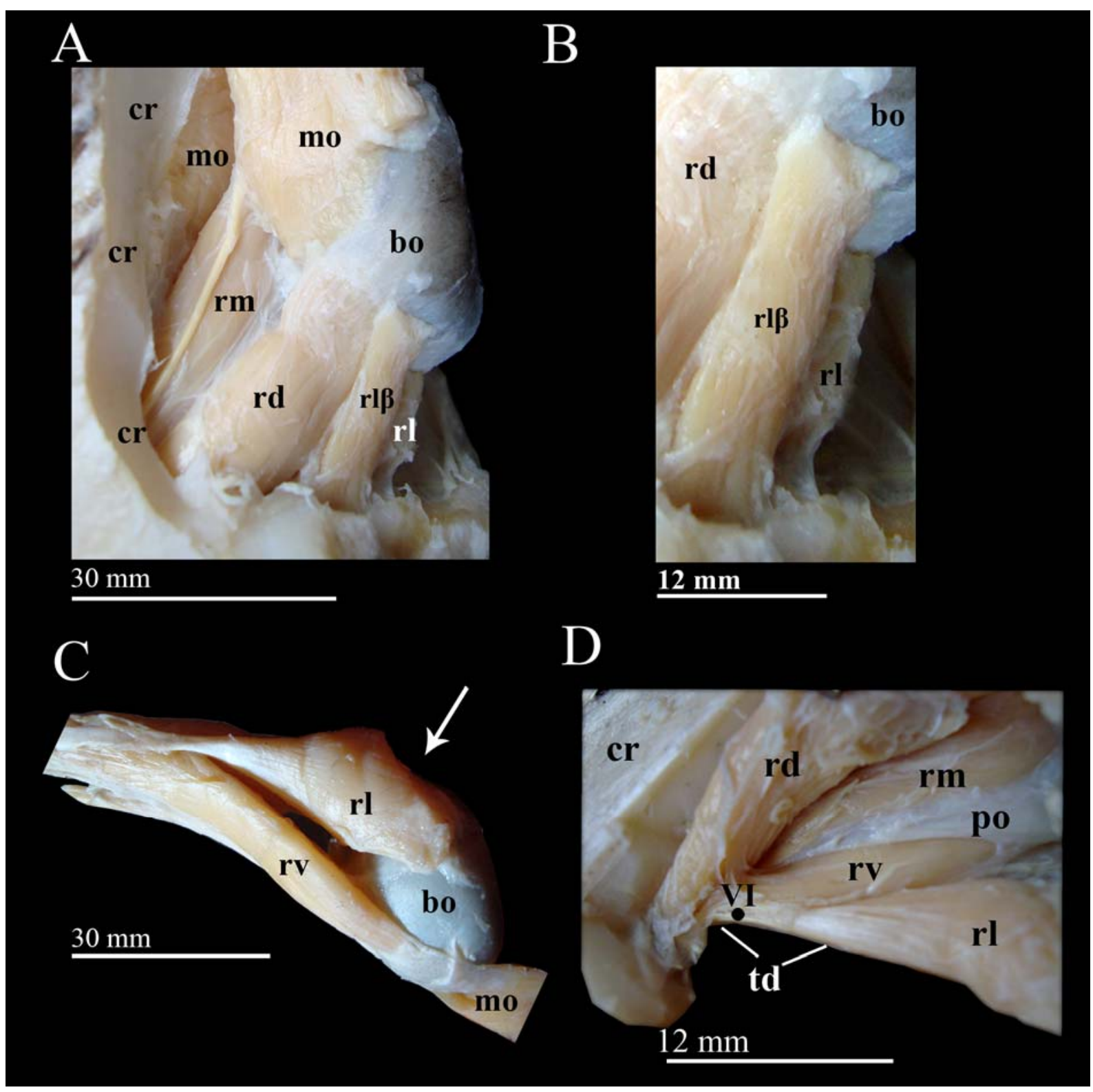

Figura $15(A-D)$ - $\quad$ Músculos extraoculares do bulbo dos olhos direito (A e D) e esquerdo (B e C) de $M$. thurstoni. A. Vista dorsal dos músculos extraoculares e suas relações com o neurocrânio e bulbo do olho; B. Detalhe do $\mathrm{m}$. reto lateral $\beta$ em vista dorsal; $\mathbf{C}$. Vista lateral da relação dos $\mathrm{mm}$. reto lateral e ventral, seta indica o ponto de inserção do $\mathrm{m}$. reto lateral $\beta$; $\mathbf{D}$. Vista das origens dos $\mathrm{mm}$. retos. Legenda: VI $\mathrm{n}$. abducente; IV, $\mathrm{n}$. troclear; bo, bulbo do olho; cr, condrocrânio; mo, m. oblíquo; no, nervo óptico; po, pedículos óptico; rd, m. reto dorsal; rv, m. reto ventral; rl, $\mathrm{m}$. reto lateral; $\mathbf{r l} \boldsymbol{\beta}, \mathrm{m}$. reto lateral $\beta ; \mathbf{r m}, \mathrm{m}$. reto medial 


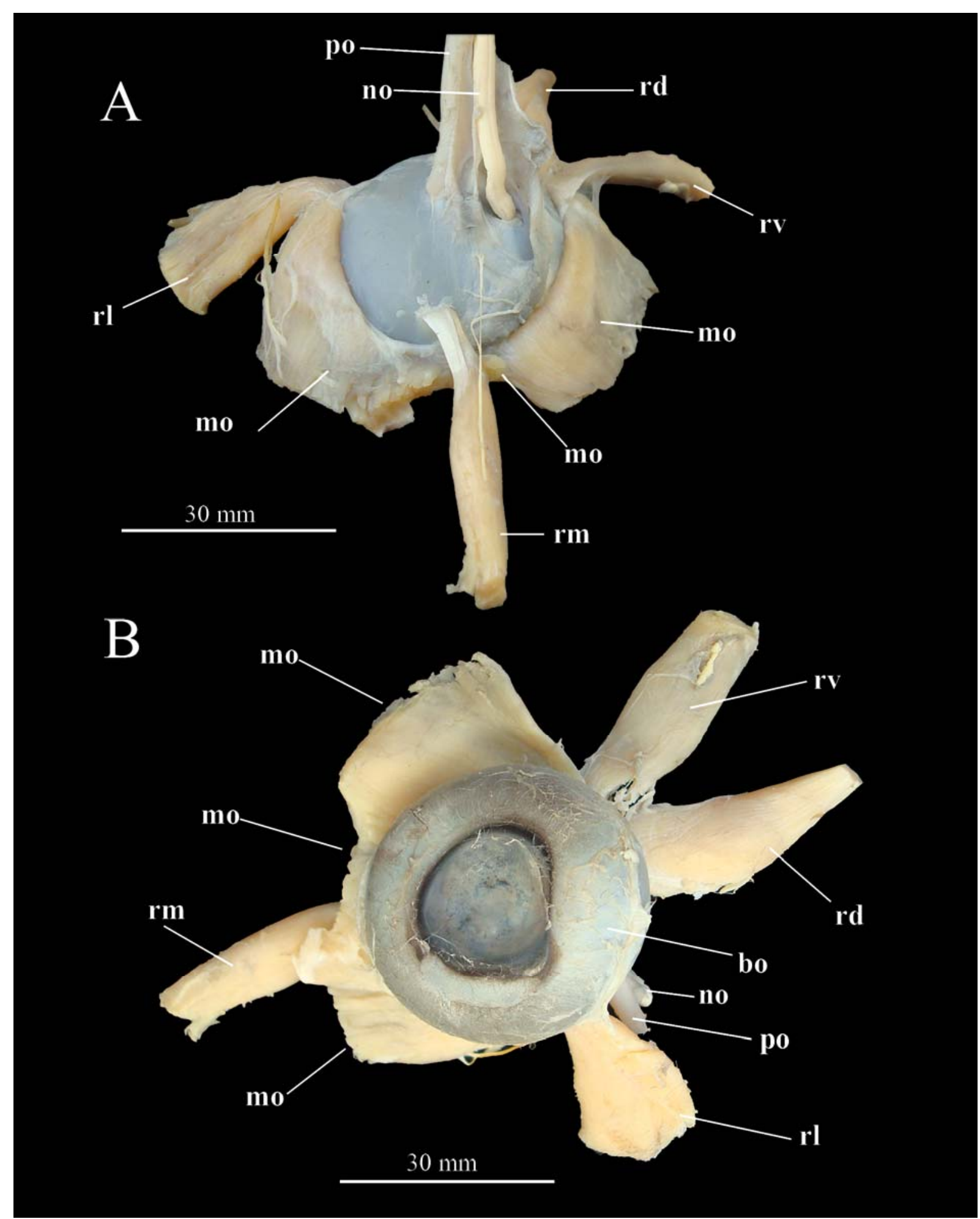

Figura 16 (A e B) - Músculos extraoculares do bulbo do olho direito de M. thurstoni. A. Vista anterior do bulbo; B. vista posterior do bulbo. Legenda: bo, bulbo do olho; mo, m. oblíquo; no, nervo óptico; po, pedículo óptico; rd, m. reto dorsal; rl, m. reto lateral; rm, $\mathrm{m}$. reto medial; rv, $\mathrm{m}$. reto ventral 


\subsubsection{Músculo Reto Ventral}

O músculo reto ventral $(55,3 \pm 1,11 \mathrm{~mm})$ se origina ventralmente às origens dos $\mathrm{mm}$. retos dorsal, medial e lateral (Figura 15-C e D), por meio de um longo tendão (14,6 $\pm 0,78 \mathrm{~mm})$. É um músculo delgado, fusiforme e achatado dorsoventralmente, cujo ventre $(10,7 \pm 0,66 \mathrm{~mm})$ é mais largo que a cauda e praticamente da mesma largura que a cabeça (Figura 15-C). Em seu trajeto segue paralelamente ao pedículo óptico e ao nervo óptico (II) em sua parte proximal (Figura 15-D). O ventre se alarga gradativamente, afunilando bruscamente quando se aproxima da inserção na esclera (Figura 16-A), que o corre ventralmente e entre o equador do bulbo e o limbo corneal (Figura 17-A e B), em um ponto adjacente à parte ventral da inserção do m. oblíquo; este, por sua vez, recobre a sua inserção (Figura 17-A e B). O curto tendão de inserção $(4,33 \pm 0,50 \mathrm{~mm})$ configura uma linha de fixação côncava em relação ao equador do bulbo.

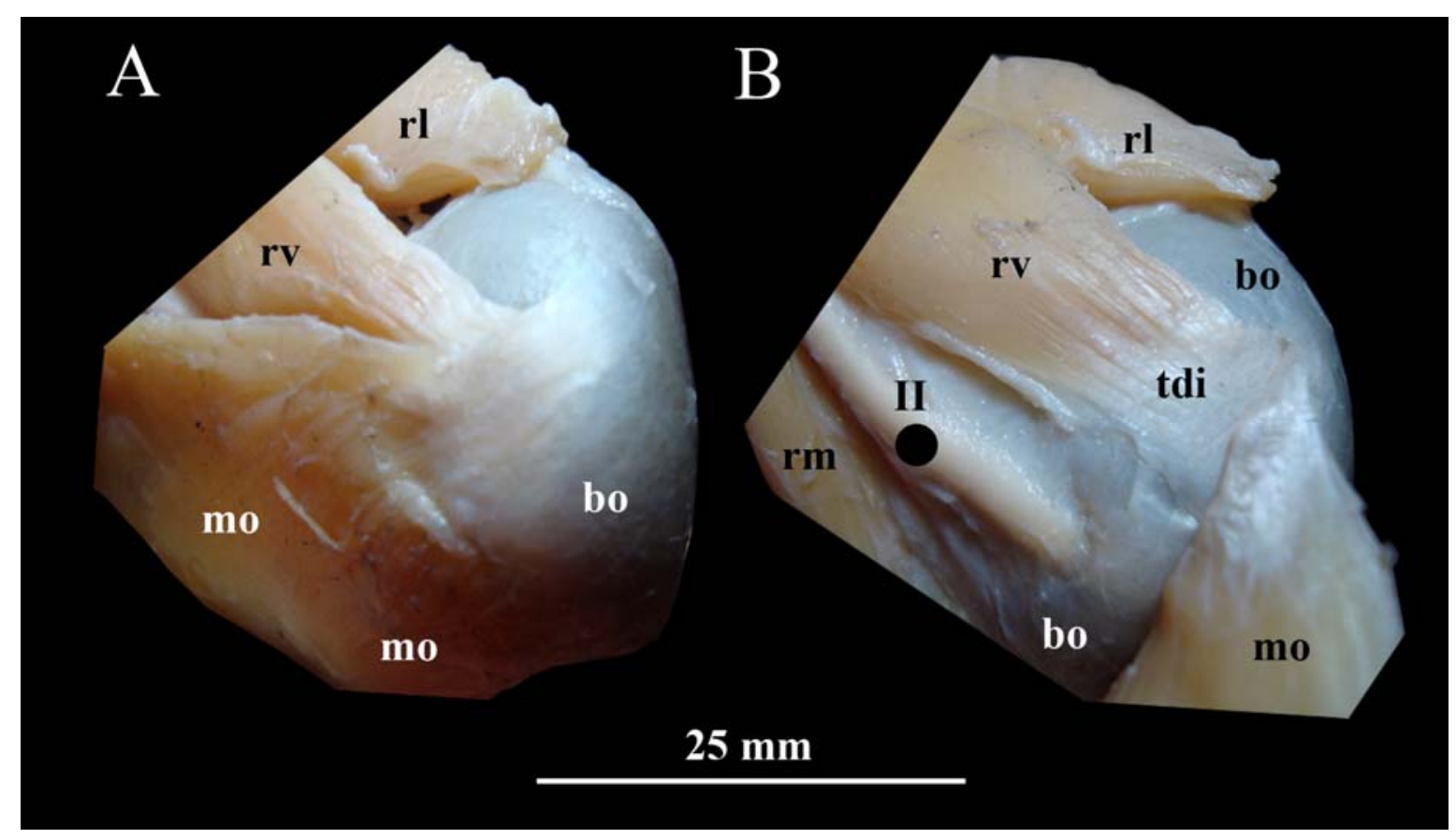

Figura 17 (A-B) - $\quad$ Relação dos músculos extraoculares do bulbo do olho esquerdo de M. thurstoni. A. Vista lateroventral do bulbo; B. vista ventral do bulbo, com a parte ventral do $\mathrm{m}$. oblíquo rebatida. Legenda: II, nervo óptico; bo, bulbo do olho; mo, m. oblíquo; rl, m. reto lateral; rm, m. reto medial; rv, $\mathrm{m}$. reto ventral 


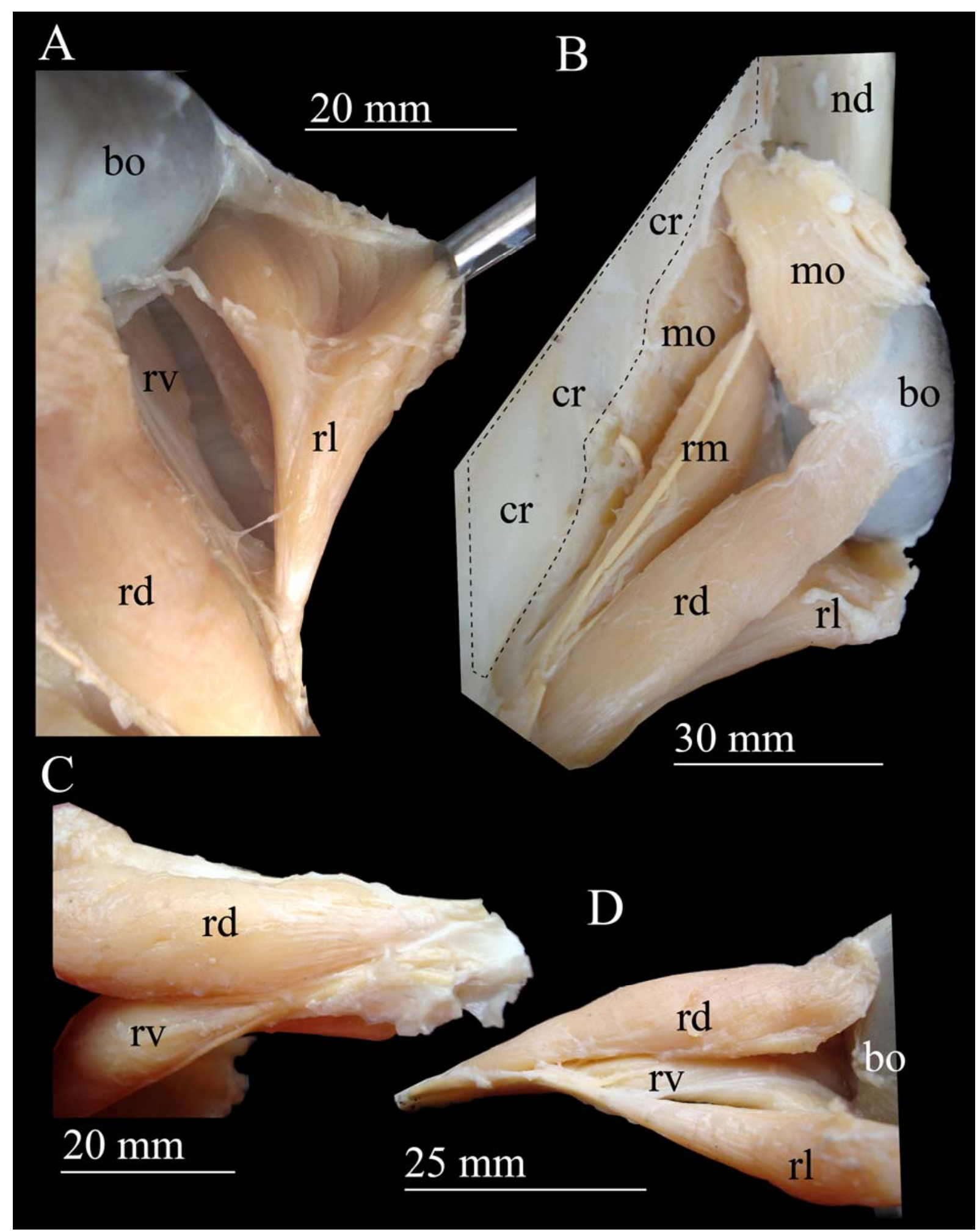

Figura 18 (A-D) - Músculos extraoculares do bulbo do olho direito de M. thurstoni. A. Vista laterodorsal; B. vista dorsal; C. vista anterodorsal; D. vista posterolateral. Legenda: bo, bulbo do olho; cr, condrocrânio; mo, m. oblíquo; no, nervo óptico; rd, m. reto dorsal; rm, m. reto medial; rl, m. reto lateral; $\mathbf{r v}, \mathrm{m}$. reto ventral 


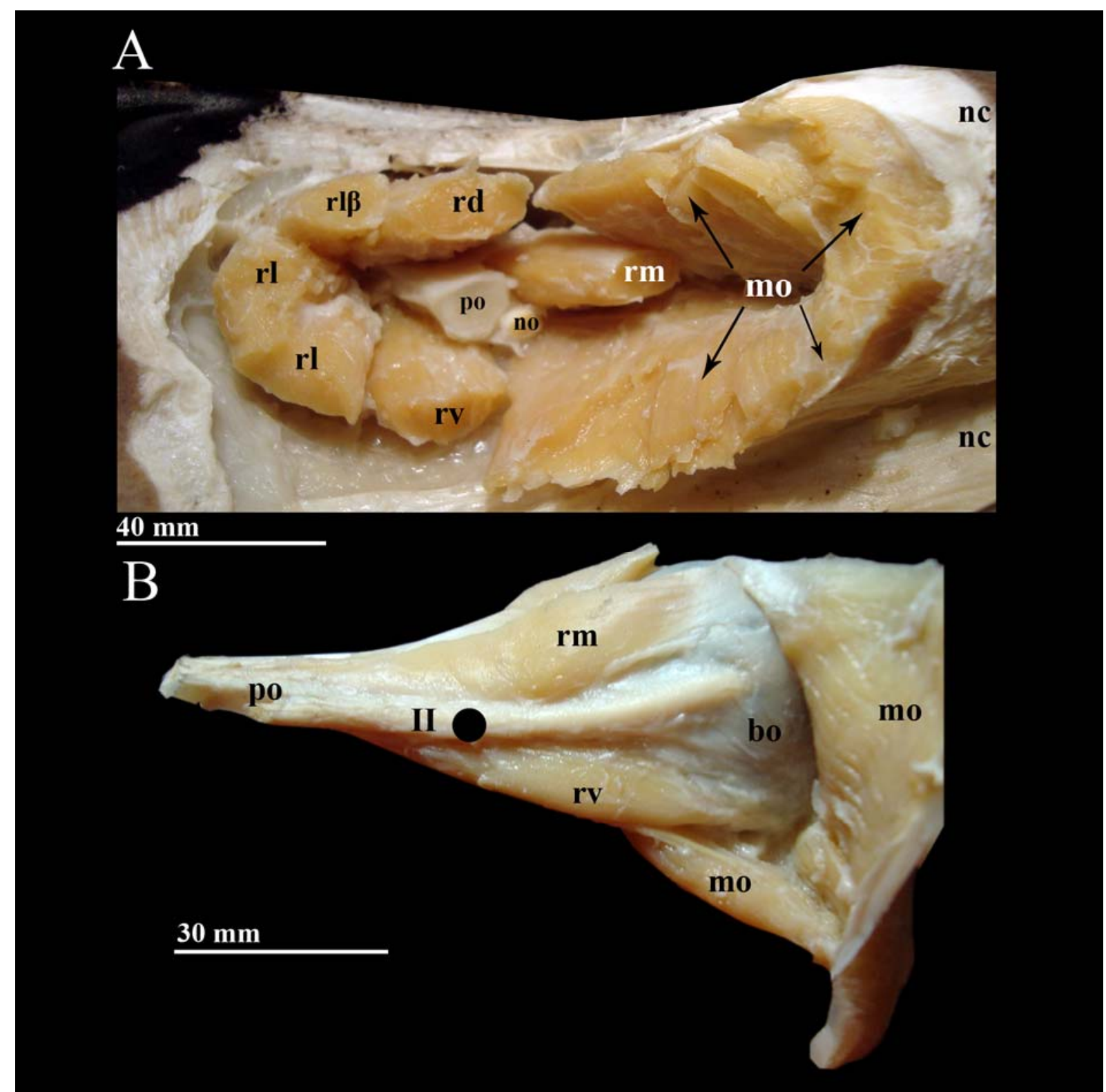

Figura $19(\mathrm{~A}$ e B) - Músculos extraoculares do bulbo do olho direito de M. thurstoni. A. Órbita com bulbo do olho removido; B. vista ventral. Legenda: II, n. óptico; IV, nervo troclear; bo, bulbo do olho; cr, condrocrânio; mo, m. oblíquo; nd, nadadeira cefálica; po, pedículo óptico; rd, m. reto dorsal; $\mathbf{r l}, \mathrm{m}$. reto lateral; $\mathbf{r l} \boldsymbol{\beta}, \mathrm{m}$. reto lateral $\beta ; \mathbf{r m}, \mathrm{m}$. reto medial; $\mathbf{r v}, \mathrm{m}$. reto ventral 


\subsubsection{Músculo Reto Lateral $\beta$}

O músculo reto lateral $\beta(27,1 \pm 1.15 \mathrm{~mm})$ possui em sua origem um curto tendão $(>1,0 \mathrm{~mm})$, posicionado dorsalmente sobre a margem caudal do $\mathrm{m}$. reto dorsal e a margem cranial do $\mathrm{m}$. reto lateral. (Figura 15-A e B). É um músculo fino, levemente achatado dorsoventralmente, cuja largura do ventre $(8,4 \pm 0,84 \mathrm{~mm})$ se mantém praticamente do mesmo tamanho da origem a inserção (Figura 15-B). Em seu trajeto, da origem à inserção, sua face ventral segue paralelamente à margem caudal do $\mathrm{m}$. reto dorsal e à margem cranial do $\mathrm{m}$. reto lateral (Figura 15-B). Inserese na sobre o m. reto lateral, em um ponto próximo a sua inserção por um curto tendão (>1,0 mm). Seu tendão de inserção configura uma linha obliqua em relação ao equador do bulbo.

\subsubsection{Músculo Oblíquo}

O músculo oblíquo possui duas cabeças e uma cauda. Após a origem as cabeças se unem no terço médio do ventre do músculo. Um amplo tendão de inserção se fixa na esclera a uma curta distância anteriormente ao equador e se estende na face medial do bulbo, desde o ponto mediodorsal ao ponto medioventral. É um músculo delgado e achatado dorsoventralmente (Figura 19-A e B). O tendão da cabeça dorsal é muito curto $(>1,0 \mathrm{~mm})$ e está posicionado perpendicular à origem do tendão da cabeça ventral (Figura 14-A). Seu ventre $(17,2 \pm 0,66 \mathrm{~mm}$ ) se alarga em sua parte média e, gradativamente, suas fibras se unem às fibras da cabeça ventral (Figura 16-A e B). A cabeça dorsal se alarga a medida que avança para se unir à cabeça ventral. Em seu trajeto, cruza dorsalmente o $\mathrm{m}$. reto medial, próximo à sua inserção (Figura 18-B). A cabeça ventral $(32,7 \pm 0,97 \mathrm{~mm})$ se origina por um tendão muito curto $(>1,0 \mathrm{~mm})$, dorsocaudalmente à cabeça dorsal e ventralmente à margem da crista cranial (Figuras 14-A e 18-B). Seu ventre $(15,1 \pm 1,06 \mathrm{~mm}$ ) se alarga em sua parte média e, em seu trajeto suas fibras gradativamente se unem às fibras da cabeça dorsal e passam sobre a inserção dos mm. retos ventral (Figura 17-A e B) e 
medial (Figura 19-B). O tendão de inserção se fixa à esclera $(3,2 \pm 0,44 \mathrm{~mm})$ configurando uma linha de inserção côncava em relação ao equador do bulbo.

\subsubsection{Pteroplatytrygon violacea (Bonaparte, 1832)}

Nas seções a seguir serão apresentados os resultados obtidos de Pteroplatytrygon violacea.

\subsubsection{1 Órbita e Esclera}

Os olhos de Pteroplatytrygon violacea se localizam nas extremidades laterais da cabeça (Figuras 3-A, B e C e 20-A). O bulbo do olho $(25,6 \pm 5,44 \mathrm{~mm}$ ) é levemente voltado para frente, formando um ângulo aproximado de $22^{\circ}$ em relação à linha mediana do corpo (Figura 8-D).

A cavidade orbital de $P$. violavea é profunda e o bulbo do olho a preenche amplamente, restringindo o espaço ocupado pelos mm. extraoculares (Figura 20-A). Tanto os músculos retos, como os músculos oblíquos se originam da parede dorsal da cavidade orbital. No entanto, os primeiros partem rostralmente e, os últimos, caudalmente (Figura 20-B e C).

\subsubsection{Músculo Reto Lateral}

O m. reto lateral $(24, \pm 0,53 \mathrm{~mm}$ ) (Figuras 20-C, 22-A e 23-A e B) se origina ventralmente ao $\mathrm{m}$. reto dorsal e caudoventralmente aos $\mathrm{mm}$. reto ventral e medial (Figura 23-A) por um fino tendão $(>1,0 \mathrm{~mm})$. O músculo é fusiforme e achatado dorsoventralmente. A largura do seu ventre $(5,9 \pm 0,31 \mathrm{~mm})$ é maior que a da cabeça e menor que a da cauda. Em seu trajeto segue paralelamente ao $\mathrm{m}$. reto dorsal, desde a origem até a inserção, de tal forma que sua face dorsal fica próxima 
à face ventral do $\mathrm{m}$. reto dorsal (Figura 23-B). Insere-se no pólo posterior da esclera por um tendão longo $(7,8 \pm 0,91 \mathrm{~mm}$ ) (Figura 22-A) que configura uma linha de fixação oblíqua em relação ao limbo corneal.

\subsubsection{Músculo Reto Medial}

$\mathrm{O} \mathrm{m}$. reto medial $(21,6 \pm 0,51 \mathrm{~mm})$ possui em sua origem um fino e longo tendão $(1,7 \pm 0,40 \mathrm{~mm})$, localizado cranialmente às origens dos $\mathrm{mm}$. reto dorsal $\mathrm{e}$ reto lateral e dorsalmente a origem do $\mathrm{m}$. reto ventral (Figura 23-A). É um músculo fusiforme, cujo ventre $(5,0 \pm 0 \mathrm{~mm})$ é praticamente da mesma largura que a cabeça e a cauda (Figura 23-A). Em seu trajeto segue paralelamente ao $\mathrm{m}$. reto ventral e cruza ventralmente o m. oblíquo dorsal (Figura 23-A). Insere-se na da esclera por um curto tendão $(2,3 \pm 0,48 \mathrm{~mm})$, em um ponto entre o equador e o ponto de emergência do n. óptico (Figura 24-C e D). Na inserção, o tendão configura uma linha de fixação côncava em relação ao equador do bulbo. 


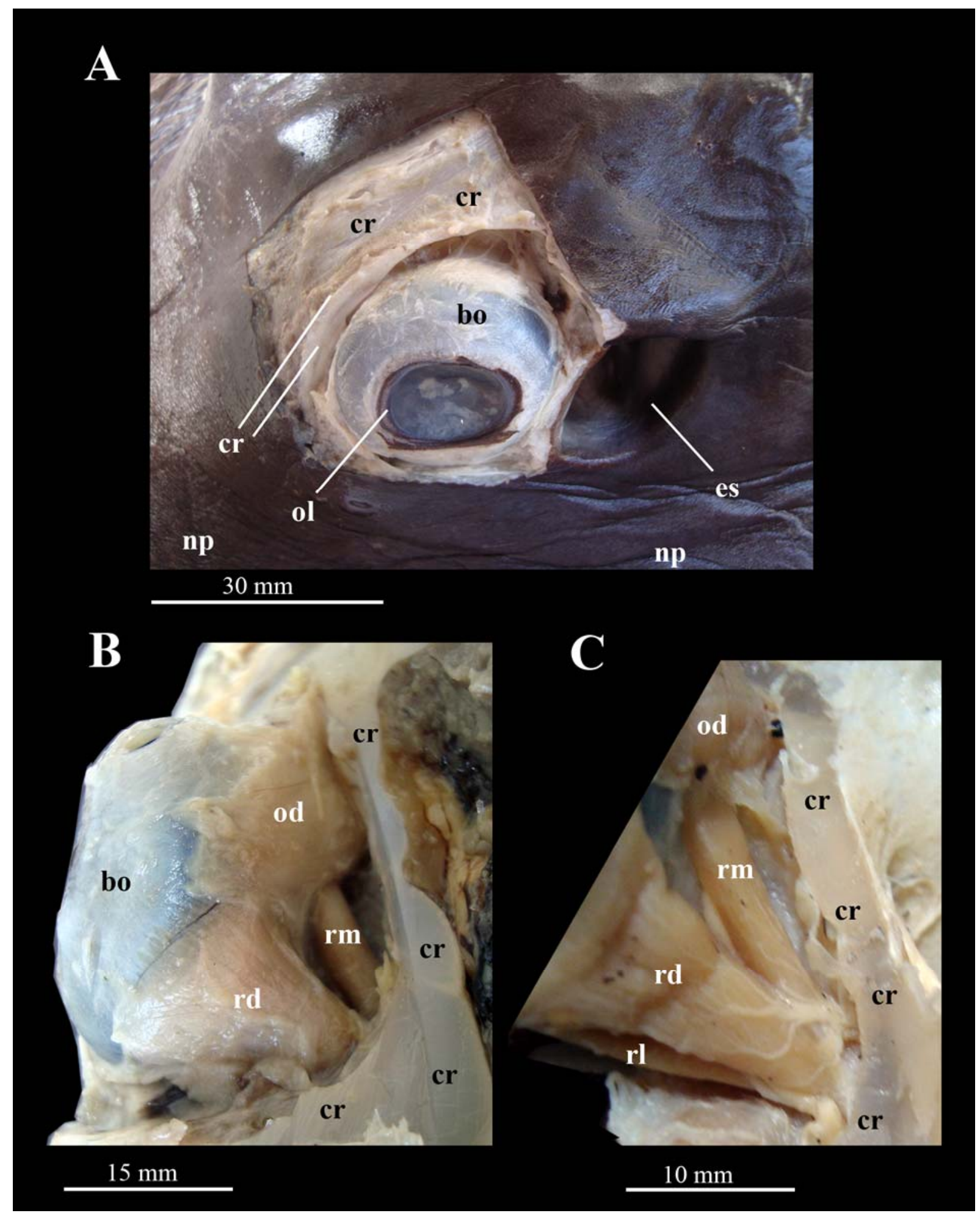

Figura $20($ A-C) - Bulbo do olho e músculos extraoculares de $P$. violacea. A. Vista laterodorsal do bulbo do olho in situ. B. Vista dorsal do bulbo do olho e as relações dos $\mathrm{mm}$. retos medial e dorsal; e $\mathrm{m}$. oblíquo dorsal; $\mathbf{C}$. Relações das origens dos $\mathrm{mm}$. retos medial e dorsal; e m. oblíquo dorsal. Legenda: bo, bulbo do olho; cr, condrocrânio; nd, nadadeira cefálica; rd, m. reto dorsal; rl, m. reto lateral; rm, m. reto medial 


\subsubsection{Músculo Reto Dorsal}

O músculo reto dorsal $(16,4 \pm 1,57 \mathrm{~mm})$ se origina por um tendão muito curto $(>1,0$ $\mathrm{mm}$ ) localizado dorsalmente à origem do $\mathrm{m}$. reto lateral e caudalmente à origem dos mm. retos ventral e medial (Figura 23-A). É um músculo longo e achatado dorsoventralmente, cuja largura do ventre $(6,80 \pm 0,91 \mathrm{~mm})$ é maior que a da cabeça e menor que a da cauda (Figura 23-A e B). Em seu trajeto segue paralelamente ao m. reto lateral, desde a origem até a inserção, de tal forma que sua face ventral fica próxima à face dorsal do $\mathrm{m}$. reto lateral (Figura 23-B). Seu tendão de inserção $(6,1 \pm$ $0,83 \mathrm{~mm}$ ) se fixa na esclera, adjacente à inserção do m. oblíquo dorsal (Figura 22C), praticamente sobre o equador do bulbo (Figura 22-B) e de forma oblíqua em relação a este.

\subsubsection{Músculo Reto Ventral}

O músculo reto ventral $(24,5 \pm 0,70 \mathrm{~mm})$ se origina por um curto tendão $(3,0 \pm 0 \mathrm{~mm})$ que se localiza cranialmente à origem dos $\mathrm{mm}$. reto lateral e dorsal e ventralmente à origem do $\mathrm{m}$. reto medial (Figura 23-A). É um músculo longo e achatado dorsoventralmente (Figura 21-A e B), cujo ventre $(5,0 \pm 1,05 \mathrm{~mm})$ é mais largo do que a cabeça (Figura 24-D). Em seu trajeto cruza ventralmente o pedículo óptico e o ponto de emergência do nervo óptico para se inserir ventralmente ao ventre do $\mathrm{m}$. oblíquo ventral (Figuras 21-A e B e 24-D). Seu tendão de inserção (2,2 \pm 0,63 mm) configura uma linha de fixação oblíqua em relação o equador do bulbo. 


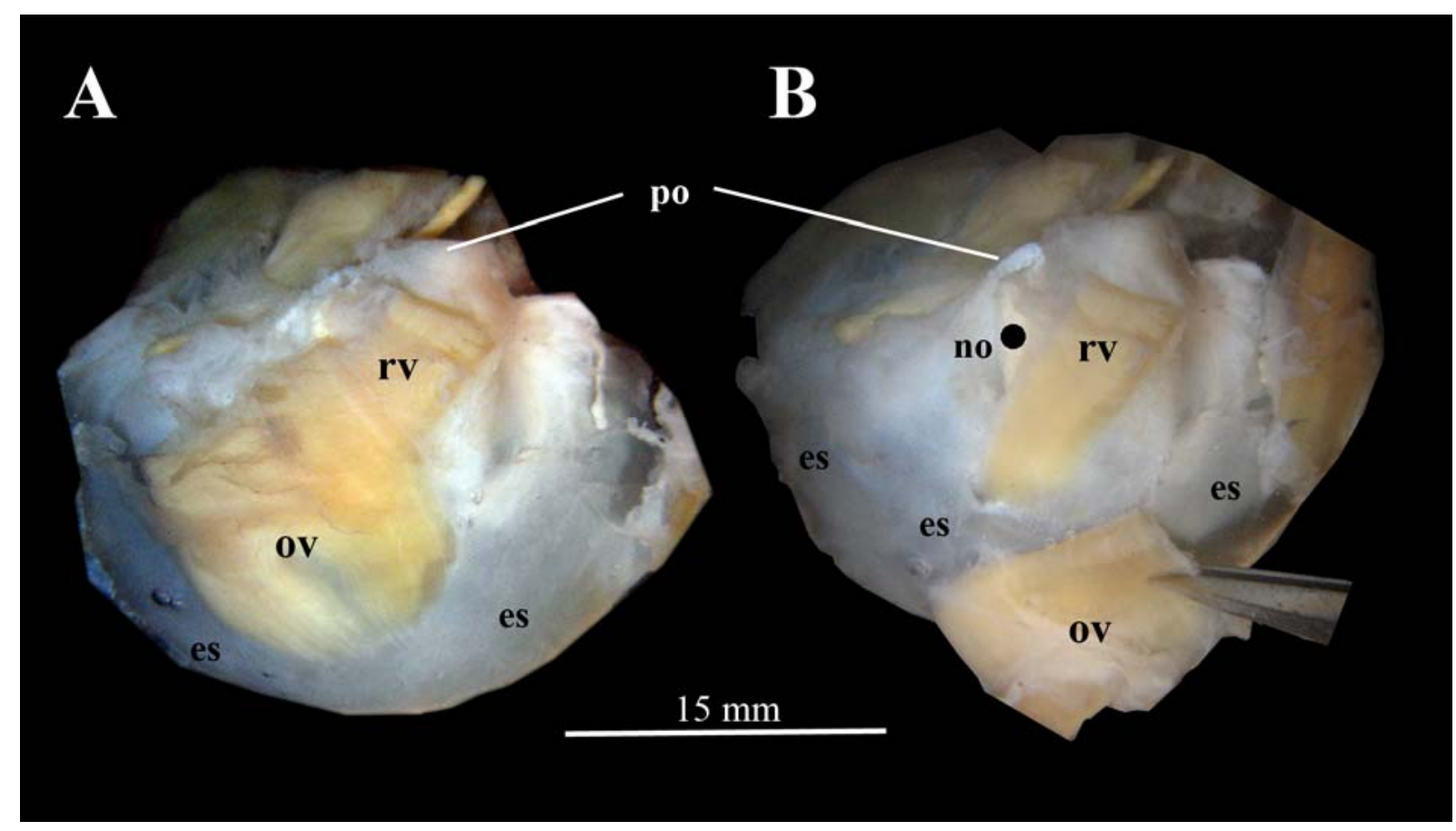

Figura 21 ( A e B) - Vistas ventrais do bulbo do olho direito de $P$. violaea. A, Relação dos $\mathrm{mm}$. oblíquo ventral e reto ventral; $\mathbf{B}$. Seqüência da dissecção de A. inserção do $\mathrm{m}$. reto ventral e sua relação com o nervo óptico; e a inserção do $\mathrm{m}$. oblíquo ventral. Legenda no, nervo óptico: po, pedículo óptico; rl, m. reto lateral; rv, m. reto ventral; ov, m. oblíquo ventral (rebatido)

Tabela 4 - Formato da inserção na esclera por espécies.

\begin{tabular}{lcccccc}
\hline \multirow{2}{*}{ Espécies } & \multicolumn{6}{c}{ Músculos } \\
\cline { 2 - 6 } & Reto & Reto & Reto & Reto & Oblíquo & Oblíquo \\
& Doreral & Dorsal & Ventral & Medial & Dorsal & Ventral \\
\hline G. altavela & Oblíqua & Reta & Oblíqua & Côncava & Oblíqua & Oblíqua \\
D. hypostigma & Oblíqua & Côncava & Côncava & Oblíqua & Côncava & Convexa \\
M. thurstoni & Convexa & Convexa & Côncava & Oblíqua & Côncava & Convexa \\
P. violacea & Côncava & Oblíqua & Oblíqua & Oblíqua & Convexa & Convexa \\
\hline
\end{tabular}




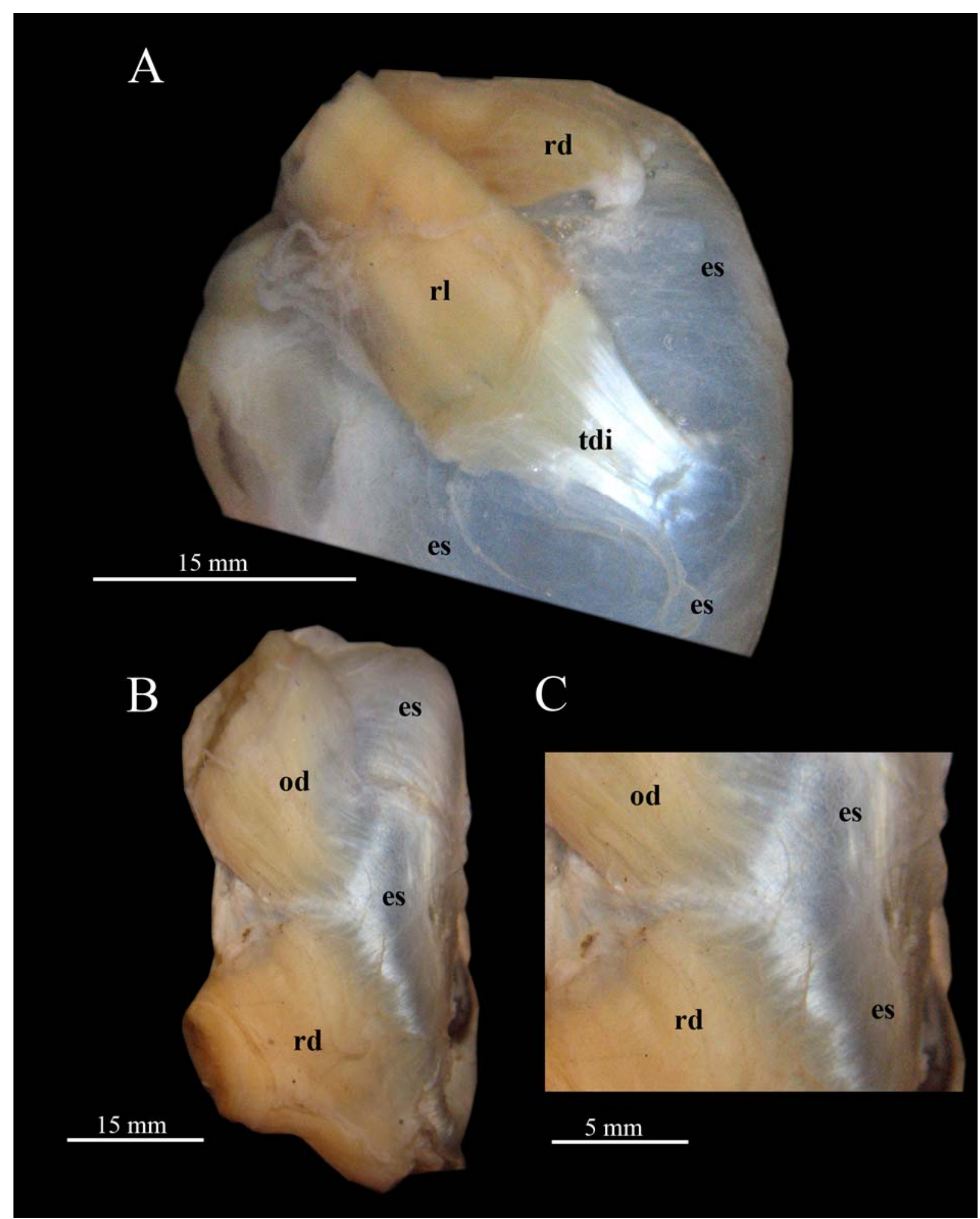

Figura $22(\mathrm{~A}-\mathrm{C})$ - $\quad$ Bulbo do olho direito com inserções musculares de $P$. violacea. A. Vista lateral, detalhe da inserção do $\mathrm{m}$. reto lateral e sua relação com o $\mathrm{m}$. reto dorsal; B. Vista dorsal; inserção dos $\mathrm{mm}$. reto dorsal e oblíquo dorsal. C. Detalhe de B; inserções dos $\mathrm{mm}$. reto dorsal e oblíquo dorsal. Legenda: es, esclera; od, m. oblíquo dorsal (B); po, pedículo óptico; rd, M. reto dorsal; rl, m. reto lateral; rm, m. reto medial; rd, m. reto dorsal; td, tendão 


\subsubsection{Músculo Oblíquo Dorsal}

O músculo oblíquo dorsal $(22,7 \pm 1,16 \mathrm{~mm})$ se origina da parte rostral da parede medial órbita, dorsalmente à origem do m. oblíquo ventral (Figura 23-A), por um tendão muito curto $(>1,0 \mathrm{~mm})$. É um músculo delgado, curto, largo e achatado dorsoventralmente. Em seu trajeto, segue dorsal e paralelamente ao $\mathrm{m}$. oblíquo ventral, desde a sua origem até o seu terço proximal (Figura 24-B) e cruza dorsalmente $\circ \mathrm{m}$. reto medial, próximo a sua inserção. Apresenta em seu ventre $(16,7 \pm 0,70 \mathrm{~mm})$, uma brusca torção medial (Figura 5-A). Em sua origem é afunilado (Figura 6-C), mas a medida que segue em direção à inserção se alarga para se inserir na esclera, em um ponto próximo ao equador do bulbo (Figura 24-A). 0 tendão de inserção $(1,80 \pm 0,42 \mathrm{~mm})$ configura uma linha de fixação de reta e paralela ao equador do bulbo.

\subsubsection{Músculo Oblíquo Ventral}

O músculo oblíquo ventral $(26,3 \pm 0,82 \mathrm{~mm})$ se origina rostralmente na parece medial da órbita, ventralmente à origem do m. oblíquo dorsal (Figura 23-A), por um tendão muito curto $(>1,0 \mathrm{~mm})$. É um músculo delgado, curto, largo e achatado dorsoventralmente (Figura 21-B). A largura do ventre $(10,9 \pm 0,56 \mathrm{~mm})$ é praticamente a mesma da cabeça, mas maior que a da cauda (Figura 21-A). Seu tendão de origem é largo, da mesma forma como o seu tendão de inserção $(1,60 \pm$ $0,51 \mathrm{~mm}$ ), que se fixa ventralmente na esclera, entre o equador e o ponto de emergência do $n$. óptico (Figura 21-A e B), configurando uma linha de fixação côncava em relação ao equador do bulbo. Em seu trajeto, cruza dorsalmente o m. reto ventral, recobrindo totalmente o ponto de inserção do mesmo (Figura 21-A e B). 


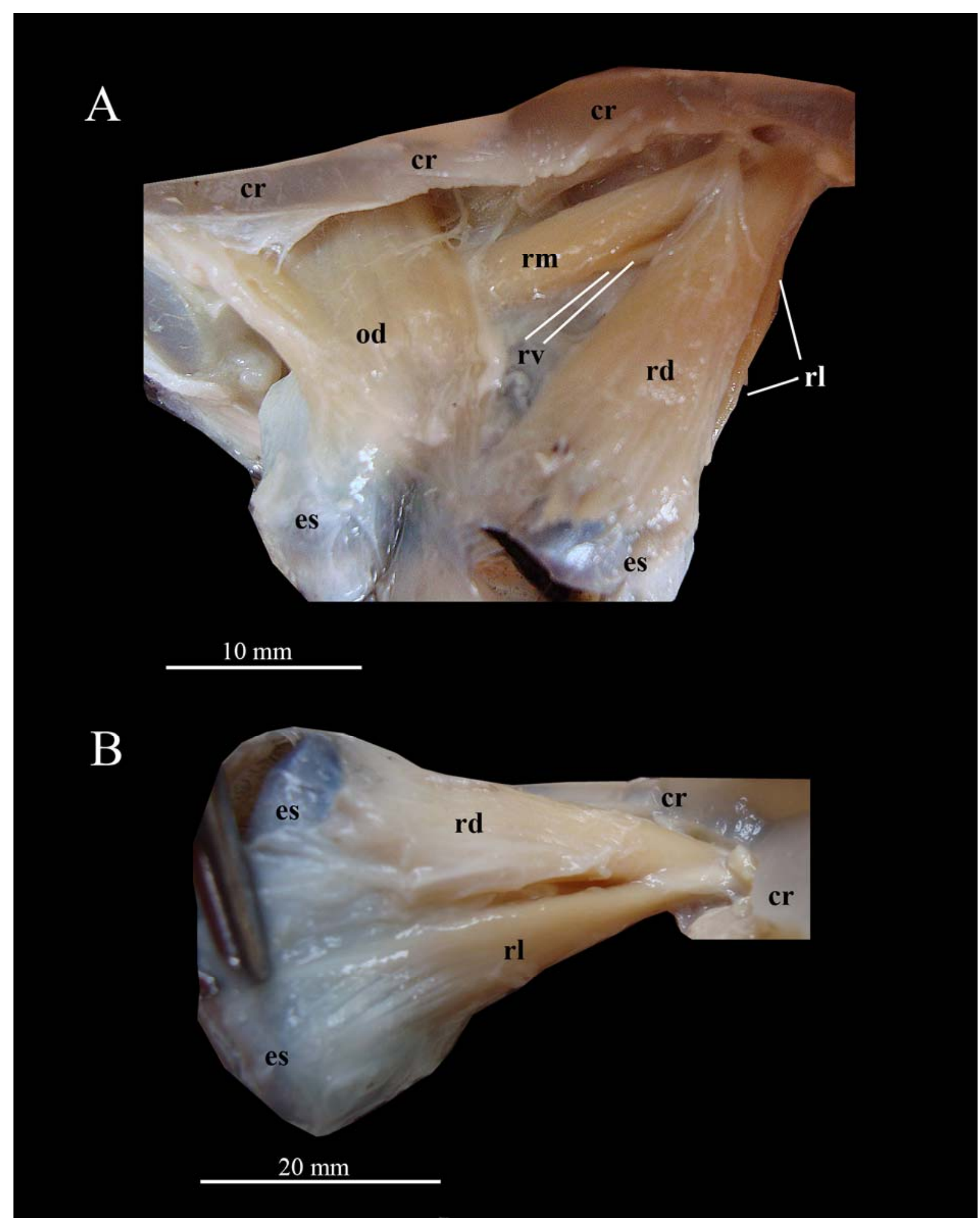

Figura $23(\mathrm{~A}$ e B) - $\quad$ Músculos extraoculares e bulbo do olho esquerdo de $P$. violacea. $\mathbf{A}$. vista dorsal e B. vista lateral. Legenda: cr, condrocrânio; es, esclera; od, m. oblíquo dorsal; rd, M. reto dorsal; rl, m. reto lateral; rm, m. reto medial; rv, m. reto ventral 


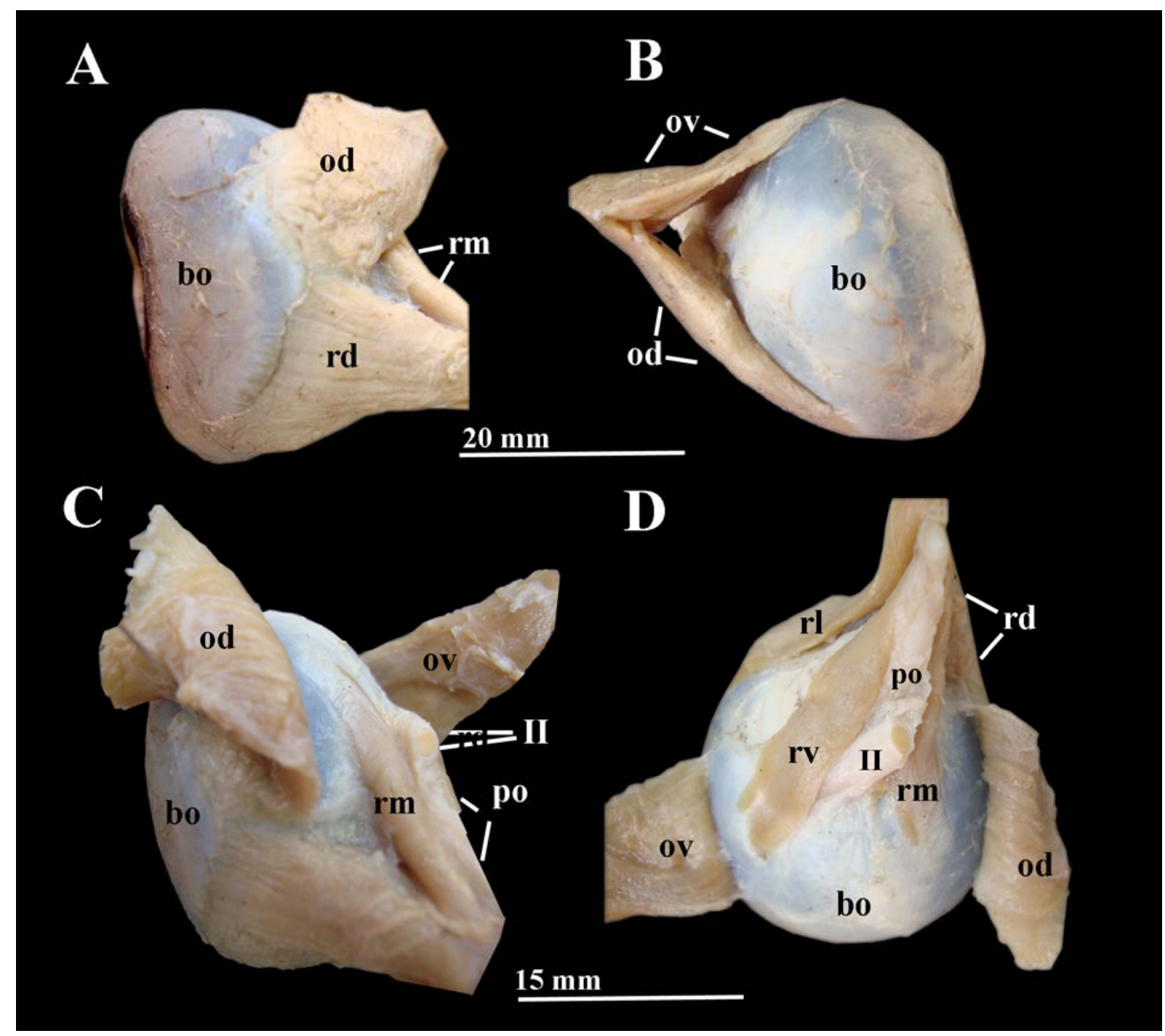

Figura $24(A-D)$ - Bulbo do olho e músculos extraoculares de $P$. violacea. A. Vista dorsal; B. vista medial; C. vista dorsocaudal com $\mathrm{m}$. oblíquo dorsal rebatido; D. vista caudal, com $\mathrm{mm}$. oblíquos dorsal e ventral rebatidos. Legenda: II, $\mathrm{n}$. óptico; bo, bulbo do olho; od, m. oblíquo dorsal; ov, m. oblíquo ventral; po, pedículo óptico; rd, m. reto dorsal; rl, m. reto lateral; rm, m. reto medial; $\mathbf{r v}, \mathrm{m}$. reto ventral 
5.2 Análise Morfométrica

\subsubsection{Análise do comprimento - ANOVA}

Todas as proporções entre os mm. analisados e o diâmetro do bulbo (DB) apresentaram diferenças significativas $(p<0,05)$ entre as espécies amostradas $(R L-$ $F=9331,7, R M-F=6907,0, R D-F=1555,5, R V-F=8907,6, O D-F=2125,9 e$

OV- F = 5776,6). O teste de Tukey mostrou que Pteroplatytrygon violacea apresentou os menores valores das proporções entre os $\mathrm{mm}$. reto e o Diâmetro do bulbo (RL/DB, RM/DB) (Gráfico 2) e Mobula thurstoni os maiores valores, exceto para RV (Gráfico 2). Para os músculos oblíquos, Dasyatis hypostigma apresentou os maiores valores das proporções OD/DO e OV/DO e nas outras espécies não houveram diferenças significativas (Gráfico 2).

\subsubsection{Análise de Componentes Principais (PCA)}

O primeiro eixo da PCA representou $94,2 \%$ da variância total e as variáveis mais importantes foram os músculos retos ventral (RV), dorsal (RD), medial (RM) e lateral (RL). O segundo eixo explicou $3,8 \%$ da variância e as variáveis mais importantes foram os $\mathrm{mm}$. oblíquos ventral (OV) e dorsal (OD). Esta mesma análise demonstrou que os dados mensurados para Mobula thurstoni se distinguiram das demais espécies por apresentarem os maiores valores para os músculos retos, enquanto as medidas de Gymnura altavela se distinguiram, principalmente, por apresentarem os menores tamanhos. Os dados obtidos de comprimento muscular não permitiram uma distinção nítida entre as espécies Pteroplatytrygon violacea e Dasyatis hypostigma (Gráfico 3). 

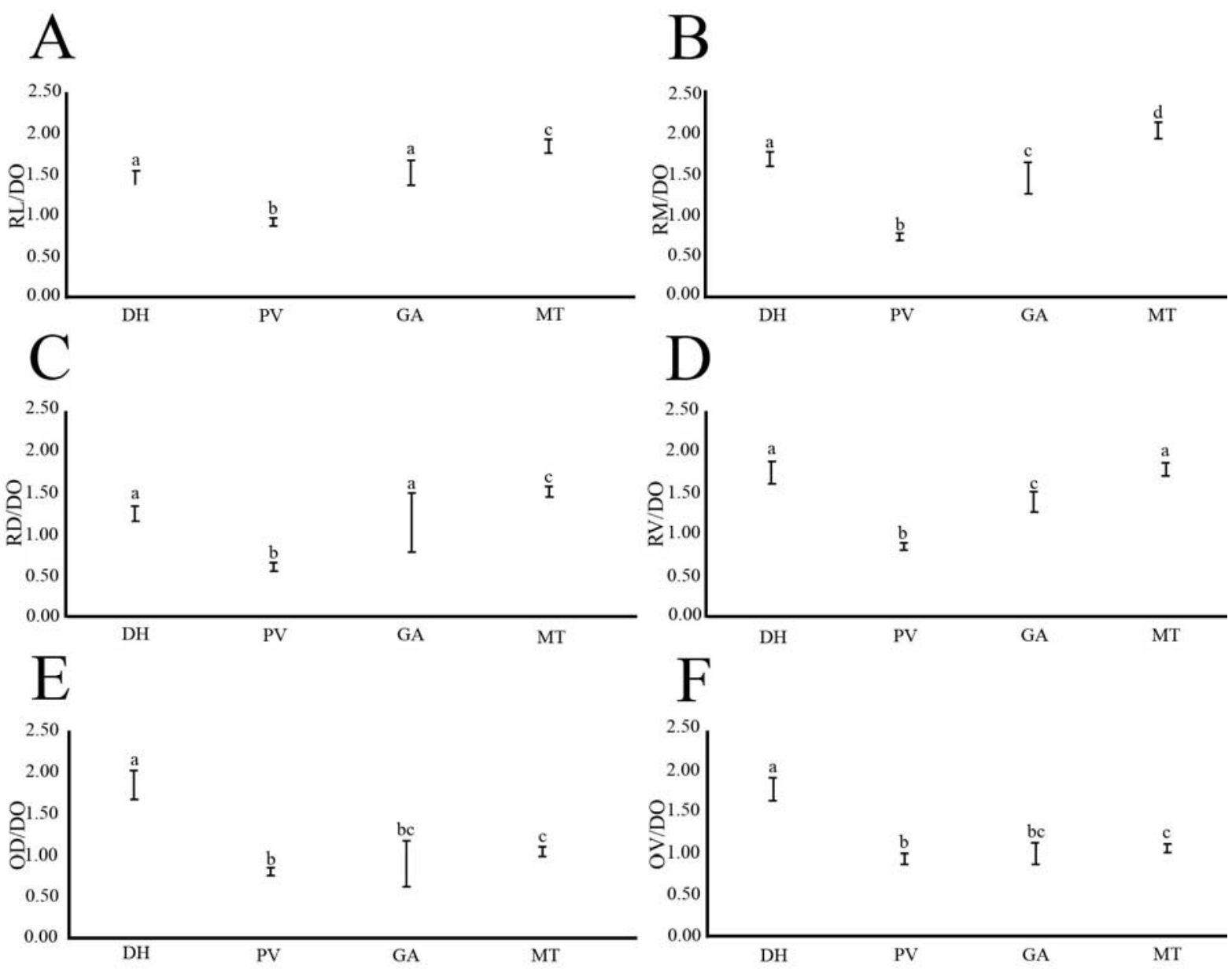

Gráfico 2 - Média e desvio padrão da relação do diâmetro do olho (DO) em relação ao comprimento dos $\mathrm{mm}$. retos medial $(R M)$, lateral $(R L)$, dorsal $(R D)$ e ventral (RV); e dos $\mathrm{mm}$. oblíquos ventral (OV) e dorsal (OD) para as espécies $D$. hypostigma (DH); G. altavela (GA); $P$. violacea (PV) e M. thurstoni (MT). As letras diferentes indicam diferenças detectadas pelo teste de Tukey 


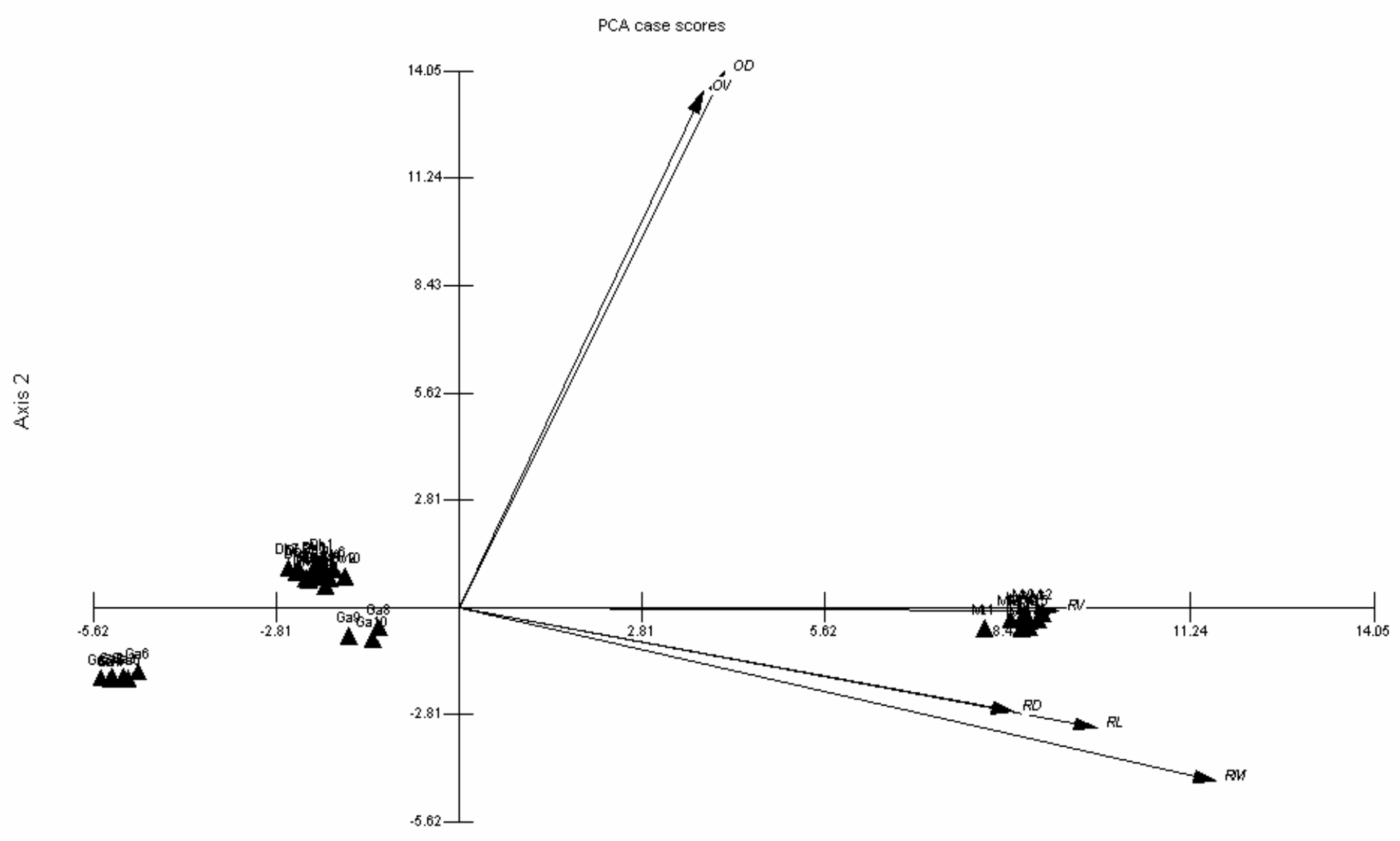

Axis 1

Vector scaling: 20.47

Gráfico 3 -

Analise de componentes Principais (PCA). Da relação do diâmetro do olho (DO) em relação ao m. reto medial (RM); $m$. reto lateral $(\mathrm{RL}) ; \mathrm{m}$. reto dorsal $(\mathrm{RD}) ; \mathrm{m}$. reto ventral $(\mathrm{RV}) ; \mathrm{m}$. oblíquo ventral $(\mathrm{OV})$ e $\mathrm{m}$. oblíquo dorsal $(\mathrm{OD})$ para as espécies D. hypostigma (DH); G. altavela (GA); P. violacea (PV) e M. thurstoni (MT) 


\section{Discussão}

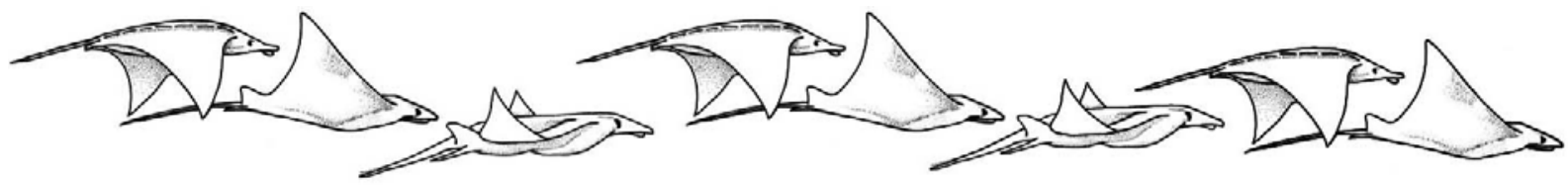




\section{DISCUSSÃO}

O presente estudo descreve os músculos extraoculares de Dasyatis hypostigma, Gymnura altavela, Mobula thurstoni e Pteroplatytrygon violacea. Para melhor entendimento, esta seção foi dividida em subseções específicas para as partes morfológicas do órgão da visão que receberam especial atenção neste estudo, assim, abordaremos a seguir o bulbo do olho e suas relações com a órbita e tendões de inserção dos músculos extraoculares. A abordagem ecológica foi baseada nos resultados obtidos, a fim de inferir sobre a funcionabilidade destes músculos.

\subsection{BULBO DO OLHO E ÓRBITA}

A localização e posição dos órgãos da visão são sugeridas por autores como Prince (1960); Carpenter (1977); Hart et al. (2006) como sendo um forte indicador do modo de vida dos animais, uma vez que de acordo com a posição poderíamos indicar o modo de vida das espécies. Os predadores (carnívoros), como os canídeos e felídeos, apresentam os olhos voltados para frente e grande amplitude de visão binocular, enquanto que os animais comumente predados, como por exemplo, animais herbívoros como os cervídeos, apresentam os olhos localizados lateralmente na cabeça e visão principalmente monocular. Ao comparar com os resultados obtidos com as raias, foi possível agrupar $D$. hypostigma, G. altavela, $P$. violacea e M. thurstoni de acordo com o seu habitat e forma de predação.

As espécies estudadas ocupam nichos e possuem hábitos de vida distintos. Dasyatis hypostigma e G. altavela são espécies costeiras e bentônicos que capturam o alimento forrageando o substrato em busca de pequenos peixes e invertebrados (SANTOS; CARVALHO, 2004; NUNES; PIORSKI 2009).

De acordo com Carvalho et al. (2004) e Nelson (2006), D. hypostigma e P. violacea apresentam um padrão de crânio muito semelhante entre si, de forma que a 
cabeça, assim como as órbitas em suas laterais, é circundada pela nadadeira peitoral, que se estende até a parte mais rostral, formando um disco. Esse padrão pode ser explicado por sua ancestralidade comum e por pertencerem à mesma família (CARVALHO et al., 2004). Apesar das semelhanças, os resultados obtidos por meio de minuciosas dissecções do bulbo do olho destas espécies possibilitaram evidenciar uma angulação aproximada de $3^{\circ}$ para $D$. hypostigma e $22^{\circ}$ para $P$. violacea do bulbo em relação à linha mediana do corpo. Desta forma, foi possível separar $D$. hypostigma e $P$. violacea de acordo com o hábito e modo de vida. Já a angulação aproximada de $4^{\circ}$, obtida para G. altavela, muito aproxima à obtida para D. hypostigma, corrobora com os hábitos de vida de ambas as espécies.

Em M. thurstoni o padrão do crânio é muito distinto dos demais grupos de raias. A órbita e o bulbo do olho se localizam cauldamente a duas estruturas cefálicas laterais que se projetam rostralmente, essas estruturas são conhecidas como nadadeiras cefálicas (NOTARBARTOLO-DI-SCIARA 1987; MCEACHRAN; CARVALHO, 2002a). Estabelecida a posição dos olhos nesta espécie, fica fácil imaginar o ângulo de $0^{\circ}$, já que a linha do equador do bulbo do olho fica paralela à linha mediana do corpo do animal.

Pteroplatytrygon violacea e $M$. thurstoni são espécies oceânicas e pelágicas (MENNI; STEHMANN, 2000), porém a primeira é predadora de peixes e cefalópodes (MCEACHRAN; CARVALHO, 2002b; SIQUEIRA; SANT'ANNA, 2007; VÉRAS et al., 2009), enquanto a segunda é filtradora de plâncton (NOTARBARTOLO-DI-SCIARA 1987; MCEACHRAN; CARVALHO, 2002a). Na maioria das espécies de elasmobrânquios pelágicos e bentopelágicos, os olhos estão situados lateralmente na cabeça, enquanto nas espécies bentônicas os olhos estão posicionados mais dorsalmente (GILBERT, 1963; HUETER et al., 2004).

Lisney e Collin (2007) demonstram, pela relação entre a largura do bulbo do olho e o comprimento total de espécies de diferentes hábitats, que elasmobrânquios que caçam presas móveis e ativas (e.g. peixes e cefalópodes), apresentam tal relação de tamanho maior do em espécies de tubarões e raias bentônicos que caçam invertebrados forrageando o substrato. Devido termos estudado apenas cabeças já separadas dos corpos, não foi possível precisar tal relação, porém, com o material obtido, ficou notória a diferença proporcional de tamanho entre os olhos 
de 3 das 4 espécies estudadas, de forma que pudemos observar que $P$. violacea, apresenta olhos prporcionalmente grandes e que D. hypostigma e G. altavela apresentam olhos proporcionalmente pequenos e pedunculados. Tal relação não ficou evidente para $M$. thurstoni devido ao tamanho avantajado que a espécie pode alcançar (aproximadamente $2 \mathrm{~m}$ ).

Em um estudo comparativo da musculatura cefálica da superfamília Myliobatoidea, Gonzales-isáis (2003) agrupou nitidamente as espécies estudadas de acordo com seus hábitos alimentares. O grau de angulação do bulbo do olho em relação à linha mediana do corpo, descrito no presente estudo, representa um fator morfológico adicional que poderá ser usado para agrupar as espécies de acordo com seus hábitos predatórios.

\subsection{TENDÃO DE INSERÇÃO}

Hifny e Misk (1982), no intuito de aprimorar e prover conhecimentos anátomocirúrgicos, estudaram os tendões de inserção dos músculos extraoculares de cavalos, mulas, jumentos, vacas, búfalos, camelos, ovinos, caprinos, suínos, cães e gatos, e demostraram que há diferenças morfológicas interespecíficas. Segundo estes autores, a forma das linhas de inserção dos tendões em relação ao equador do bulbo do olho não apresentou nenhum padrão que pudesse ser estabelecido entre cada uma das espécies. Até então, estudo similar não havia sido realizado para tendões de inserção dos músculos extraoculares de elasmobrânquios.

No presente estudo, foram encontradas diferenças espécie-específicas quanto à forma da linha descrita pelos tendões de inserção dos músculos extraoculares. O tendão de inserção do m. reto lateral descreve uma linha oblíqua em $D$. hypostigma e G. altavela, mas convexa em $M$. thurstoni e côncava em $P$. violacea. $\mathrm{O}$ tendão de inserção do $\mathrm{m}$. reto dorsal apresentou diferentes formas em cada uma das espécies: convexa em $M$. thurstoni, oblíqua em $P$. violacea, côncava em $D$. hypostigma e reta em $G$. altavela. Tanto $M$. thurstoni quanto $D$. hypostigma 
apresentam o tendão de inserção dos $\mathrm{mm}$. reto ventral e oblíquo dorsal de forma côncava e $P$. violacea e $G$. altavela de forma oblíqua. O tendão do $\mathrm{m}$. reto medial traça uma linha de inserção que se dispõe de forma oblíqua em $M$. thurstoni, $P$. violacea e $D$. hypostigma, e de forma côncava em $G$. altavela. A linha de inserção do $\mathrm{m}$. oblíquo dorsal de $D$. hypostigma apresentou o mesmo padrão encontrado no m. oblíquo de $M$. thurstoni. Os tendões dos $\mathrm{mm}$. oblíquos dorsal e ventral de $P$. violacea, do mesmo modo que o tendão do $\mathrm{m}$. oblíquo ventral de $D$. hypostigma, apresentaram linha de inserção de forma convexa. Já em G.altavela, observamos que o tendão de inserção de ambos os mm. oblíquos, dorsal e ventral, se dispõe de maneira a descrever uma linha oblíqua em relação ao equador do bulbo.

O comprimento do tendão também variou entre as espécies estudadas. Comparando os tamanhos de comprimentos médios dos desvios padrões de cada espécie, podemos dizer que estes foram mais representativos nos tendões de inserção dos $\mathrm{mm}$. reto lateral e medial dos que nos tendões dos $\mathrm{mm}$. reto ventral, dorsal e oblíquos dorsal e ventral nas quatro espécies estudas. Alguns tendões de inserção apresentaram tendões mais desenvolvidos que os demais, como em $D$. hypostigma os tendões dos $\mathrm{mm}$. oblíquos ventral $(4,3 \pm 0,65)$ e dorsal $(4,2 \pm 0,63), P$. violacea os tendões do $\mathrm{m}$. reto dorsal $(6,2 \pm 0,78)$ e em $G$. altavela e $M$. thurtoni o

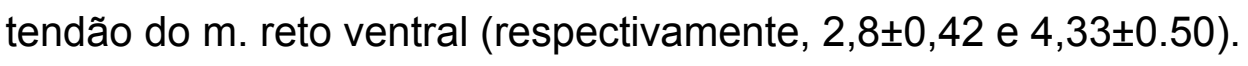

\subsection{MÚSCULOS EXTRAOCULARES}

Poucos autores discorreram sobre a musculatura extraocular em algumas espécies de tubarões e raias, dentre os quais ressaltamos Von Bonde (1933); Edgeworth (1935); Oliva (1967); Isomura (1981); Miyake (1988); Nishida (1990); Gomes, Santos e Medina (1991); Shirai (1992); Walker e Homberger (1992) e Lima et al. (1997). Todavia não foram encontrados na literatura trabalhos de descrição dos músculos extraoculares para espécies dos gêneros Gymnura, Mobula e Pteroplatytrygon. Para o gênero Dasyatis, os músculos são descritos de forma pouco descritiva para espécie D. say por Gomes, Santos e Medina (1991), espécie 
que posteriormente foi descrita como espécie nova por Santos e Carvalho (2004), que lhe conferiram o nome de $D$. hypostigma.

Para as espécies $D$. hypostigma, $P$. violacea e $G$. altavela foram encontrados seis músculos extraoculares e estes foram divididos em dois grupos distintos, retos e oblíquos, nomeados de acordo com seu ponto de inserção: reto dorsal, reto ventral, reto medial e reto lateral, oblíquo dorsal e oblíquo ventral. Tal padrão confere com o padrão estabelecido pela literatura (HARDER, 1975; ROMER; PARSONS, 1985; GOODRICH, 1986; NISHIDA, 1990 e WALKER; HOMBERGER, 1992; LIEM; SUMMERS, 1999;). Entretanto, os resultados obtidos em Mobula thurstoni contrariam tais padrões e esta aparenta ser a espécie mais divergente, pois puderam ser observadas duas diferenças morfológicas importantes, até então não relatadas em qualquer espécie conhecida até onde pudemos constatar na bibliografia consultada. A espécie $M$. thurstoni não apresenta o padrão de dois músculos oblíquos ventral e oblíquo dorsal, e sim, apenas um músculo com uma cabeça e duas caudas (bíceps).

Quanto à inervação dos músculos extraoculares, puderam ser identificados os nervos oculomotor (III), inervando os $\mathrm{mm}$. retos medial, ventral e dorsal, além do $\mathrm{m}$. oblíquo ventral; o nervo abducente $(\mathrm{VI})$, inervando o $\mathrm{m}$. reto lateral; e o nervo troclear (IV), inervando o m. oblíquo dorsal. Este padrão de inervação corrobora com o padrão descrito por Daniel (1934); Harder (1975) e Walker e Homberger (1992).

Em todas as espécies estudadas, observamos que os músculos retos se originam na parte caudal da órbita e os músculos oblíquos na parte rostral, sendo estes sempre maiores em comprimento e largura que os músculos retos, que por sua vez, sempre se apresentaram mais longos que largos que os oblíquos. Nossos resultados concordam com os encontrados em raias do gênero Raja, Torpedo e Dasyatis (OLIVA, 1967); Urotrygon (MIYAKE, 1988) e em tubarões das espécies Squalus sp., Mustelus laevis e Heptranchias perlo (EDGEWORTH, 1935); Squalus acanthias (WALKER; HOMBERGER, 1992); Sphyrna lewini, Rhizoprionodon lalandi (LIMA et al 1997); dos gêneros Squalus, Etmopterus, Squatina, Scyliorhinus, "Pristiurus" (OLIVA, 1967); e Alopias e Mustelus (ISOMURA, 1981). 
Os resultados do presente trabalho trazem detalhes descritivos até então não abordados na literatura. Gonzaléz-Isais $(2003,2007)$ e Gonzaléz-Isaís e Dominguez (2004) tratam da musculatura craniana de myliobatiformes, mas não fazem menção aos músculos extraoculares. Nishida (1990) descreve a musculatura extraocular dos myliobatiformes Urolophus maculatus, Dasyatis brevis, Myliobatis áquila e Manta birostris como tendo o padrão de quatro retos e dois oblíquos, porém se contradiz, apresentando desenhos esquemáticos distintos e não analisado descritivamente cada uma destas espécies.

Os resultados encontrados corroboram com o estudo de Nishida (1990) sobre a superfamília Myliobatoidea, que compreende as espécies aqui estudadas, quanto à origem dos músculos reto e oblíquos. Porém, diverge o autor quanto a forma de descrição dos músculos oblíquos, que segundo o mesmo, são divididos em duas partes. Nas espécies estudadas não foi encontrado nenhum tipo de divisão nos músculos oblíquos de Dasyatis hypostigma, G. altavela ou $P$. violacea. No entanto, morfologia do músculo oblíquo encontrado de $M$. thurstoni que não se constitui uma divisão e sim um único músculo, distinto com duas cabeças e uma cauda, poderia remeter a tal divisão. Ainda segundo os resultados de Nishida (1990), nenhuma menção é feita sobre a presença de um sétimo músculo, como o encontrado no presente estudo e por nós chamado aqui por de músculo reto lateral $\beta$.

O músculo reto lateral $\beta$ foi encontrado apenas em $M$. thurstoni. Esta nomenclatura, que consiste na adição de uma letra grega após um nome préexistente, foi estabelecida no presente trabalho com base no padrão sugerido para um músculo semelhante, reportado por Shirai (1992) em seu estudo de filogenia que descreve um sétimo músculo em raias da família Pristidae e tubarões das famílias Pristiophoridae e Rhinobatidae. No referido trabalho, o autor nomeou o músculo encontrado de músculo oblíquo ventral $\beta$, em alusão a segunda letra $\beta$ do alfabeto grego, e tal músculo apresentava relação de proximidade com o músculo oblíquo ventral, porém não é feita nenhuma menção ao seu ponto de inserção no bulbo do olho ou sobre outra musculatura. Embora não cite as espécies, o autor ainda relata que esse músculo oblíquo ventral $\beta$ pode ser encontrado em algumas espécies de raias Raijormes, Torpediniformes e Myliobatiformes. Nas quatro espécies de raias Myliobatiformes por nós estudadas não observamos a presença deste músculo. 
A acreditamos que a ação músculo laterla $\beta$ esteja relacionada à ação do músculo reto lateral, de forma que sugerimos que estes músculos atuem em sinergismo, uma vez que se insere no tendão de inserção deste último, logo antes deste se inserir na esclera. Além desta relação, o músculo reto lateral é morfologicamente diferente de qualquer um dos músculos retos encontrados, pois possui um sulco ventral que aparece no terço médio do ventre antes da inserção. $O$ ventre deste músculo é proporcionalmente muito maior do que o ventre dos demais músculos extraoculares desta espécie e este fato, combinado com a presença do sétimo músculo e de um músculo oblíquo, nos faz acreditar na necessidade desta espécie movimentar o bulbo do olho, rostralmente, de forma a direcionar a visão para frente, o que the conferiria maior capacidade de localizar rotas de fuga, já que é uma espécie comumente predada.

O afunilamento das fibras na direção da inserção, local de inserção dos músculos oblíquos próximos a inserção do músculo reto dorsal, posição de cruzamento dos músculos reto medial e ventral com o pedículo óptico e a posição da inserção do músculo reto dorsal, são as principais características encontradas e que agrupam as espécies de acordo com seu habitat e modo de vida, o mesmo padrão encontroado nos resultados obtidos para músculos cefálicos por Gonzaléz-Isais (2003, 2007) e Gonzaléz-Isaís e Dominguez (2004).

As fibras do ventre muscular dos músculos oblíquos dorsal e ventral de $D$. hypostigma e $G$. altavela mudam de direção e se afunilam ao se aproximar do ponto de inserção no bulbo do olho. Em $P$. violacea, as fibras destes músculos seguem sem qualquer alteração na direção desde a origem até a inserção, que ocorre no equador do bulbo. Em M. thurstoni há apenas um músculo oblíquo e suas fibras se mantêm na mesma direção até o ponto de inserção, que haja mudança na direção, e sua inserção ocorre no equador do bulbo, de forma contínua desde o ponto mediodorsal ao ponto medioventral.

Os músculos reto medial e ventral configuram trajetos diferentes nas espécies estudadas. Em Dasyatis hypostigma e G. altavela esses músculos cruzam o pedículo óptico em sua porção medial, enquanto que em $P$. violacea se cruzam na 
parte distal e em $M$. thurstoni os músculos retos medial e ventral se encontram paralelamente ao pedículo óptico.

A inserção do músculo reto dorsal também variou quanto ao ponto de inserção, de forma que em Dasyatis hypostigma e G. altavela se insere no pólo anterior logo anteriormente ao equador do bulbo do olho, e em $P$. violacea e $M$. thurstoni a inserção ocorre imediatamente sobre o equador do bulbo.

\subsection{RELAÇÕES MORFO-ECOLÓGICAS}

As duas espécies demersais, D. hypostigma e G. altavelta alimentam principalmente sobre fauna bentônica, onde a visão provavelmente não desempenha um papel importante na detecção de presas. Na verdade, com os olhos posicionados dorsalmente e a boca posicionada ventralmente, em tese essas espécies nunca podem ver o que comem, utilizando-se de receptores extremamente sensíveis (MARUSKA; TRICAS, 1998) e de eletroreceptores (BLONDER; ALEVIZON, 1998; SISNEROS; TRICAS, 2002) para localizar suas presas.

Segundo Wilson e Beckett (1970), P. violacea é uma espécie predadora, que se alimenta de peixes e lulas. Ao contrário das espécies associadas ao ambiente bêntico, $P$. violacea vive em regiões onde a profundidade ultrapassa 1000 metros. São espécies que nadam na coluna de água onde a linha lateral e o sistema de eletrorecepção que funcionam a curta distância, não seriam capazes de fornecer informações sobre o movimento de presas num substrato tão distante. Isso responderia a angulação de $22^{\circ}$ do bulbo do olho em $P$. violacea, haja vista a necessidade de olhos aparentemente maiores e de $3^{\circ}$ e $4^{\circ} \mathrm{D}$. hypostigma e $\mathrm{G}$. altavelta, espécies que pouco utilizam os olhos para predação.

Os mesmos parâmetros se aplicam para essas espécies quando pensamos nelas como presas, já que $D$. hypostigma e $G$. altavelta possuem a capacidade de se enterrarem e camuflar no substrato, o que diminuiria a necessidade de atenção aos predadores. O mesmo não acontece com a $P$. violacea. 
Morfologicamente Mobula thurstoni apresenta os olhos posicionados lateralmente e cranialmente às nadadeiras peitorais, assim como em Rhinoptera bonasus. Segundo McComb e Kajiura (2008), as Rhinoptera bonasus, possuem o campo visual binocular que permite um campo de visão de $46^{\circ}$, mesmo padrão que se espera encontrar em Mobula thurstoni. Ainda segundo McComb e Kajiura (2008) as raias apresentam diferentes dinâmicas do campo visual horizontal, podendo apresentar os olhos completamente divergidos ou convergidos. Espera-se que $M$. thurstoni tenha visão monocular, já que seus olhos estão completamente lateralizados. Na verdade, a região orbital de $M$. thurstoni, é rasa, podendo oferecer maior mobilidade do bulbo do olho e por consequência maior dinâmica do campo visual horizontal. Esta ação pode ser amplificada com a movimentação sinérgica dos músculos que se inserem nas partes anterior ( $\mathrm{m}$. obliquo) e posterior $(\mathrm{mm}$. reto dorsal, reto lateral e reto lateral $\beta$ ) do bulbo do olho. Este movimento poderia aumentar o campo visual horizontal permitindo maior amplitude do campo visual cranial e caudal. Desta forma, há um aumento da capacidade de percepção visual do meio, o que potencializa a detecção de predadores, visualização de presas e rotas de fuga. Em $M$. thurstoni os músculos oblíquo e acessório do bulbo do olho dão maior força para movimentar o olho para região cranial e caudal.

Tanto as variações morfológicas encontradas quanto as combinações dessas variações com relação ao habitat e hábitos de vidas dessas espécies demonstram um potencial do uso da musculatura extrínseca do olho para o entendimento de sua biologia, trazendo subsídios para formulação de inferências evolutivas e ecológicas, além de se mostrar como um importante seguimento da anatomia a ser explorado. 
Conclusão

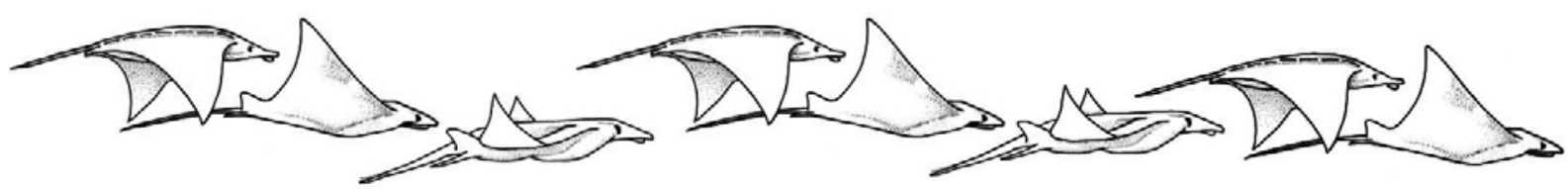




\section{CONCLUSÃO}

Com base nas observações realizadas durante a elaboração deste estudo, concluímos que:

Os músculos extraoculares de Pteroplatytrygon violacea, Dasyatis hypostigma e Gymnura altavela são: músculo reto dorsal, músculo reto ventral, músculo reto lateral e músculo reto medial, músculo oblíquo dorsal e músculo oblíquo ventral.

$>$ Os músculos extraoculares de Mobula thurstoni são: músculo reto dorsal, músculo reto ventral, músculo reto lateral e músculo reto medial, músculo reto lateral $\beta$, e o músculo oblíquo.

A espécie Mobula thurstoni foi a única espécie estudada cujo padrão de arranjo dos músculos extraoculares diferiu do padrão estabelecido para vertebrados.

A angulação formada pelo bulbo do olho e a linha mediana do corpo variou entre as quatro espécies estudadas. 


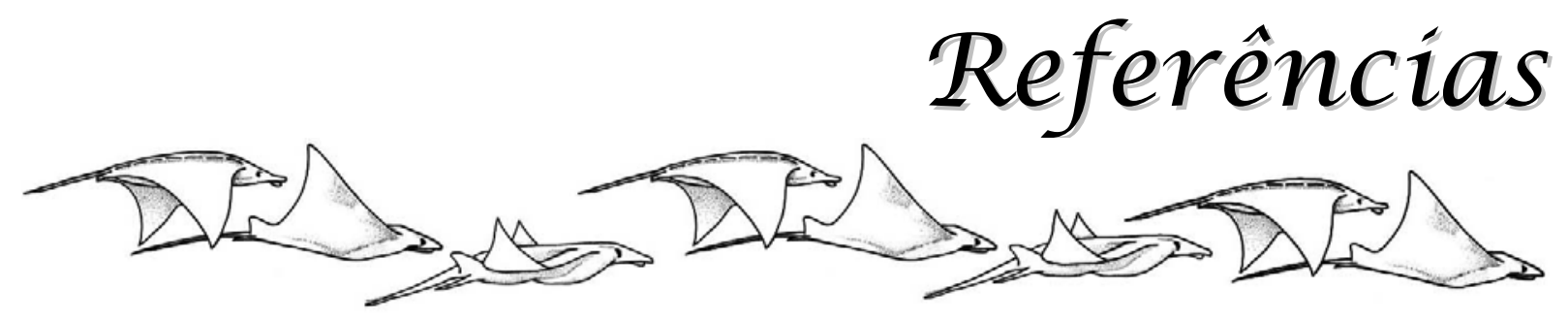




\section{REFERÊNCIAS}

ANDRÉS, A. M.; GUZMAN, J. M. G.; MUÑOZ-CHAPULI, R. Ventral cephalic musculature in elasmobranchii: some functional and phylogenetic implications. IN: EUROPEAN CONGRESS OF ICHTHYOLOGY, 5, 1987, Stockholm. Proceedings...

BIGELOW, H. B.; SCHROEDER, W. C. Sawfishes, guitarfishes, skates, and rays. Fishes of the Western North Atlantic. Memoirs of the Sears Memorial Foundation for Marine Research, v. 1, n. 2, p. 1-514, 1953.

BORNATOWSKIA, H.; ABILHOA, V.; CHARVET-ALMEIDA, P. Elasmobranchs of the Paraná Coast, southern Brazil, south-western Atlantic. Marine Biodiversity Records, v. 2, p. e158, 2009.

CAPAPÉ, C.; ZAOUALI, J.; TOMASINI, J. A.; BOUCHEREAU, J. L. Reproductive biology of the spiny butterfly ray, Gymnura altavela (Linnaeus, 1758) (Pisces: Gymnuridae) from off the Tunisian coasts. Scientia Marina, v. 56, n. 4, p. 347-355, 1992.

CARPENTER, R. H. S. Movements of the eyes. $1^{\text {a }}$ ed. Londres: Pion-London, 1977. 420p.

CARVALHO, M. R. de; MAISEY, J. G.; GRANDE, L. Freshwater stingrays of the Green River Formation of Wyoming (early Eocene), with the description of a new genus and species and an analysis of its phylogenetic relationships (Chondrichthyes, Myliobatiformes). Bulletin of the American Museum of Natural History, v. 284, p. 1-136, 2004.

CASAS, A. L. S. Inervação da musculatura mandibular de Carcharias taurus (Rafinesque, 1810). (Odontaspididae, Lamniformes, Elasmobranchii). 2004. $79 \mathrm{f}$. Dissertação (Mestrado) - Faculdade de Medicina veterinária e Zootecnia, Universidade de São Paulo, São Paulo, 2004.

CASAS, A. L. S.; INTELIZANO, W.; CASTRO, M. F. S.; MARIANA, A. N. B. Nerves of the mandibular musculature of the sand tiger shark Carcharias taurus (Rafinesque, 1810) (Chondrichthyes: Odontaspididae). International Journal of Morphology, v. 23, n. 4, p. 387-392, 2005.

CASAS, A. L. S.; CUNHA, C. M.; INTELIZANO, W.; GONZALEZ, M. M. B. Record of a pregnant bentfin devilray, Mobula thurstoni (Lloyd) (Elasmobranchii, Mobulidae) caught in Southwestern Brazil. Pan-American Journal of Aquatic Sciences, v. 1, n. 2, p. 66-68, 2006.

COHEN, J. L. Functional pathways in the elasmobranch retina. Journal Journal of Experimental Zoology, Supplement 2, p. 75-82, 1989.

COMPAGNO, L. J. V. Alternative life-history styles of cartilaginous fishes in time and space. Envirommental biology of fishes, v. 28, n. 1-4, p. 33-75, 1990. 
COMPAGNO, L. J. V. Gogolia filewoodi, a new genus and species of shark from new guinea (Carcharhiniformes: Triakidae), with a redefinition of the family triakidae and a key to triakid genera. Proceedings of the Califórnia Academy of Sciences, v. 39, n. 19, p. 383-410, 1973.

COMPAGNO, L. J. V. Systematics and body form. In: HAMLETT, W. C. (Ed). Sharks, skates and rays - The biology of elasmobranch fishes. Maryland: John Hopkins University, 1999. 515 p.

COMPAGNO, L. J. V.; ROBERTS, T. R. Freshwater stingrays (Dasyatidae) of southwest Ásia and New Guinea, with description of a new species of Himantura and reports of unidentified species. Environmental Biology of Fishes, v. 7, p. 321-339, 1982.

DAIBER, F. C.; BOOTH, R. A. Notes on the biology of the butterfly rays, Gymnura altavela and Gymnura micrura. Copeia, v. 2, p. 137-139, 1960.

DANIEL, J. F. The Elasmobranch fishes. 3. ed. Berkeley: University of Califórnia Press, 1934, 332 p.

DEAN, M. N.; MOTTA, J. P. Anatomy and functional morphology of the feeding apparatus of the lesses electric ray, Narcine brasiliensis (Elasmobranchii: Batoidea). Journal of Morphology, v. 262, p. 462-483, 2004.

DOMINGUEZ, H. M. M.; GONZÁLEZ-ISÁIS, M. Contribution to the Knowledge of anatomy of species of genus Mobula Rafinesque 1810 (Chondrichthyes: Mobulidae). The Anatomical Record, v. 290, p. 920-931, 2007.

EDGEWORTH, F. H. The cranial muscles of vertebrates. London, Camdridge University Press. 1935, viii. 493 p.

ELLIS, J. R. Occurrence of pelagic stingray Pteroplatytrygon violacea Bonaparte, 1832) in the North Sea. Journal of Fish Biology., v. 71, p. 933-937, 2007.

FANTA, E.; MEYER, A. A.; GRÖTZNER, S. R.; LUVIZOTTO, M. F. Comparative study on feeding strategy and activity patterns of two Antartic fish: Trematomus newnesi Boulenger, 1902 and Gobionotothen gibberifrons (Lönnberg, 1905) (Pisces, Nototheniidae) under different light conditions. Antarctic Record, v. 38, n. 1, p. 1329. 1994.

FIGUEIREDO, J. L. Manual de peixes marinhos do Sudeste do Brasil: I Introdução. Cações, raias e quimeras. São Paulo: Museu de Zoologia da Universidade de São Paulo, 1977. 104 p.

GADIG, O. B. F. Peixes cartilaginosos da costa do Estado de São Paulo. Revista Ceciliana (Santos), v. 8, n. 9, p. 41-51, 1998 
GADIG, O. B. F.; NAMORA, R. C.; MOTTA, F. S. Occurrence of the bentfin devil ray, Mobula thurstoni (Chondrichthyes: Mobulidae), in the western Atlantic. Journal of the Marine Biological Association of the UK. v. 83, n. 4, p. 869-870. 2003.

GANS, C.; PARSONS, T. S. (Ed.). A photographic atlas of sharks anatomy. The gross morphology of Squalus acanthias. London: Academic Press, 1964. 106p.

GILBERT, P. W. The visual apparatus of sharks. In: GILBERT P. W. (Ed.). Sharks and survival. Boston: D. C. Heath, 1963. p. 283-326.

GOODRICH, S. E. Studies on the structure and development of vertebrates. New York: Dover. 1958. 485 p.

GOODRICH, S. E. Studies on the structure and development of vertebrates. [with a new foreword by Keith S. Thomson]. Chicago. 1986. 837 p.

GOHAR, H. A. F.; BAYOUMI, A. R. On the Anatomy of Manta Ehrenbergi with notes on Mobula Kuhlii. Publications of the Marine Biological Station Al-Ghardaqa (Red Sea), v. 10, p. 191-238, 1959.

GOHAR, H. A. F.; HAMDY, A. R. The jaws and teeth of Aetobatus narinari. Publications of the Marine Biological Station Al-Guardaqa (Red Sea), v. 12, p. 177-190, 1963.

GOMES, U. L.; SANTOS, H. R. S.; MEDINA, A. E. 1991. Anophthalmia in Dasyatis sayi (Lesueur, 1817) (Myliobatiformes, Dasyatidae). Anais da Academia Brasileira de Ciências, v. 63, n. 3, p. 307-313, 1991.

GONZALÉZ-ISÁIS, M. Anatomical comparison of the cephalic musculature of some members of the superfamily myliobatoidea (Chondrichthyes): Implications for evolutionary understanding. The Anatomical Record, Part A, v. 271A, p. 259-272, 2003.

GONZALÉZ-ISÁIS, M.; DOMÍNGUEZ, H. M. M. Comparative anatomy of the superfamily myliobatoidea (Chondrichthyes) with some comments on phylogeny. Journal of Morphology, v. 262, p. 517-535. 2004.

GRUBER, S. H.; COHEN, J. L. Visual system of the elasmobranch: state of the art 1960-1975. In: HODGSON E. S; MATHEWSON, R. F. (Ed.). Sensory biology of sharks, skates and rays. Arlington: Office of Naval Research, 1978. p. 11-116.

GRUBER, S. H.; HAMASAKI, D. I.; BRIDGES, C. D. B. Cones in the retina of the lemon shark (Negaprion brevirostris). Vision Research, v. 3, p. 397-399, 1963.

HAIRSTON JR., N.; LI, K. T.; EASTER JR., S. S. Fish vision and the detection of planktonic prey. Science (Washington DC), v. 218, p. 1240-1242, 1982.

HAMASAKI, D. I.; GRUBER, S. H. The photoreceptors of the nurse shark Ginglymostoma cirratum and the sting ray, Dasyatis sayi. Bulletin of Marine Science, v. 15, p. 1051-1059, 1965. 
HAMDY, A. R. The development of the Branchial Arches of Rhinobatus halawi. Publications of the Marine Biological Station Al-Ghardaqa (Red Sea), v. 11, p. 205-214, 1961.

HAMDY, A. R. The head skeleton of Rhinoptera bonasus (Mitchill). Proceedings of the Egyptian Academy of Sciences, v. 13, p. 74-80, 1959.

HARDER, W. Anatomy of fishes. Sttutgat: E. Schweizerbart'sche verlagsbuchhandlung (Nägele u. Obermiller), 1975, v. 1; 612 p..

HIFNY, A.; MISK, A. A comparative study of the surgical anatomy of the tendons of insertions of the extrinsic muscles of the eyeball in different domestic animal. Anatomia, Histologia, Embryologia, v. 11, p. 19-26, 1982.

HOLMGREN, N. Studies on the head in fishes. Part II. Comparative anatomy of the adult selachian skull with remarks on the dorsal fins in sharks. Acta Zoologica (Stockholm), v. 22, p. 1-100, 1941.

INGLE, D. Vision: The experimental analysis of visual behavior. In: HOAR, W. S.; RANDALL, D. J. (Ed). Fish physiology. New York: Academy Press, 1971. p. 59-78.

INTELIZANO, W. Origem e distribuição das artérias coronárias em carpa-capim Ctenopharyngodon idella Valenciennes, 1884 (Cyprinidae, Ostariophysii). 1999. 120 f. Tese (Doutorado em Cirurgia) - Faculdade de Medicina Veterinária e Zootecnia, Universidade de São Paulo, São Paulo, 1999.

ISOMURA, G. Comparative anatomy of the extrinsic do olho muscles in vertebrates. Anatomischer Anzeiger, v. 150, p. 498-515, 1981.

LAGLER, K. F.; BARDACH, J. E.; MILLER, R. R.; PASSINO, D. R. M. Ichthyology. 2. ed. New York: John Wiley \& Sons, 1977. 506 p.

LESSA, R.; SANTANA, F. M.; RINCÓN, G.; GADIG, O. B. F.; EL-DEIR, A. C. Biodiversidade de elasmobranquios do Brasil. Ministério do Meio Ambiente: Projeto de Conservação e Utilização Sustentável da Diversidade Biológica Brasileira - PRONABIO. Brasília, DF. 1999, 173 p.

LIEM, K. F.; SUMMERS, A. P. Muscular system: Gross anatomy and functional morphology of muscles. In: HAMLETT, W.C. (Ed). Sharks, skates and rays - The biology of elasmobranch fishes. Maryland: John Hopkins University, 1999. 515 p.

LIMA, M. C.; GOMES, U. L.; SOUZA-LIMA, W; PARAGÓ, C. Estudo anatômico comparativo da região cefálica pré-branquial de Sphyrna lewini (griffith \& Smith) e Rhizoprionodon lalandii (Valenciennes) (Elassmobranchii, Carcharhiniformes) relacionados com a presença do cefalofólio em Sphyrna Refinesque. Revista Brasileira de Zoologia, v. 14, n. 2, p. 347-370, 1997.

LISNEY, T. J.; COLLIN, S. P. Relative eye size in elasmobranchs. Brain, Behavior and Evolution, v. 69, n. 4, p. 266-279, 2007. 
LOVEJOY, N. R. Systematics of myliobatoid elasmobranchs: with emphasis on the phylogeny and historical biogeography of neotropical freshwater stingrays (Potamotrygonidae: Rajiformes). Zoological Journal of the Linnean Society, v. 117, n. 3, p. 207-257, 1995.

MANLY, B. F. J. Multivariate statistical methods: A primer. London: Chapman \& Hall, 1986, 159 p.

MARSHALL, A. D.; COMPAGNO, L. J. V.; BENNETT, M. B. Redescription of the genus Manta with resurrection of Manta alfredi (Krefft, 1868) (Chindrichthyes; Myliobatoidei; Mobulidae). Zootaxa, v. 2301, p. 1-28, 2009.

MAZZOLENI, R. C.; SCHWINGEL, P. R. Aspectos da biologia das espécies capturadas por espinhel pelágico na região Sul das Ilhas de Trindade e Martin Vaz no verão de 2001. Notas técnicas da FACIMAR, Itajaí, v. 6, p. 51-57, 2002.

McCOMB, D. M.; KAJIURA, S. M. Visual fields of four batoid fishes: a comparative study. Journal of Experimental Biology, v. 211, p. 482-490, 2008.

MCEACHRAN, J. D.; CARVALHO, M. R. de. Dasyatidae. In: K. E. CARPENTER. (Org.). The Living Marine Resources of the Western Central Atlantic. Roma: FAO, 2002b. v. 1, p. 562-571.

MCEACHRAN, J. D.; CARVALHO, M. R. de. Gymnuridae. In: K. E. CARPENTER. (Org.). The Living Marine Resources of the Western Central Atlantic. Roma: FAO, 2002c. v. 1, p. 575-577.

MCEACHRAN, J. D.; CARVALHO, M. R. de. Mobulidae. In: K. E. CARPENTER. (Org.). The Living Marine Resources of the Western Central Atlantic. Roma: FAO, 2002a. v. 1, p. 586-589.

MENEZES, N. A.; WAGNER, H. J.; ALF, M. A. Retinal adaptations in fishes from a floodplain enviroment in the central amazon basin. Revenue Canada Biological Montreal, v. 40, n. 1, p. 111-132, 1981.

MENNI, R. C.; STEHMANN, M. F. Distribution environmental and biology of batoid fishes off Argentina, Uruguay and Brazil - A Review. Revista del Museo Argentino de Ciencias Naturales, v. 2, n. 1, p.69-109, 2000.

MIYAKE, T. The systematic of the stingray genus Urotrygon with commentas on the interrelationships within Urolophidae (Chondrichthyes, Myliobatiformes). Unpubl. Ph.D. dissert. Texas A. e M. University, College Station. Texas, 1988. 490 p.

MIYAKE, T.; MCEACHRAN, J. D. The morphology and evolution of the ventral gill arch skeleton in batoid fishes. Zoological Journal of the Linnean Society, v. 102, p. 75-100, 1991.

MIYAKE, T.; MCEACHRAN, J. D.; HALL, B. K. Edgeworth's legacy of cranial muscle development with an analisys of muscles in the gill ventral arch region of batoid 
fishes (chondrichthyes: Batoidea). Journal of Morphology, v. 212, p. 213-256, 1992.

MOLLET, H. F. Distribution of the pelagic stingray, Dasyatis violacea (Bonaparte, 1832) off California, Central America and wordwide. Marine and Freshwater Research. v. 53, p. 525-530, 2002.

MOTTA, P. J.; WILGA C. D. Advances in the study of feeding mechanisms, mechanics, and behaviors of sharks. Environmental Biology of Fishes, v. 60, $p$ 131-156, 2001.

MOTTA, P. J.; WILGA, C. D. Anatomy of the feeding apparatus of the lemon shark, Negaprion brevirostris. Journal of Morphology, v. 226, p. 309-329, 1995.

MOTTA, P. J.; WILGA C. D. Anatomy of the feeding apparatus of the nurse shark, Ginglymostoma cirratum. Journal of Morphology, v. 241, p. 33-60, 1999.

MUNZ, F. W. Vision: visual pigments. In: HOAR, W. S.; RANDALL, D. J. (Ed). Fish physiology. New York: Acad. Press, 1971. p. 59-78.

MURAKAMI, T. A revised tannic-osmium method for noncoated scanning electron microscope specimens. Archivum histologicum japonicum, v. 36, p. 189-193, 1974

MURRAY, R. W. The response of the ampullae of Lorenzini of elasmobranches to electrical stimuli. Journal of Experimental Biology, v. 39, p. 119-128. 1962.

MURRAY, R. W. The response of the ampullae of Lorenzini of elasmobranches to mechanical stimuli. Journal of Experimental Biology, v. 37, p. 417-424. 1960.

NAKAYA, K. Classification and evolution of hammerhead sharks. Marine Science Montreal, v. 10, n. 3, p. 171-177, 1978.

NAKAYA, K. Taxonomy, comparative anatomy and pylogeny of japanese catsharks Scyliorhinidae. Memoirs of the Faculty of Fisheries, Hokkaido, v. 23, p. 1-94, 1975.

NEAL, H. V. The history of the eye muscles. Journal of Morphology, v. 30, n. 2, p. 443-453, 1918.

NELSON, G. J. Gill arches of fishes. Bulletin of the American Museum of Natural History, v. 141, p. 512-519, 1969.

NELSON, J. S. Fishes of the world. 2. ed. New York: John Wiley and Sons. 1984. $523 \mathrm{p}$.

NELSON, J. S. Fishes of the world. 4. ed. New York: John Wiley \& Sons, Inc., New York. 2006. 601 p.

NICOL, J. A. C. The eyes of fishes. Oxford: Claredon Pres, 1989. 308 p. 
NISHIDA, K. Phylogeny of the suborder Myliobatidoidei. Memoirs of the Faculty of Fisheries, Hokkaido University, v. 37, n. 1-2, p. 1-108, 1990 (serial, 54).

NOTARBARTOLO-Di-SCIARA, G. A revisionary study of the genus Mobula Rafinesque, 1810 (Chondrichthyes: Mobulidae) with the description of a new species. Zoological Journal of the Linnean Society, v. 91, p. 1-91, 1987.

NUNES, J. L. S.; PIORSKI, N. M. A dorsal fold in Gymnura micrura (Bloch and Scheneider, 1801) (Chondrichthyes: Gymnuridae). Brazilian Archives of Biology and Technology., v. 52, n. 2, p. 479-482, 2009.

OLIVA, O. On topography of eye muscles of several elasmobranchs with regard to their life habits. Acta Society Zoology Bohemoslovaca, v. 31, n. 1, p. 51-67, 1967.

PANTANO-NETO, J.; SOUZA, A. M. Anatomia da musculatura oro-branquial asociada à alimentação de duas espécies de raias de água doce (Potamotrygonidae; Elasmobranchii). Publicações Avulsas do Instituto Pau Brasil de História Natural. n 5, p. 53-66, 2002.

POUGH, F. H.; HEISER, J. B.; MCFARLAND, W. N. A vida dos vertebrados. 2. ed. São Paulo: Atheneu, 1999. 798 p.

PRINCE, J. H. Anatomy and histology of the eye and orbit in domestic animals. Thomas, Springfield. 1960. 307 p.

PRINCE, J. H. Comparative anatomy of the eye. Thomas, Springfield, 1956. 418 p.

ROMER, A. S.; PARSONS, C. M. Anatomia comparada dos vertebrados. São Paulo: Atheneu, 2002. $435 \mathrm{p}$.

ROSA, R. S.; CASTELLO, H. P.; THORSON, T. B. Plesiotrygon iwamae, a new genus and species of neotropical freshwater stingray (Chondrichthyes:

Potamotrygonidae). Copeia. v. 2, p. 447-458, 1987.

SANTOS, H. R. S.; CARVALHO, M. R. Description of a new species of whiptailed stingray from the southwestern Atlantic Ocean (Chondrichthyes, Myliobatiformes, Dasyatidae). Boletim do Museu Nacional. Zoologia (Brasil) v. 516, p. 1-24, 2004.

SHIRAI, S. Squalean Phylogeny a new framework of "Squaloid" sharks and related taxa. Hokkaido: Hokkaido University Press, 1992. 139 p.

SIQUEIRA, A. E.; SANT'ANNA, V. B. Data on the Pelagic Stingray, Pteroplatytrygon violacea (Bonaparte, 1832) (Myliobatiformes: Dasyatidae) caught in the Rio de Janeiro Coast. Brazilian Journal of Oceanography, v. 55, n. 4, p. 323-325, 2007.

SLONAKER, J. R. The development of the eye and its accessory parts in the english sparrow. Journal of morphology, v. 35, p. 263-357, 1921. 
TAYLOR, W. R.; VAN DYKE, G. C. Revised procedures for staining and clearing small fishes and others vertebrates for bones and cartilage study. Cybium, v. 9, n. 2, p. 107-119, 1985.

THEISEN, B.; ZEISKE, E.; BREUCKER, H. Functional morphology of the olfactory organs in the spiny dogfish (Squalus acanthias L.) and the small-spotted catshark (Scyliorhinus canicula L.). Acta Zoologia, v. 67, p. 73-86, 1986.

VÉRAS, D. P.; VASKE JUNIOR, T.; HAZIN, F. H. V.; LESSA, R. P.; TRAVASSOS, P. E.; TOLOTTII, M. T.; BARBOSA, T. M. Stomach contents of the pelagic stingray (Pteroplatytrygon violacea) (Elasmobranchii: Dasyatidae) from the tropical Atlantic. Brazilian Journal of Oceanography, v. 57, n. 4, p. 339-343, 2009.

VON BONDE, C. Contributions to the morphology of the elasmobranchii. Journal of Comparative Neurology, v. 58, n. 2, p. 377-403, 1933.

VOOREN, C. M.; LAMÓNACA, A. F. Rhinoptera brasiliensis. In: IUCN 2008. 2008 IUCN Red List of Threatened Species. Disponível em: <www.iucnredlist.org>. Acesso em: 21 de maio de 2009.

WALKER, W. F.; HOMBERGER, D. G. Vertebrate dissection. 8. ed. New York: Saunders College Publishing, 1992. 459 p.

WALLS, G. L. The Vertebrate eye and its adaptative radiation. New York: Hafner Publisher, 1967. 785 p.

WILGA, C. D. Morphology and evolution of the jaw suspension in lamniform sharks. Journal of Morphology. v. 265, p. 102-119, 2005.

WILGA C. D.; MOTTA, P. J. Feeding mechanism of the Atlantic guitarfish Rhinobatos lentiginosus: Modulation of kinematic and motor activity. Journal of Experimental Biology, v. 201, p. 3167-3184, 1998.

WILLIAMSON, M.; KEAST, A. Retinal structure relative to feeding in the rocks bass (Ambloplites rupestris) and bluegill (Lepomis macrochirus). Canadian Journal of Zoology, Ottawa, v. 66, p. 2840-2846, 1988.

WILSON, P. C.; BECKETT, J. S. Atlantic ocean distribution of the pelagic stingray, Dasyatis violacea. Copeia, v. 4, p. 696-707, 1970.

YOUNG, G. C. The relationships of placoderm fishes. Zoological journal of the Linnean Society, v. 88, p. 1-57, 1986. 